\title{
miRNA-325-3p overexpression mitigates partial bladder outlet obstruction (PBOO) by regulating the TLR4/NF-кB(p65) pathway
}

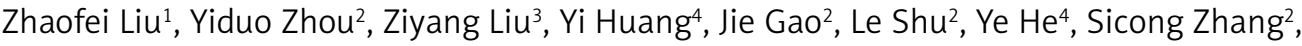 \\ Zhengsen Chen'2, Baixin Shen², Zhongqing Wei², Liucheng Ding²
}

\author{
${ }^{1}$ Department of Urology, Affiliated Lianyungang Hospital of Nanjing University of \\ Chinese Medicine, Lianyungang, China \\ ${ }^{2}$ Department of Urology, The Second Affiliated Hospital of Nanjing Medical University, \\ Nanjing, China \\ ${ }^{3}$ Major in Clinical Medicine, Nanjing Medical University, Nanjing, China \\ ${ }^{4}$ Department of Urology, Jiangnan University Affiliated Hospital, Wuxi, China
}

Submitted: 26 May 2021; Accepted: 20 July 2021

Online publication: 4 August 2021

Arch Med Sci

DOI: https://doi.org/10.5114/aoms/140353

Copyright $\odot 2021$ Termedia \& Banach

\section{Abstract}

Introduction: MicroRNA (miRNA) is a noncoding RNA that plays an important role in many diseases. Partial bladder outlet obstruction (PBOO) is a blockage between the outlet of the neck of the bladder and the external urethral orifice secondary to prostate hyperplasia and urethral stricture, and causative of morphological and functional abnormalities in the bladder. We examine the effects of miRNA-325-3p on PBOO and related mechanisms through an in-vitro study.

Material and methods: Primary bladder smooth muscle cells (BSMCs) were extracted from SD rats and subjected to TGF- $\beta 1$ stimulation to form a cell model of PBOO. Cell proliferation was measured by CCK- 8 assay, and the gene and protein expression levels were measured by RT-qPCR, western blot, and immunofluorescence. The correlation between miRNA-325-3p and ILK was analyzed through a double-luciferase target experiment.

Results: The proliferation of BSMCs in the model group increased more significantly than in the normal group $(p<0.001)$ with miRNA-325-3p repression, and led to activation of the ILK and the TLR4/NF-KB(p65) pathway as well as significant changes in the marker proteins. With miRNA-325-3p transfection, the rate of cell proliferation of the miRNA-325-3p group was significantly suppressed with ILK repression compared with that of the model group, and led to the suppression of TLR4/NF- $\mathrm{B}(\mathrm{p} 65)$ activity and the regulation of protein expression. However, the miRNA-325-3p treatment's effects disappeared as ILK was supplemented. The double-luciferase experiment helped miRNA-325-3p target ILK in BSMCs.

Conclusions: miRNA-325-3p overexpression may play a key role in PBOOinduced cell proliferation by targeting ILK and suppressing the TLR4/ $\mathrm{NF}-\kappa \mathrm{B}(\mathrm{p} 65)$ signaling pathway.

Key words: miRNA-325-3p, ILK, PBOO, BSMC, TLR4, NF-kB(p65).

\section{Introduction}

Partial bladder outlet obstruction (PBOO) is a blockage between the neck of the outlet of the bladder and the external urethral orifice that

\author{
Corresponding author: \\ Liucheng Ding \\ Department of Urology \\ The Second Affiliated \\ Hospital of Nanjing \\ Medical University \\ Nanjing, China \\ E-mail: \\ dingliucheng0409@163.com
}


is secondary to prostate hyperplasia and urethral stricture as well as causative of morphological and functional abnormalities in the bladder [1]. Conventional treatment aims at clearing the urinary obstruction through medical and surgical approaches, which in most cases attain the goal of treatment without improving lower urinary tract symptoms (LUTS). Evolving interest in exploring bladder dysfunction in the context of PBOO suggests a shift in emphasis in research from obstruction removal. LUTS are considered to be more closely associated with pathological changes secondary to PBOO than with the condition itself, and this highlights the significance of appropriately understanding the potential mechanism of PBOO-induced morphological and functional changes in the bladder smooth muscle and the relevant biological processes at the molecular level [2].

PBOO-induced abnormal proliferation of the bladder smooth muscle cells (BSMCs) is considered to be a major contributor to faltering recovery of the bladder function [3]. Studies have shown that in the case of bladder impairment, the phenotypic plasticity of BSMCs is a key player in the development and progression of human diseases [4, 5]. However, little is known about the molecular mechanism of phenotypic plasticity in BSMCs. A variety of signaling molecules, such as PDGFPDGF-BB, TGFTGF $\beta$, and ECM, as well as environmental factors, such aS ischemia, hypoxia, vesical pressure, and mechanical stretch, are known to have regulatory effects on BSMCs in terms of phenotypic plasticity and proliferation [5].

MicroRNAs (miRNAs) are a class of small, single-stranded non-coding RNAs that affect such physiological and pathological processes as cell proliferation, mutation, and apoptosis as post-transcriptional regulators of the target gene expression through translational repression and mRNA decay by imperfectly binding to their target mRNAs at the 3'UTR or 5'UTR [6]. Imperfect base pairing is involved in this mechanism, and makes it possible to efficiently predict the miRNA target. Regulatory effects based on the imperfect nature of binding and base pairing imply the formation of a wide and intricate network to regulate gene expression mediated by miRNAs. In spite of the subtle differences in their expression, it has been suggested that miRNAs play a critical role in a wide range of physiological and pathological processes [6]. Variations in the profiles of MiRNA expression have been observed at different time points after the onset of PBOO. Ekman et al. [7] discovered low expression of miRNA-29c in the case of PBOO. The miRNA-29 family is known to have strong anti-fibrotic effects that can help mediate the expression of over 50 target extracellular matrix (ECM) genes, such as mRNA expression of types I and III collagens, and elastin. Increased TGF- $\beta 1$ expression has been detected in the case of PBOO [8]. Previous authors [9] reported that members of the miRNA-29 family [7], and miRNA-132/212 [10], miRNA-133, and miRNA-101 [11] are expressed in PBOO.

Gheinani et al. [12] and Wu et al. [13] observed a significant increase in miRNA-21 expression in models of rats and mice with $\mathrm{PBOO}$. This indicates that the pathogenesis of PBOO may involve the abnormal expression of miRNAs. Abnormalities in miR-325-3p expression are reported to be strongly correlated with renal fibrosis [14].

\section{Material and methods}

\section{Materials}

The following experimental materials were used in this study: integrin-linked kinase (ILK) (KeyGen Biotech, China, \#KGYT2346-7), TRIzol reagent (Invitrogen, USA, \#15596-026), PrimeScript RT master mix (Takara, Japan, \#RR036B), and One Step TB Green PrimeScript RT-PCR Kit II (SYBR Green) (TaKaRa, Japan, \#RR086B).

\section{Isolation of primary BSMCs of rat}

Once the rats had been anesthetized, the bladder detrusor muscle layer was removed from each adult rat. This was followed by removal of the uroepithelium, lamina propria, serous membrane, and fat tissue. The detrusor smooth muscle tissue was obtained, cut into three fragments each with a diameter of $1 \mathrm{~mm}$, and digested in trypsin/EDTA for $30 \mathrm{~min}$ at $37^{\circ} \mathrm{C}$. The fragments were then minced into smaller pieces using scissors and placed onto a thermostatic shaking table for further digestion in $0.1 \%$ collagenase I for $30 \mathrm{~min}$ at $37^{\circ} \mathrm{C}$. The resulting suspension was filtered through a 200-mesh cell strainer and centrifuged to collect cells from the filtrate. The cell pellet was washed twice with PBS and resuspended in DMEM/F12 containing 10\% FBS. The culture medium was replaced with a fresh medium every 3 or 4 days.

\section{Immunofluorescence (IF) staining}

The cell samples (smears or slides) were airdried and placed in a $4 \%$ paraformaldehyde (PFA) solution overnight. They were then permeabilized and rinsed three times ( 3 min each) with PBS. Each section was treated with two drops of a methanol solution with $3 \% \mathrm{H}_{2} \mathrm{O}_{2}$ and blocked for $10 \mathrm{~min}$ at room temperature $\left(15-25^{\circ} \mathrm{C}\right)$ before being rinsed with PBS three times. Following the addition of $100 \mu \mathrm{l}$ of normal goat serum (ready to use) and incubation for $20 \mathrm{~min}$ at room temperature, each 
Table I. Primer sequences

\begin{tabular}{|c|c|c|}
\hline Gene name & $F:\left(5^{\prime}-3^{\prime}\right)$ & $R:\left(5^{\prime}-3^{\prime}\right)$ \\
\hline ILK & TTCGTTGTGGACCAGAGCCAAG & AGTGCGTGCCGAGGTATGAGA \\
\hline TLR4 & TCCAGAGCCGTTGGTGTATCTT & ACAATTCGACCTGCTGCCTCA \\
\hline MyD88 & CGTCGCATGGTGGTGGTTGTT & TCGCTTCTGTTGGACACCTGGA \\
\hline$N F-\kappa B(p 65)$ & TGTGGTGGAGGACTTGCTGAGG & GGAGTGCTGCCTTGCTGTTCTT \\
\hline Myocardin & CAAGGGTGTGCACAGATGAC & TAGGATGGGGGCTGGGTTAT \\
\hline SRF & CATGACGTCGTCTGTACCCA & GAGGTGGGGGCATACATCAC \\
\hline miRNA-325-3p & CGCGCCTAGTAGGTGCTCAGT & AGTGCAGGGTCCGAGGTATT \\
\hline U6 & CTCGCTTCGGCAGCACA & TGGTGTCGTGGAGTCG \\
\hline GAPDH & CGGCAAGTTCAACGGCACAGT & CGCTCCTGGAAGATGGTGATGG \\
\hline
\end{tabular}

section was incubated with $50 \mu$ of primary antibody (diluted at $1: 100$ ) in a humid incubator for $2 \mathrm{~h}$ at $37^{\circ} \mathrm{C}$. Then, the cells were rinsed three times with PBS, incubated with $50 \mu \mathrm{l}$ of FITC (diluted at 1 : 100) for $1 \mathrm{~h}$ in a dark environment at $37^{\circ} \mathrm{C}$, and then rinsed three times once again with PBS. Following this, the cells were counterstained. After mounting them, protein expression in the cells was observed through a microscope and three high-expression areas were photographed.

\section{Real-time qf-PCR}

Total RNAs were extracted from the smooth muscle tissues or SMCs using the TRIzol reagent. The PrimeScript RT master mix was used for reverse transcription to obtain cDNA for amplification. The primer sequences were as shown in Table I. Real-time qf-PCR was performed to determine the relative levels of expression of the relevant mRNAs with the $2^{-\Delta \Delta c t}$ method.

\section{Cell transfection}

The primary BSMCs were transfected after passage twice. The MiR-325-3p and LV-ILK used had both been designed, constructed, and transfected by Nanjing KeyGen Biotech Co., Ltd.

\section{Western blot (WB) test}

The smooth muscle tissues or SMCs were added to a $1 \mathrm{ml}$ lysis buffer and placed on a shaking table at $4^{\circ} \mathrm{C}$ for gentle oscillation for $15 \mathrm{~min}$, followed by centrifugation at $14000 \mathrm{rpm}$ for $15 \mathrm{~min}$ at $4^{\circ} \mathrm{C}$. The isolated supernatant was collected for the quantitative determination of total protein concentration using the BCA method. Proteins at a concentration of $100 \mathrm{~g} / \mathrm{l}$ were analyzed with SDS-PAGE before membrane transfer and mounting. Primary and secondary antibodies (diluted at $1: 1,000)$ were added for incubation. The cultures were analyzed using enhanced chemiluminescence, and the optical densities (ODs) were deter- mined using LabWorks 4.0. The protein expression levels were represented by the ratio of the corresponding OD to the GAPDH.

\section{Dual-luciferase reporter assay}

The primary BSMC culture was performed in a routine fashion using an incubator at $37^{\circ} \mathrm{C}$ with $5 \% \mathrm{CO}_{2}$. The primary BSMCs were harvested in the exponential phase of growth and inoculated into a 96-well culture plate at a density of $1.5 \times$ $10^{4}$ cells per well, where each well had a capacity of $100 \mu \mathrm{l}$, and were cultured for $24 \mathrm{~h}$. Following this, the miRNA mimics, their negative controls, and the reporter gene vector of the target mRNA 3'UTR Lipofectamine 2000 were diluted in media and mixed thoroughly. After letting them stand for $20 \mathrm{~min}$, the solutions were added to the respective cells. Experiments were performed in triplicate. The substrates were added $48 \mathrm{~h}$ after transfection to determine the fluorescent intensity.

\section{Statistical analysis}

The software SPSS 22.0 was used for data analysis. The measurement data are labeled as mean \pm standard deviation (mean \pm SD). The intergroup comparison was examined by the $t$-test (two groups) or by ANOVA (three or more groups), with the results considered to be significant if $p<0.05$.

\section{Results}

\section{Primary BSMC identification and construction of PBOO cell model}

$\alpha$-SMA is a marker protein of BSMCs. Once the BSMCs had been extracted, the cell immunofluorescence assay revealed that both the cellular morphology and the $\alpha$-SMA expression were consistent with BSMC criteria (Figure 1 A). TGF- $\beta 1$ was used to stimulate the BSMCs and construct an in-vitro cell model of PBOO. When stimulated with TGF- $\beta 1$ at different concentrations, the rate of cell proliferation and level of expression of F-ac- 
A
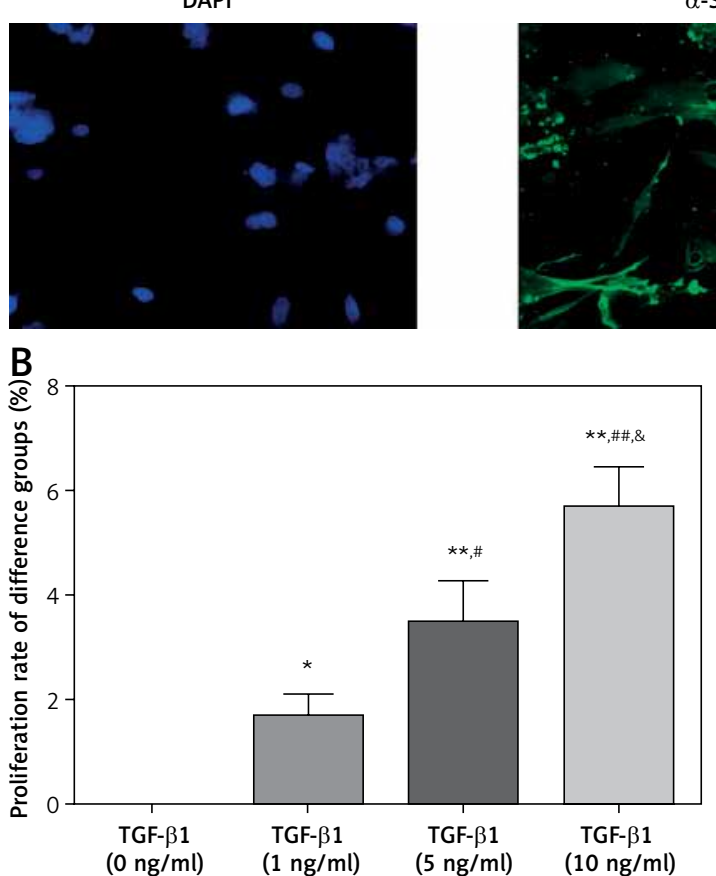

C

DAPI

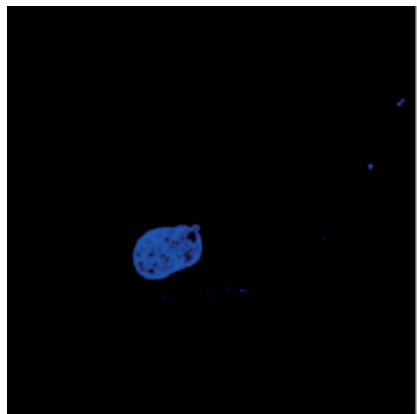

TGF- $\beta 1$

$(1 \mathrm{ng} / \mathrm{ml})$

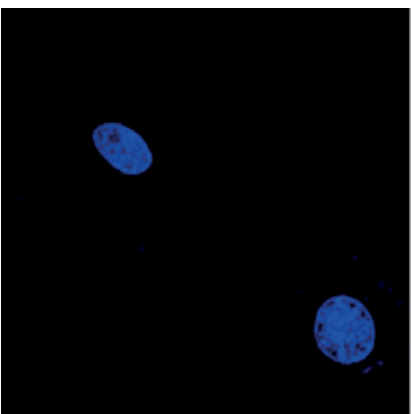

TGF- $\beta 1$ $(5 \mathrm{ng} / \mathrm{ml})$

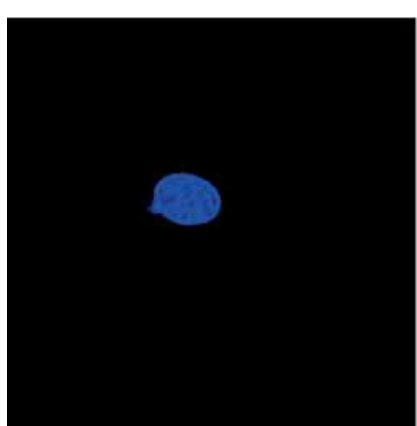

$\alpha-S M A$
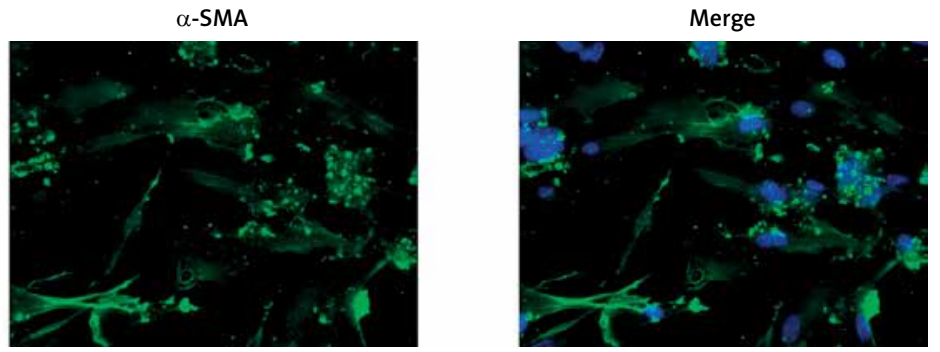

-actin
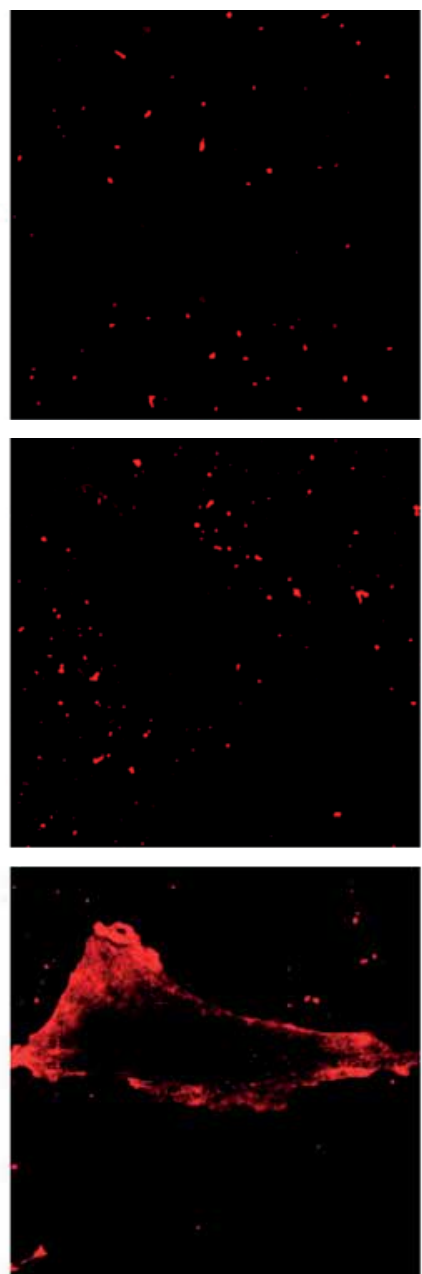

Merge
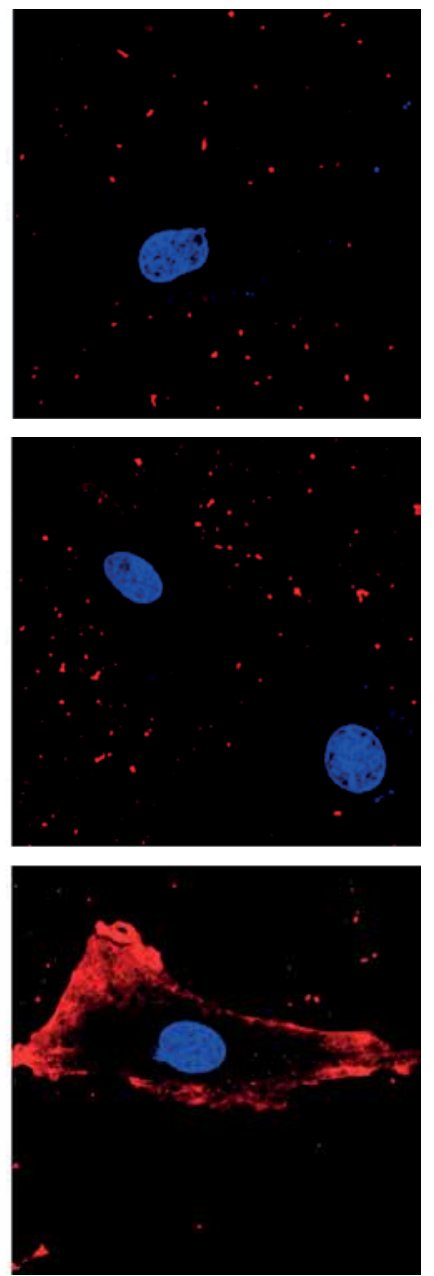

Figure 1. Primary BSMC cell identification and PBOO cell model construction. A - $\alpha$-SMA protein by immunofluorescence assay (200x). B - Proliferation rate of different groups. C - F-actin protein expression of different groups by immunofluorescence assay $(200 \times)$

${ }^{\star} p<0.05,{ }^{* *} p<0.01,{ }^{* * *} p<0.001$, compared with TGF- $\beta 1(0 \mathrm{ng} / \mathrm{ml}) ;{ }^{*} p<0.05,{ }^{\# \#} p<0.01$, compared with TGF- $\beta 1(1 \mathrm{ng} / \mathrm{ml}$ $\& p<0.05$, compared with TGF- $\beta 1(5 \mathrm{ng} / \mathrm{ml})$. 

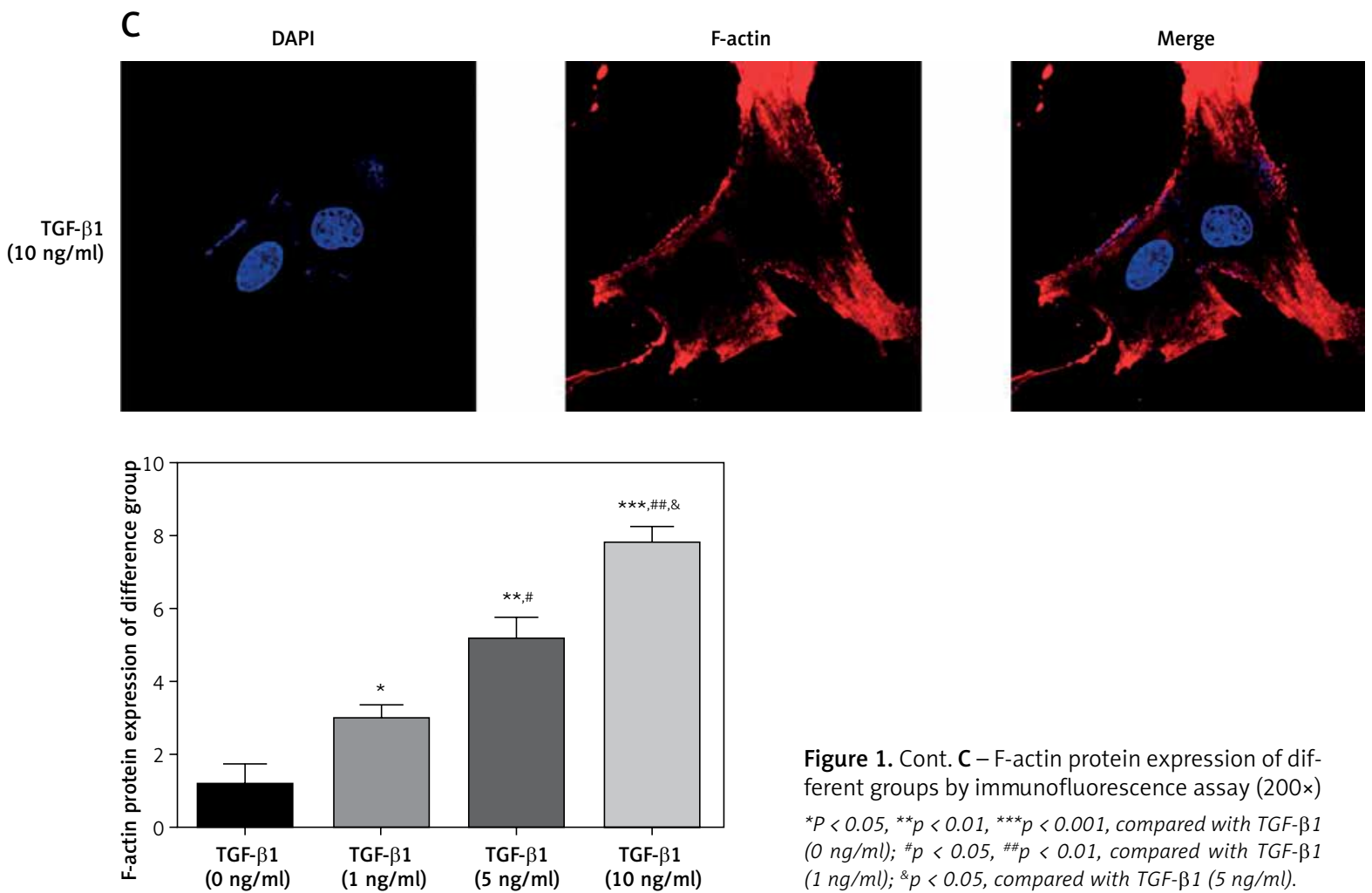

Figure 1. Cont. C - F-actin protein expression of different groups by immunofluorescence assay $(200 x)$ ${ }^{*} p<0.05,{ }^{* *} p<0.01,{ }^{* * *} p<0.001$, compared with TGF- $\beta 1$ (0 ng/ml); $\# p<0.05,{ }^{\# \#} p<0.01$, compared with TGF- $\beta 1$ (1 $\mathrm{ng} / \mathrm{ml})$; ${ }^{\&} p<0.05$, compared with TGF- $\beta 1(5 \mathrm{ng} / \mathrm{ml})$.

tin significantly increased compared with those of the TGF- $\beta 1(0 \mathrm{mg} / \mathrm{ml})$ group $(p<0.001$, Figures 1 $B, C)$, and the dose-effect relation was identified by using the TGF- $\beta 1$ concentration $(p<0.05$, Figures $1 \mathrm{~B}, \mathrm{C})$.

\section{Expression levels of $\alpha$-SM-actin and SM $22 \alpha$ upon TGF- $\beta 1$ stimulation at various concentrations}

The cell immunofluorescence assay indicated that compared with the TGF- $\beta 1(0 \mathrm{mg} / \mathrm{ml})$ group, the groups stimulated with TGF- $\beta 1$ showed significant differences in the levels of expression of $\alpha$-SM-actin and SM22 $\alpha(p<0.05$, Figures $2 \mathrm{~A}, \mathrm{~B})$, and exhibited a significant dose-effect relation with TGF- $\beta 1$ (each $p<0.05$, Figures $2 \mathrm{~A}, \mathrm{~B}$ ).

\section{Expression of ILK, TLR4, MyD88,} and NF- $\mathrm{B}(\mathrm{p} 65)$ proteins detected

Compared with the TGF- $\beta 1(0 \mathrm{mg} / \mathrm{ml})$ group, TGF- $\beta 1$ intervention raised the levels of expression of ILK, TLR4, MyD88, and NF-אB(p65) ( $p<$ 0.05 , Figures $3 A-D$, respectively), and a dose-effect relationship with TGF- $\beta 1$ concentration was detected ( $p<0.05$, Figures 3 A-D, respectively).

\section{Expression of myocardin and SRF proteins}

Compared with the TGF- $\beta 1$ ( $0 \mathrm{mg} / \mathrm{ml})$ group, TGF- $\beta 1$ intervention raised the levels of expres- sion of myocardin and SRF proteins $(p<0.05$, Figures $4 \mathrm{~A}, \mathrm{~B}$, respectively), and a dose-effect relationship with TGF- $\beta 1$ concentration was detected ( $p<0.05$, Figures $4 \mathrm{~A}, \mathrm{~B}$, respectively).

\section{Relative gene and protein expression}

The results of RT-qPCR assay showed that compared with the TGF- $\beta 1(0 \mathrm{mg} / \mathrm{ml})$ group, expression levels of ILK, TLR4, MyD88, NF-кB(p65), myocardin, and SRF genes and proteins were significantly up-regulated, and that of miRNA-325$3 p$ was significantly down-regulated in the TGF$\beta 1$-treated groups in a dose-dependent manner $(p<0.05$, Figures $5 \mathrm{~A}, \mathrm{~B}$, respectively).

\section{Cell proliferation and F-actin expression in different groups}

The results of CCK- 8 assay showed that the rate of proliferation of the TGF- $\beta 1$ group was significantly higher than that of the blank group ( $p<0.001$, Figure 6 A). When miRNA-325-3p was supplemented, the rate of proliferation of the TGF- $\beta 1+$ miRNA-325-3p group was significantly lower compared with that of the TGF- $\beta 1$ group $(p<0.001$, Figure $6 \mathrm{~A}$ ). With ILK transfection, the rate of proliferation of the TGF- $\beta 1+$ miRNA-325-3p + LV-ILK group was significantly higher compared with that of the TGF- $\beta 1+$ miRNA-325-3p group $(p<0.001$, Figure 6 A). With cellular immunofluorescence, the F-actin protein expression of the 
A

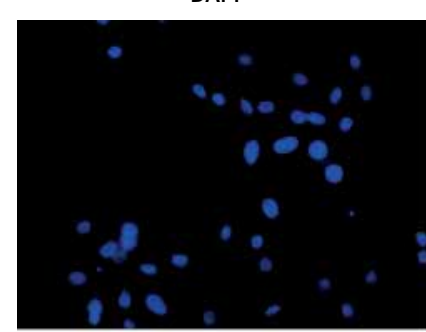

$\mathrm{TGF}-\beta 1$
$(0 \mathrm{ng} / \mathrm{ml})$
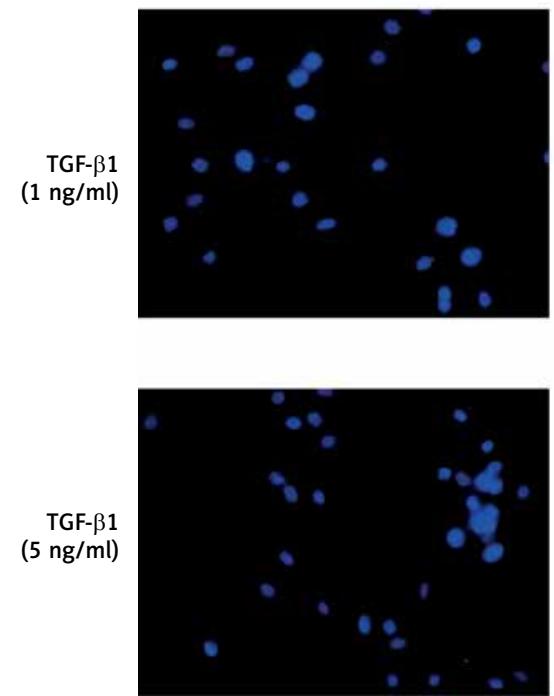

TGF- $\beta 1$ $(5 \mathrm{ng} / \mathrm{ml})$

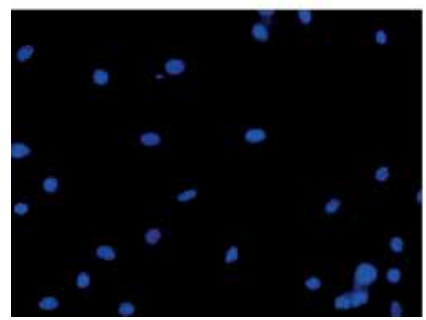

$\alpha-S M-a c t i n$
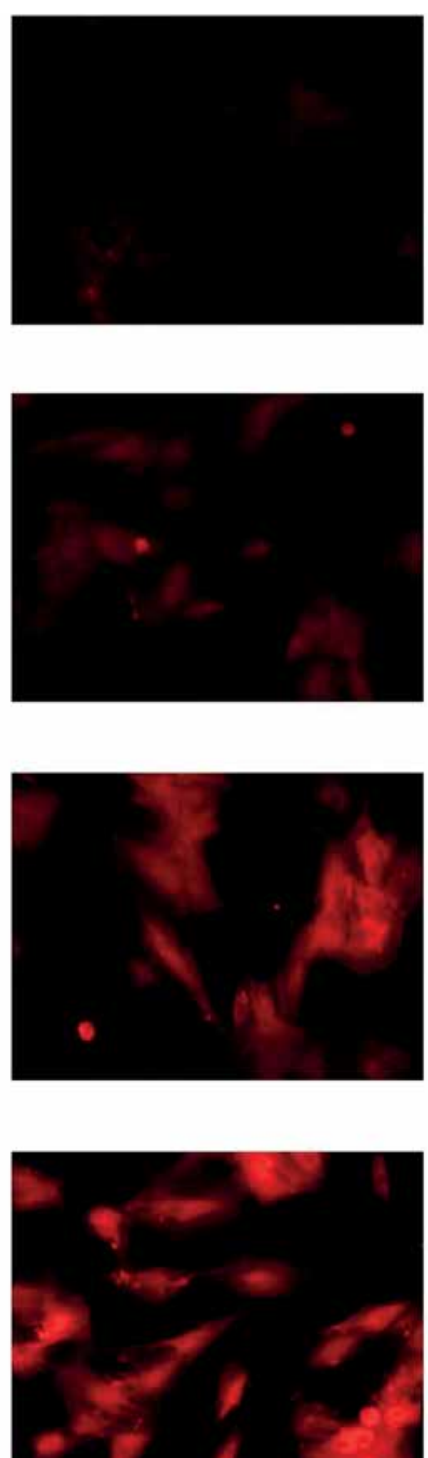

Merge
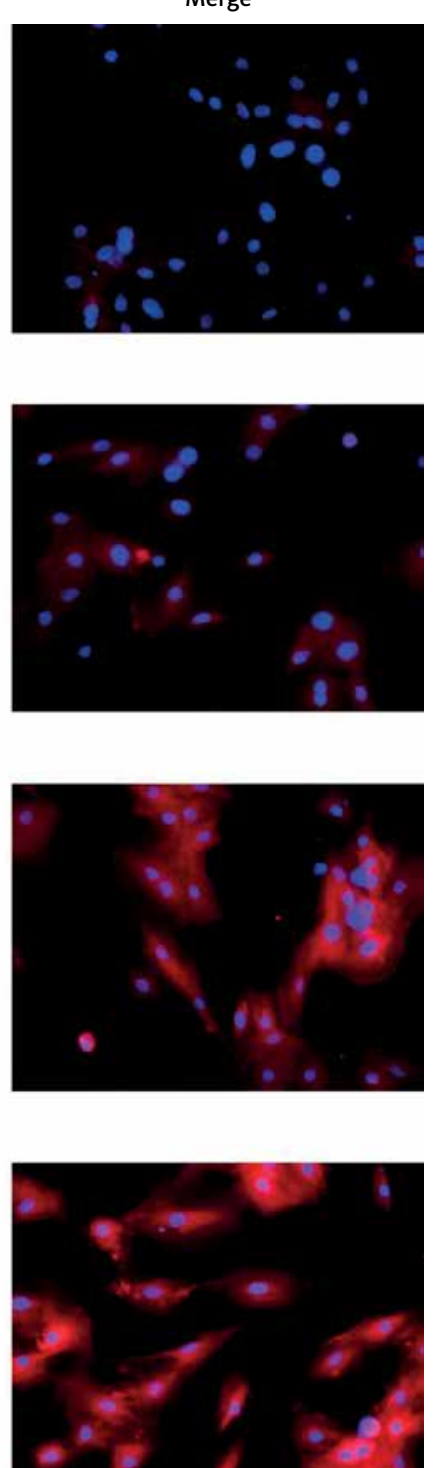

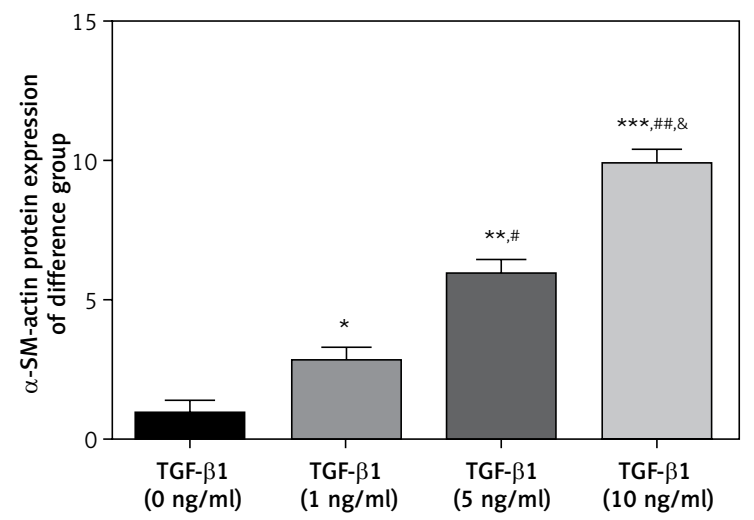

Figure 2. Expression levels of $\alpha$-SM-actin and SM22 $\alpha$ upon TGF- $\beta 1$ at various concentrations. A $-\alpha$-SM-actin protein expression of different groups $(200 x)$

${ }^{*} p<0.05,{ }^{* *} p<0.01,{ }^{* *} p<0.001$, compared with TGF- $\beta 1$ $(0 \mathrm{ng} / \mathrm{ml}) ;{ }^{\#} p<0.05,{ }^{\# \#} p<0.01$, compared with TGF- $\beta$ (1 $\mathrm{ng} / \mathrm{ml}) ;{ }^{\&} p<0.05$, compared with TGF- $\beta 1(5 \mathrm{ng} / \mathrm{ml})$. 
B

DAPI
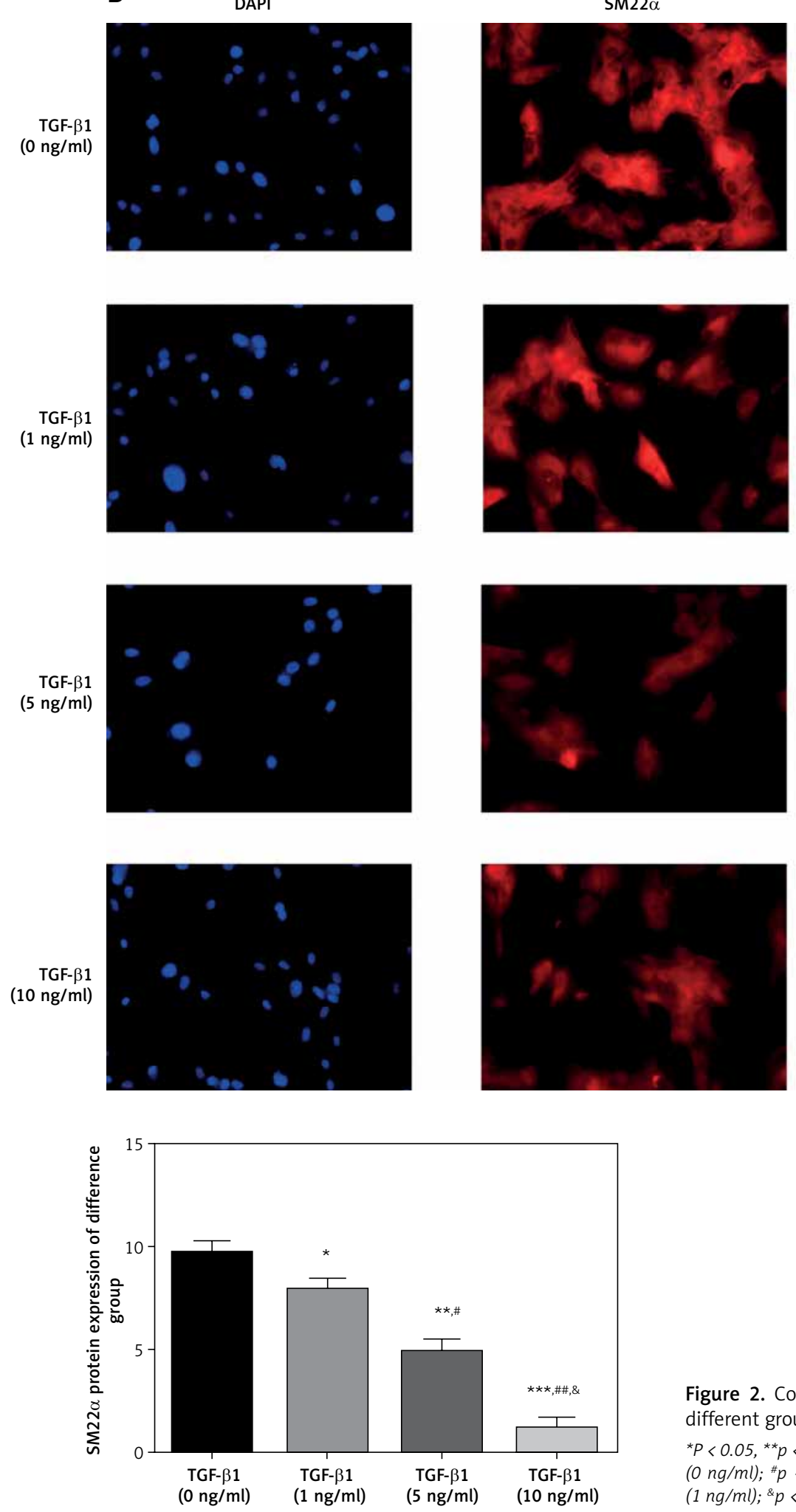
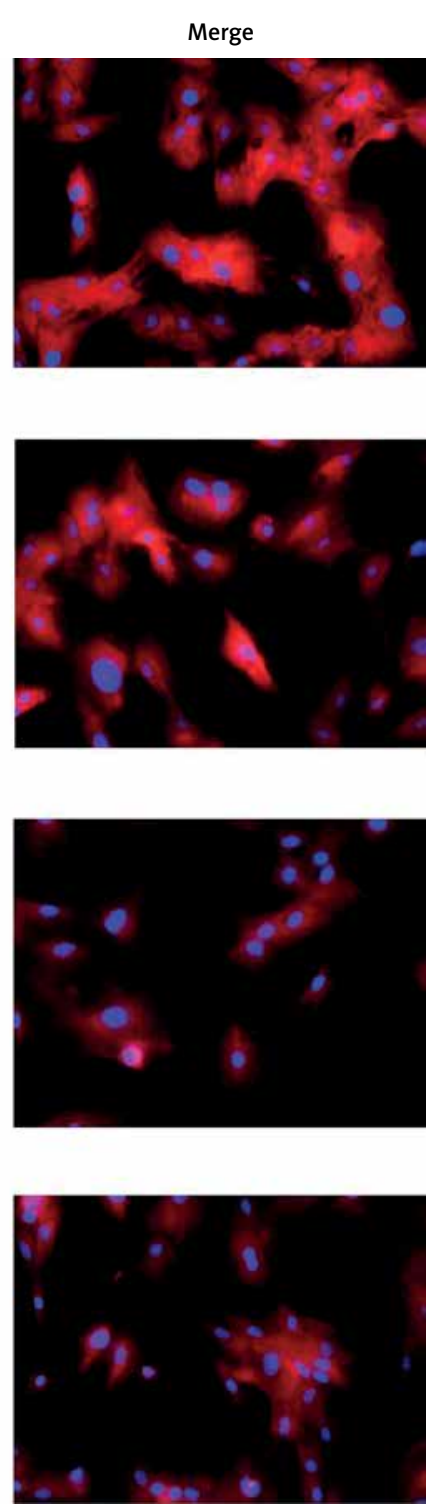

Figure 2. Cont. B - SM-22 2 protein expression of different groups $(200 \times)$

${ }^{*} P<0.05,{ }^{* *} p<0.01,{ }^{* * *} p<0.001$, compared with TGF- $\beta 1$ (0 ng $/ \mathrm{ml}) ; " \#<<0.05$, \# $p<0.01$, compared with TGF- $\beta 1$ (1 ng/ml); ${ }^{*} p<0.05$, compared with TGF- $\beta 1(5 \mathrm{ng} / \mathrm{ml})$. 
A
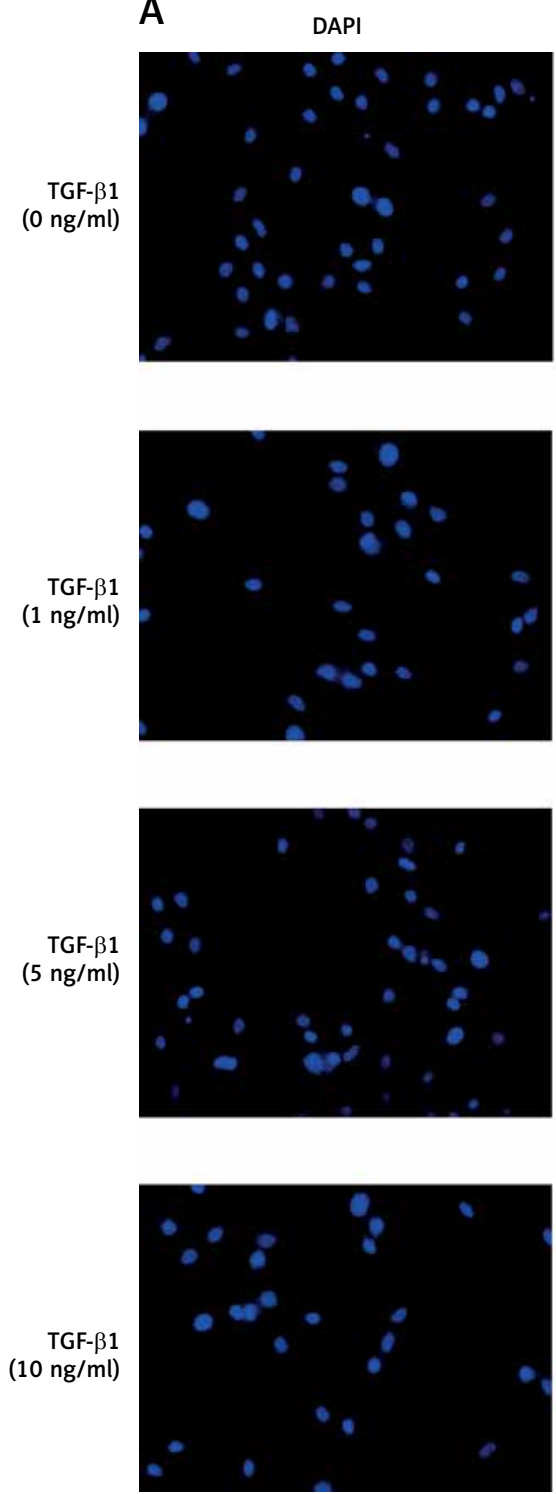

ILK
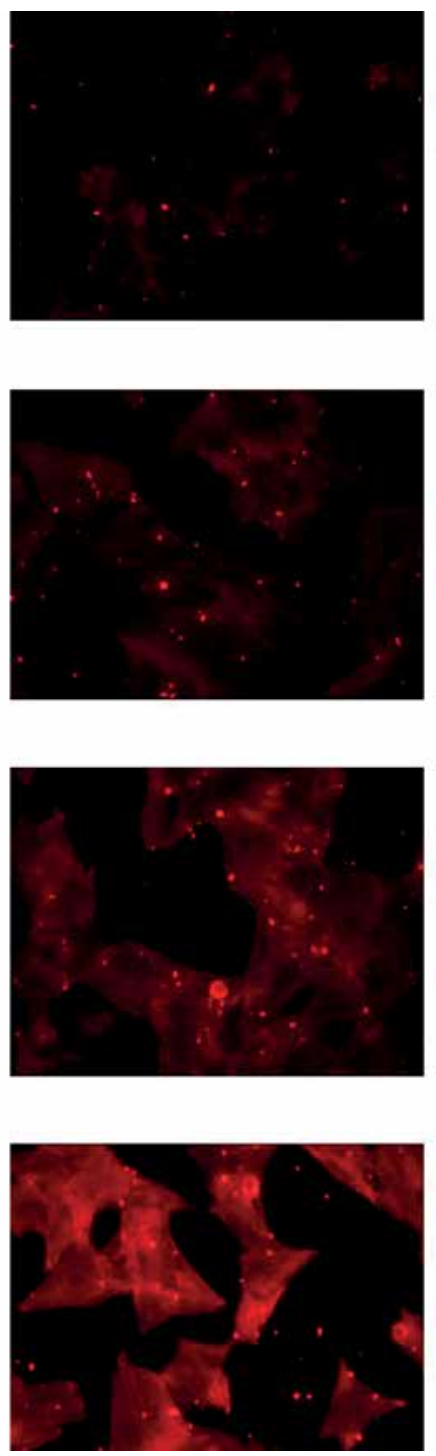

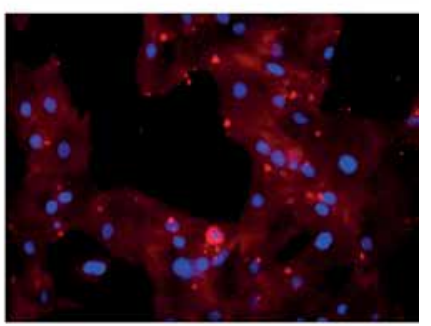

Merge
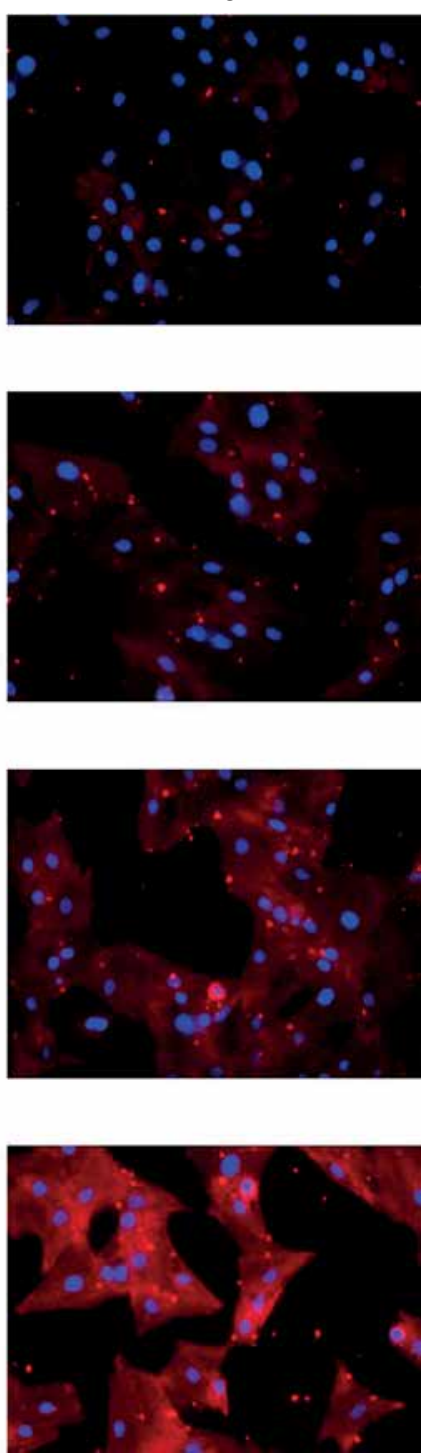

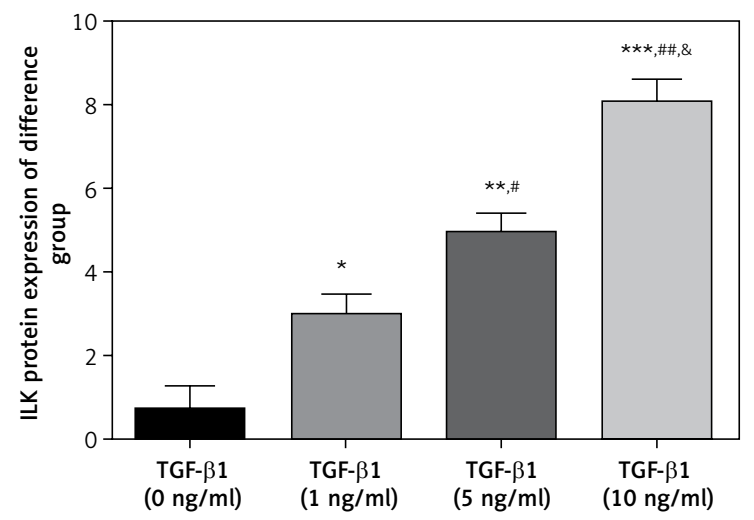

Figure 3. Expression of ILK, TLR4, MyD88 and NF$\kappa B$ (p65) proteins detected with cell immunofluorescence assay. A - ILK protein expression of different groups (200x)

${ }^{*} P<0.05,{ }^{* *} p<0.01,{ }^{* * *} p<0.001$, compared with TGF- $\beta 1$ (0 ng/ml); $\#<<0.05, \# p<0.01$, compared with TGF- $\beta 1$ $(1 \mathrm{ng} / \mathrm{ml}) ;{ }^{*} p<0.05$, compared with TGF- $\beta 1(5 \mathrm{ng} / \mathrm{ml})$. 
B
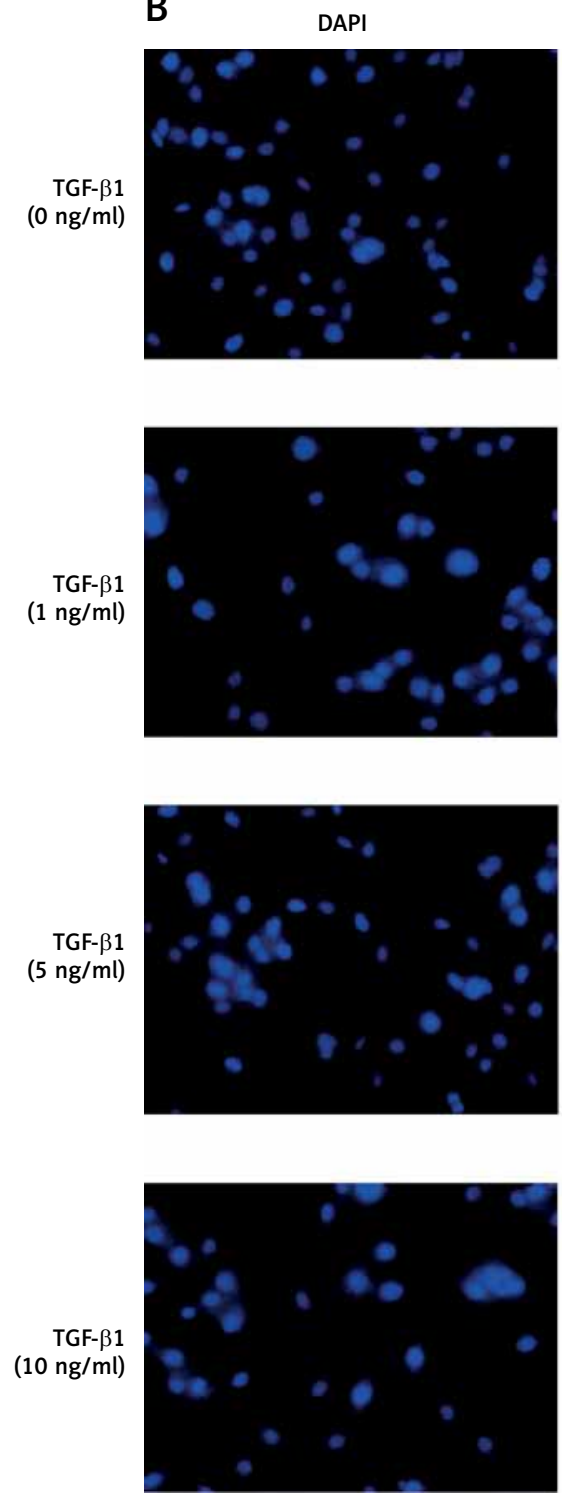

TLR4
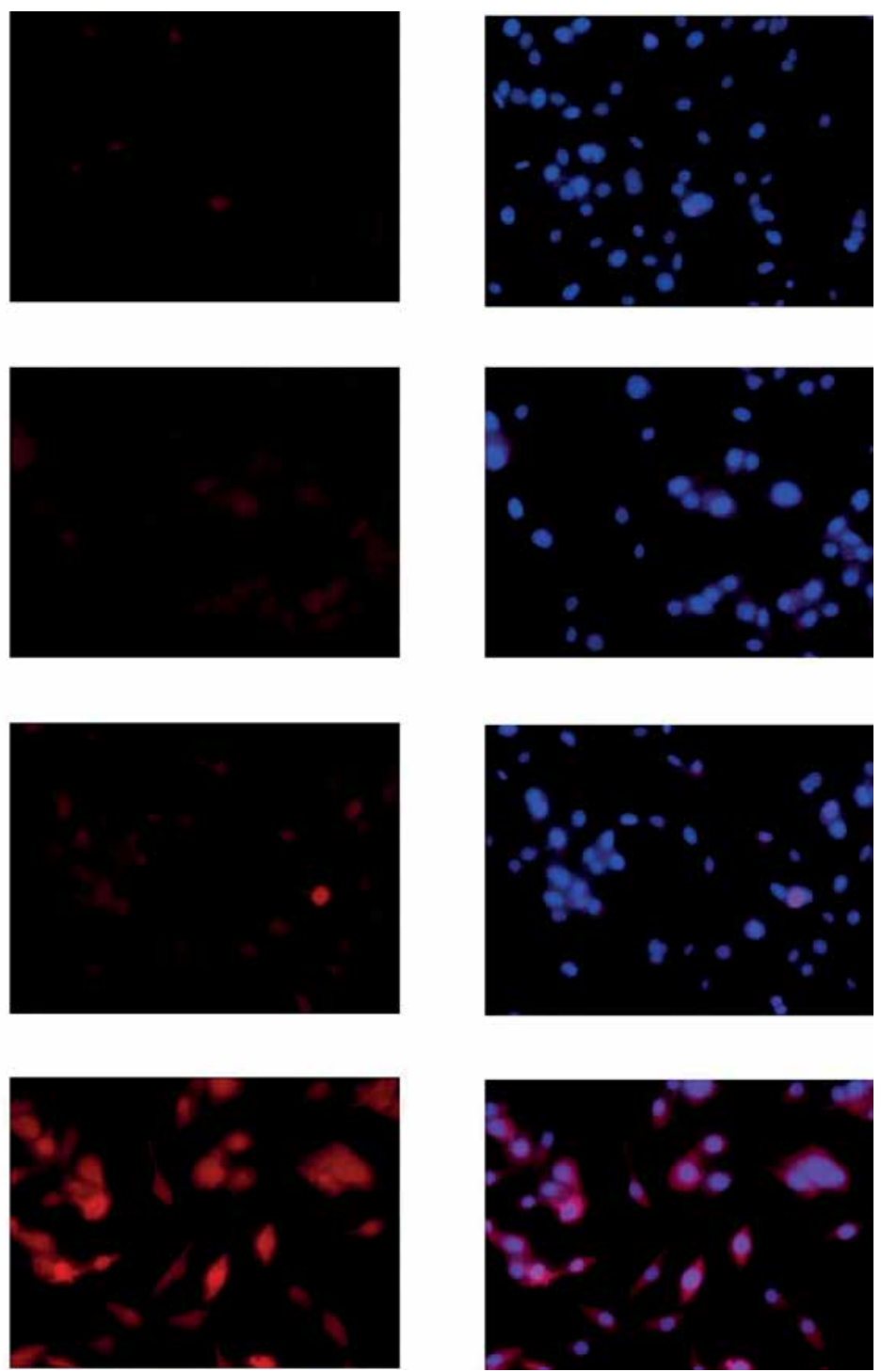

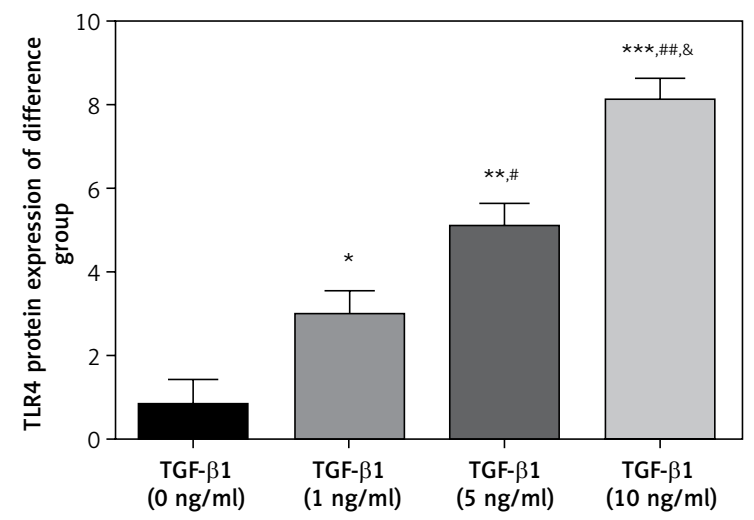

Figure 3. Cont. B - TLR4 protein expression of different groups (200x)

${ }^{*} P<0.05,{ }^{* *} p<0.01,{ }^{* * *} p<0.001$, compared with TGF- $\beta 1$ $(0 \mathrm{ng} / \mathrm{ml}) ; \# p<0.05, \# p<0.01$, compared with TGF- $\beta 1$ $(1 \mathrm{ng} / \mathrm{ml}) ;{ }^{\&} p<0.05$, compared with TGF- $\beta 1(5 \mathrm{ng} / \mathrm{ml})$. 
C
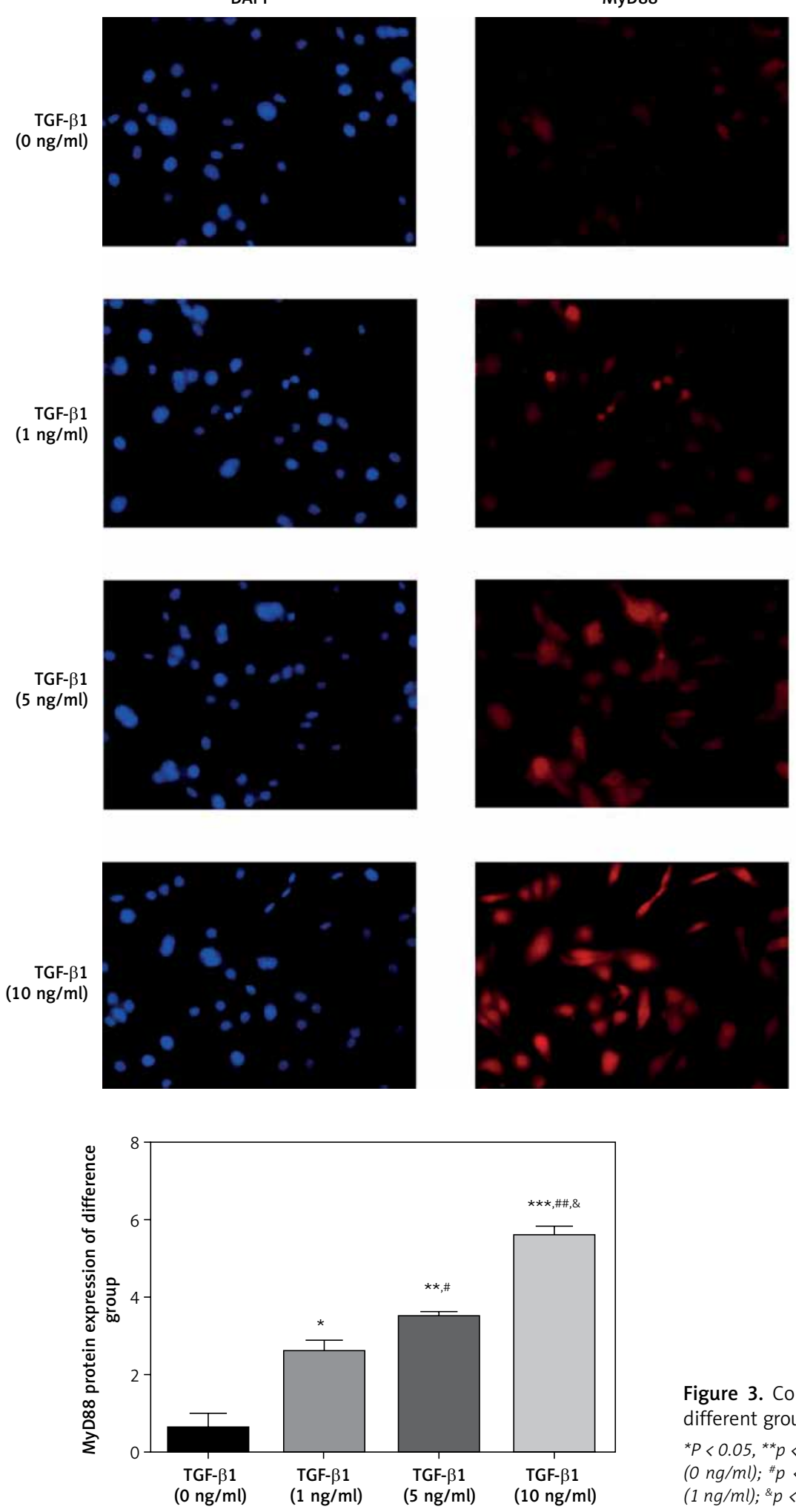
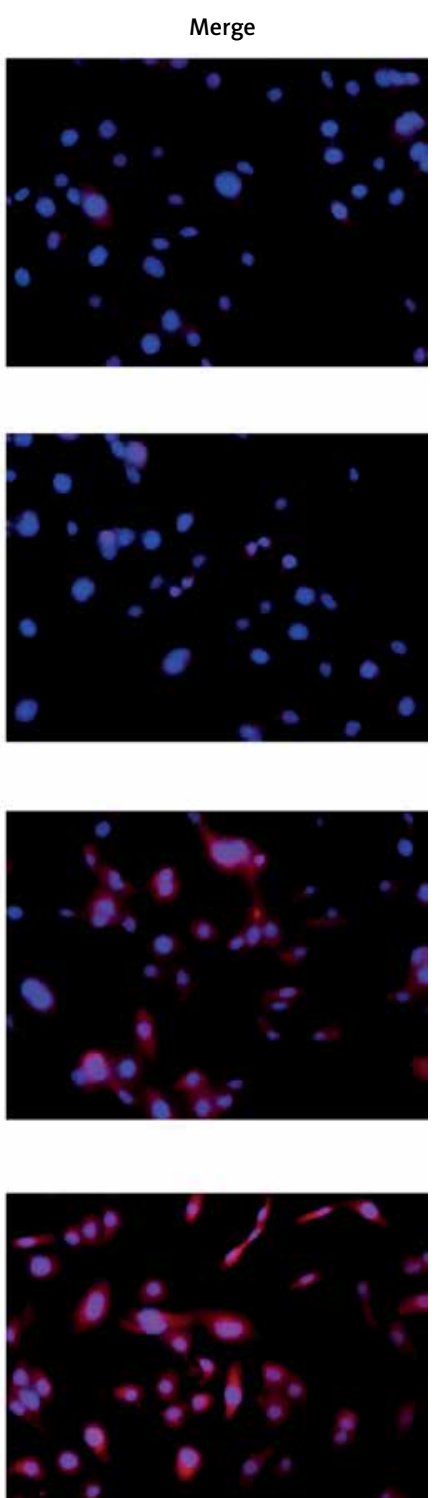

Figure 3. Cont. C - MyD88 protein expression of different groups $(200 x)$

${ }^{*} P<0.05,{ }^{* *} p<0.01$, ${ }^{\star * *} p<0.001$, compared with TGF- $\beta 1$ (0 ng/ml); $\# p<0.05, \# p<0.01$, compared with TGF- $\beta 1$ $(1 \mathrm{ng} / \mathrm{ml}) ;{ }^{*} p<0.05$, compared with TGF- $\beta 1(5 \mathrm{ng} / \mathrm{ml})$. 
D

DAPI
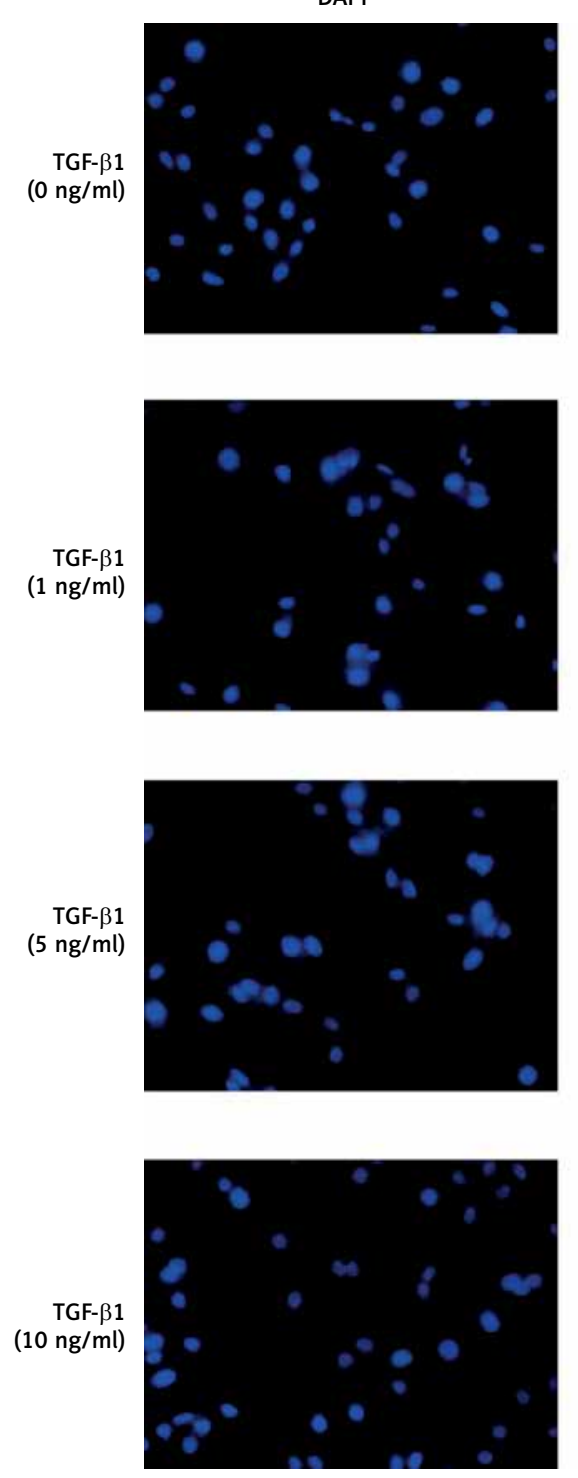

$\mathrm{NF}-\mathrm{\kappa} B(\mathrm{p} 65)$
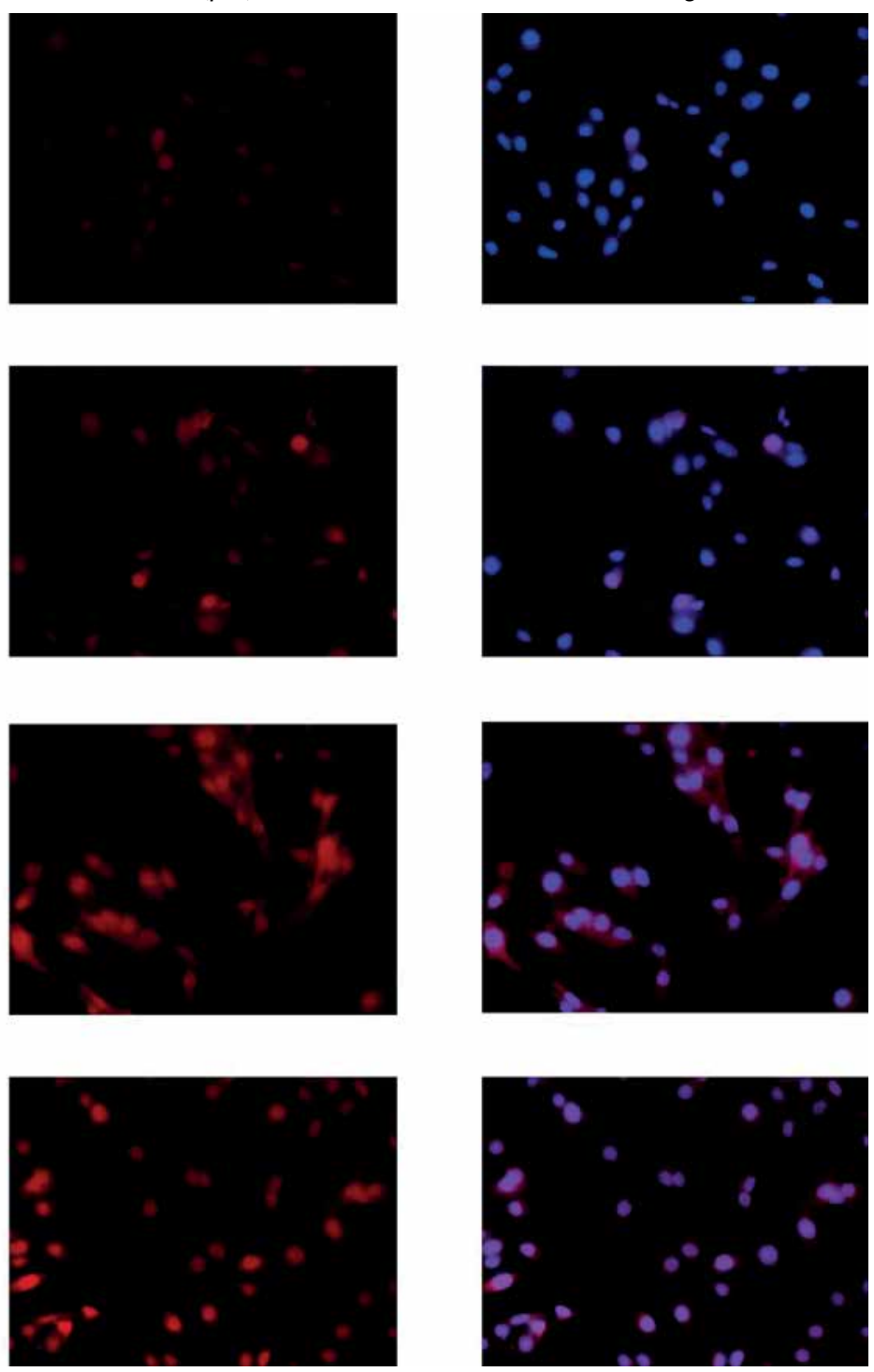

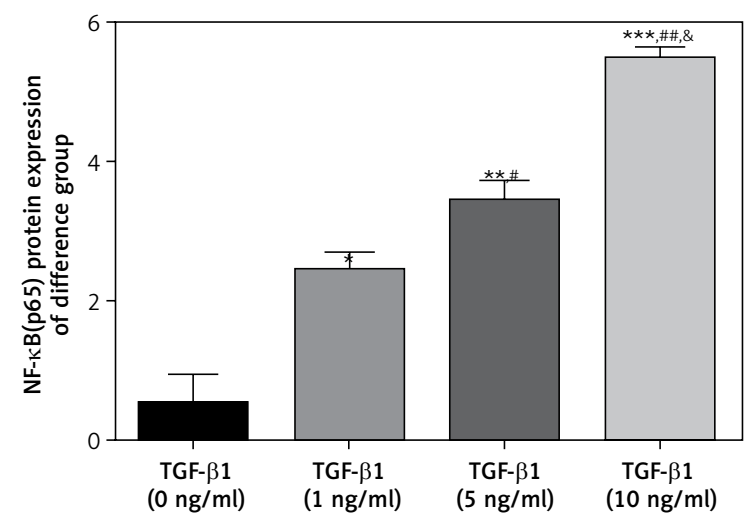

Figure 3. Cont. $\mathbf{D}-\mathrm{NF}-\kappa \mathrm{B}(\mathrm{p} 65)$ protein expression of different groups $(200 x)$

${ }^{*} P<0.05,{ }^{* *} p<0.01,{ }^{* * *} p<0.001$, compared with TGF- $\beta 1$ (0 ng $/ \mathrm{ml}) ; " \#<<0.05$, \# $p<0.01$, compared with TGF- $\beta 1$ (1 ng/ml); ${ }^{*} p<0.05$, compared with TGF- $\beta 1(5 \mathrm{ng} / \mathrm{ml})$. 
A

DAPI
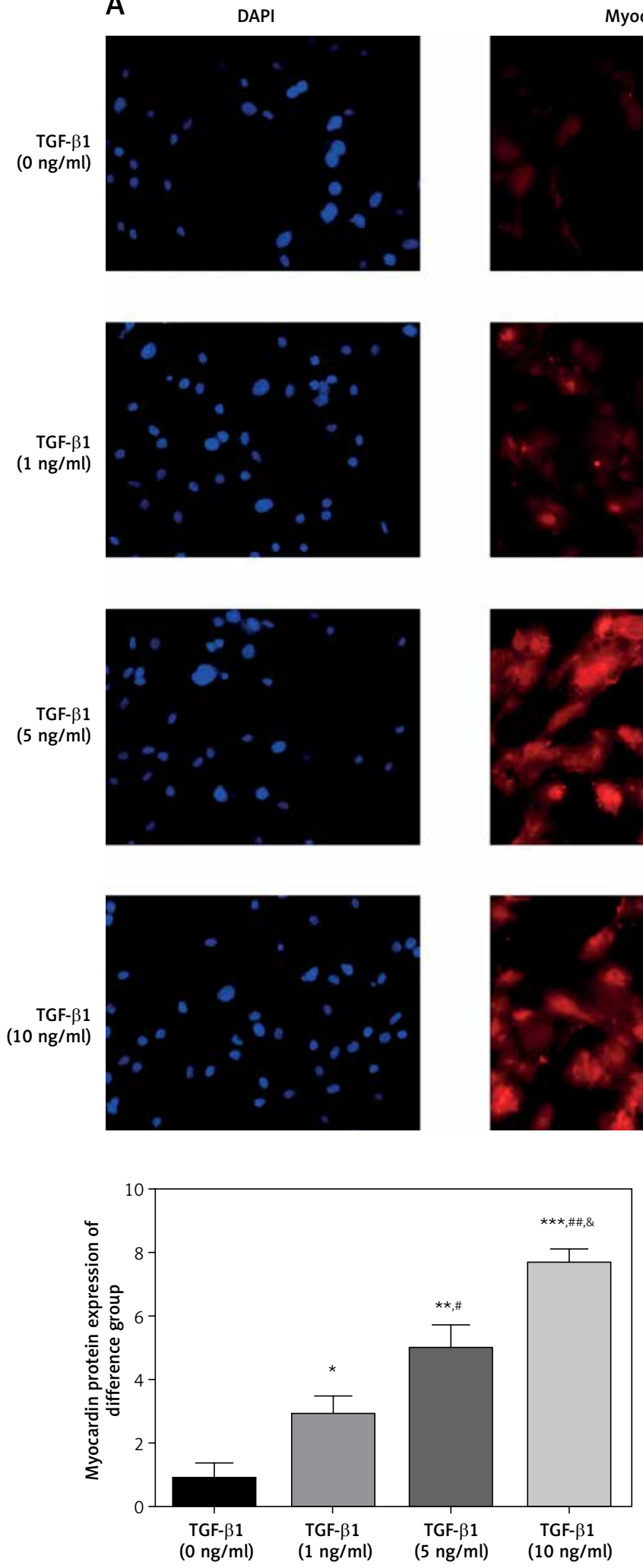

Myocardin
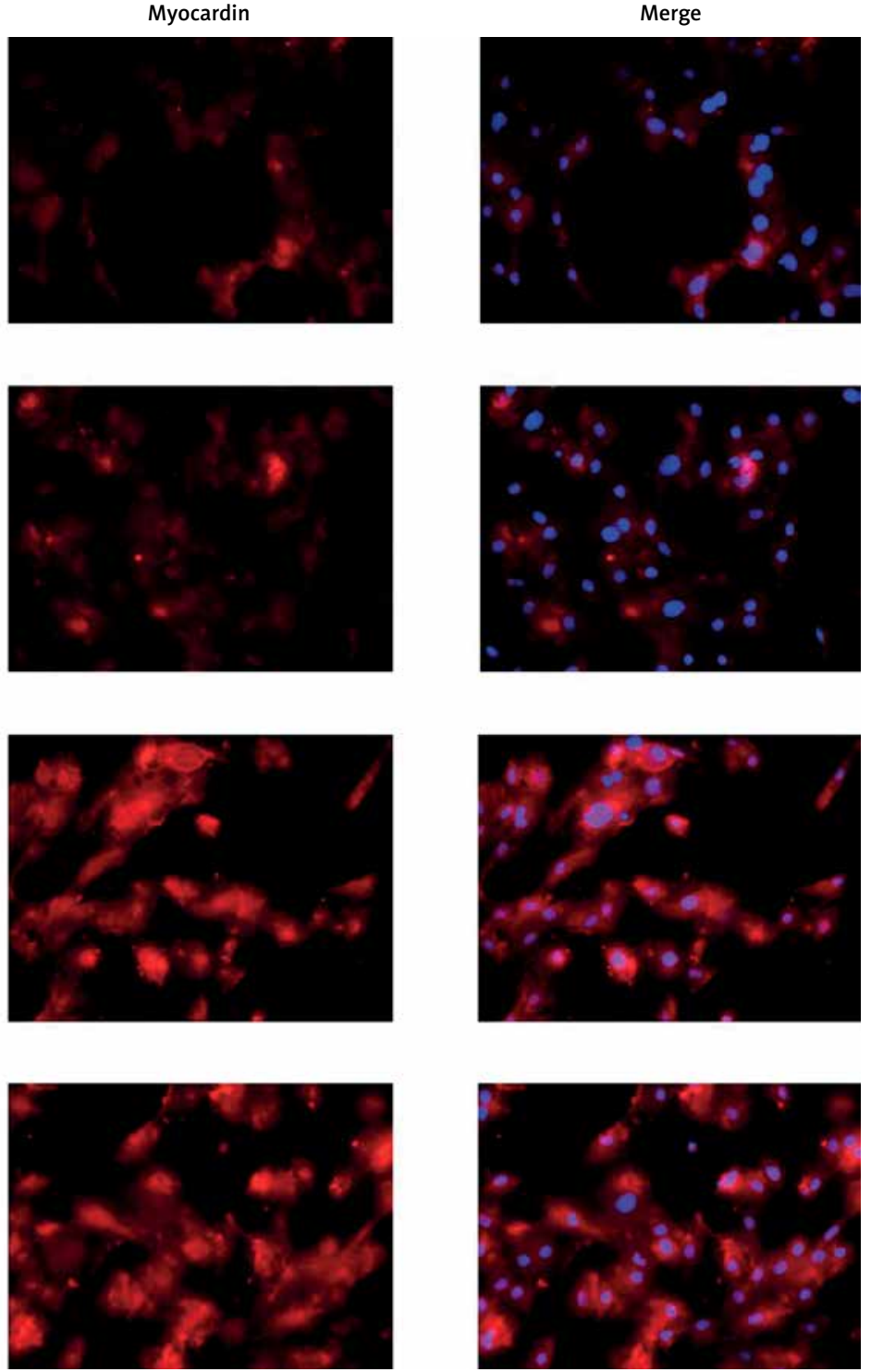

Figure 4. Expression of myocardin and SRF proteins as detected with cell immunofluorescence. A - Myocardin protein expression of different groups (200x)

${ }^{*} P<0.05,{ }^{* *} p<0.01,{ }^{* * *} p<0.001$, compared with TGF- $\beta 1$ (0 ng/ml); $\# p<0.05$, \#\#p<0.01, compared with TGF- $\beta 1$ $(1 \mathrm{ng} / \mathrm{ml}) ;{ }^{*} p<0.05$, compared with TGF- $\beta 1(5 \mathrm{ng} / \mathrm{ml})$. 

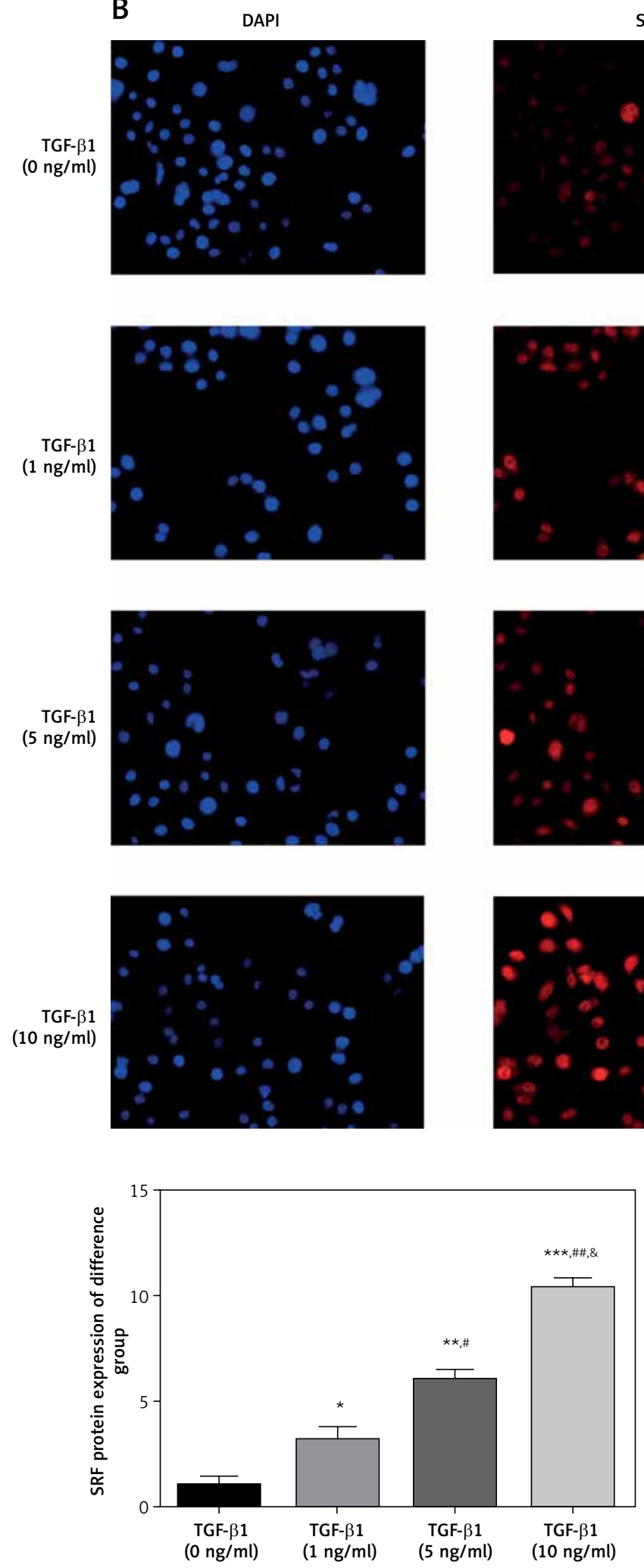

SRF
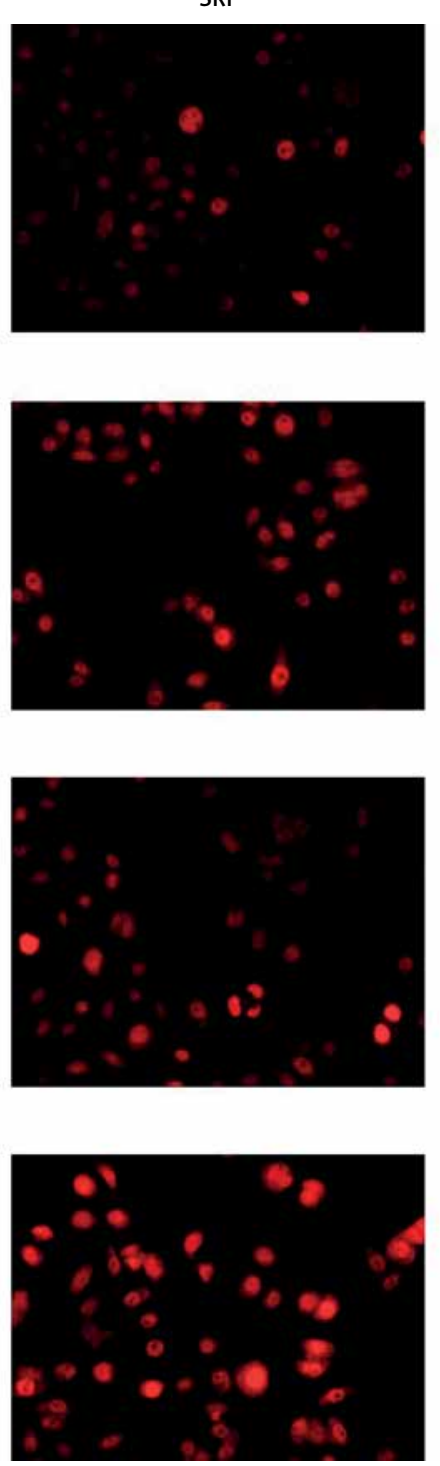

Merge
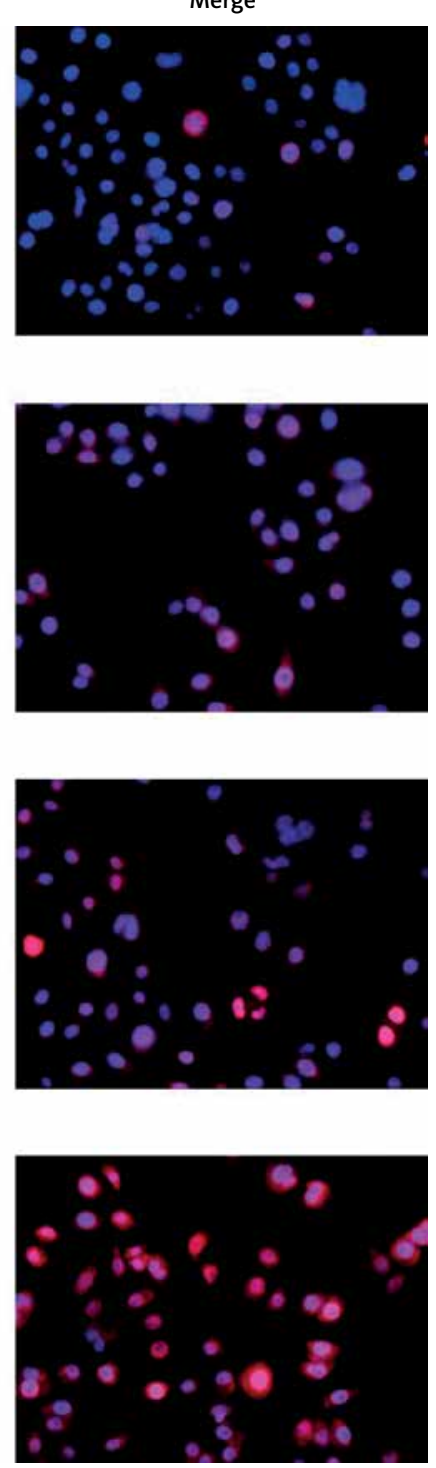

Figure 4. Cont. B - SRF protein expression of different groups (200x)

${ }^{*} P<0.05,{ }^{* *} p<0.01,{ }^{* * *} p<0.001$, compared with TGF- $\beta 1$

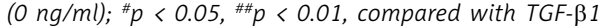
$(1 \mathrm{ng} / \mathrm{ml}) ;{ }^{*} p<0.05$, compared with TGF- $\beta 1(5 \mathrm{ng} / \mathrm{ml})$. 

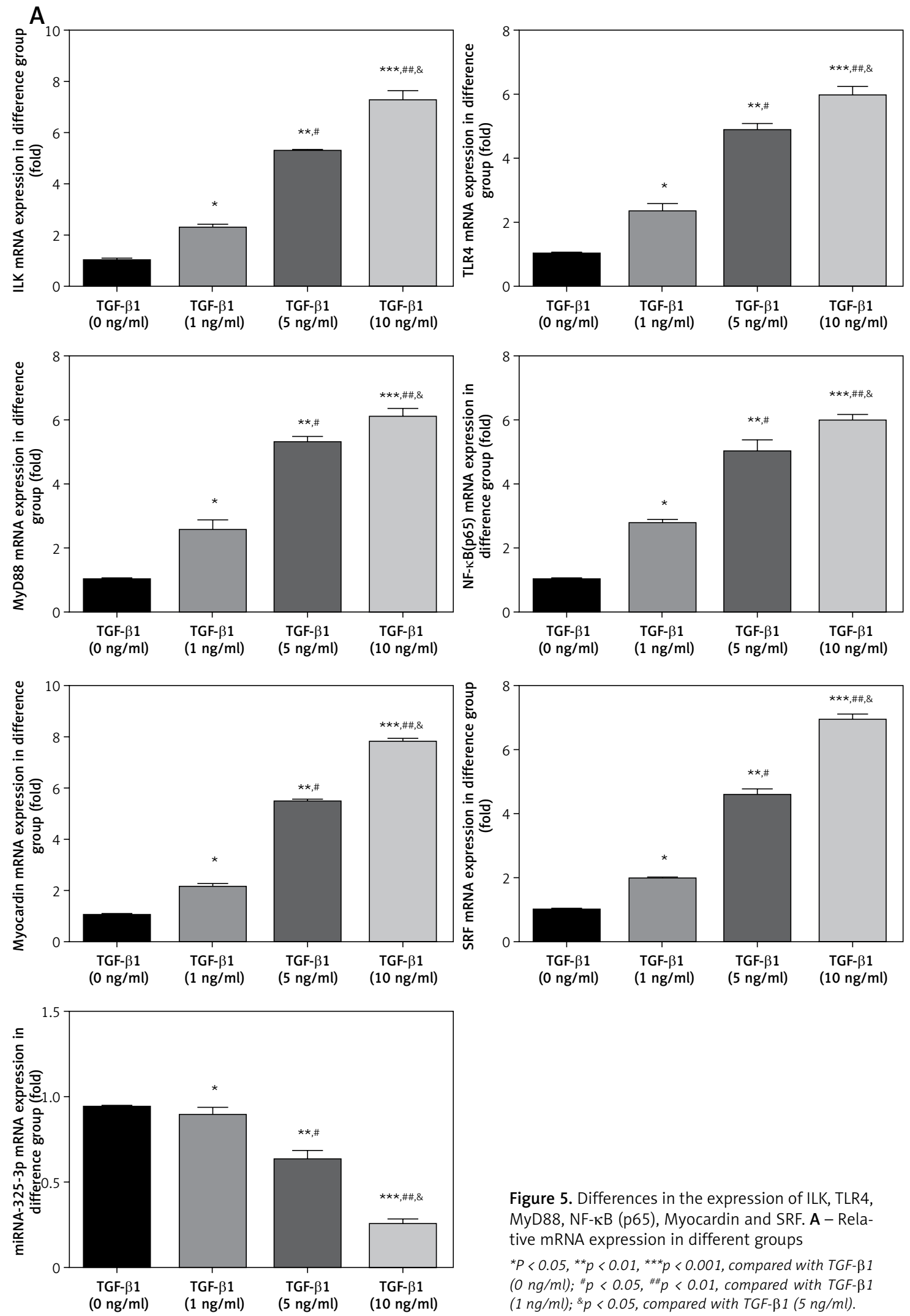

Figure 5. Differences in the expression of ILK, TLR4, MyD88, NF-кB (p65), Myocardin and SRF. A - Relative $\mathrm{mRNA}$ expression in different groups

${ }^{*} P<0.05,{ }^{* *} p<0.01,{ }^{* * *} p<0.001$, compared with TGF- $\beta 1$ $(0 \mathrm{ng} / \mathrm{ml}) ; \# p<0.05$, \#\#p<0.01, compared with TGF- $\beta 1$ (1 $\mathrm{ng} / \mathrm{ml}) ;{ }^{\&} p<0.05$, compared with TGF- $\beta 1(5 \mathrm{ng} / \mathrm{ml})$. 

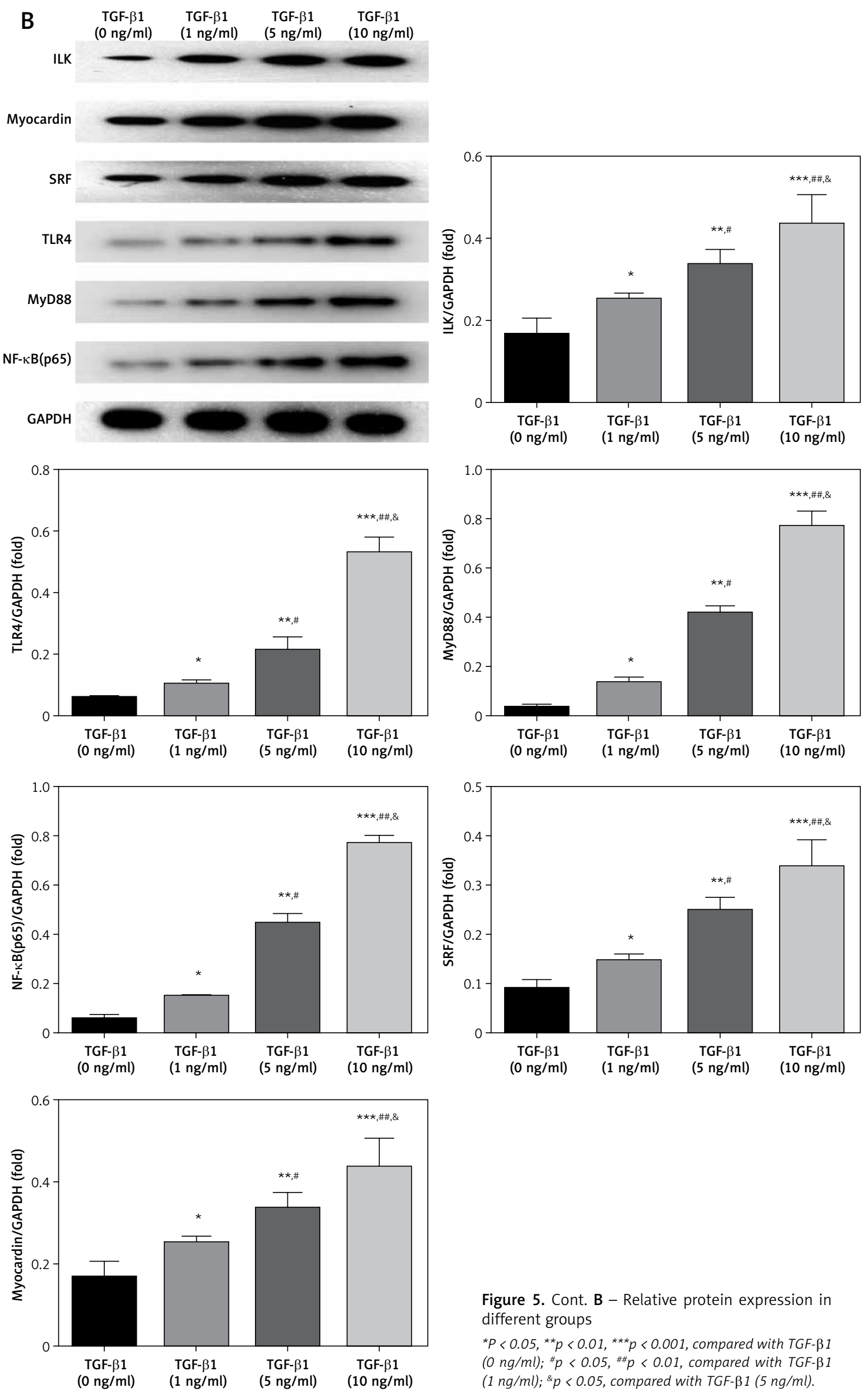

Figure 5. Cont. B - Relative protein expression in different groups

${ }^{*} P<0.05,{ }^{* *} p<0.01,{ }^{* * *} p<0.001$, compared with TGF- $\beta 1$ ( $0 \mathrm{ng} / \mathrm{ml}) ;{ }^{*} p<0.05,{ }^{*} p<0.01$, compared with TGF- $\beta 1$

(1 $\mathrm{ng} / \mathrm{ml}) ;{ }^{\&} p<0.05$, compared with TGF- $\beta 1(5 \mathrm{ng} / \mathrm{ml})$. 


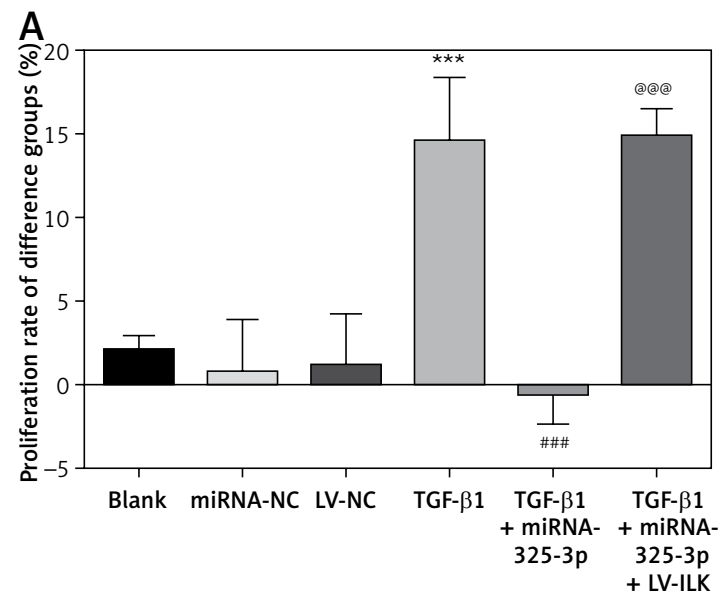

B

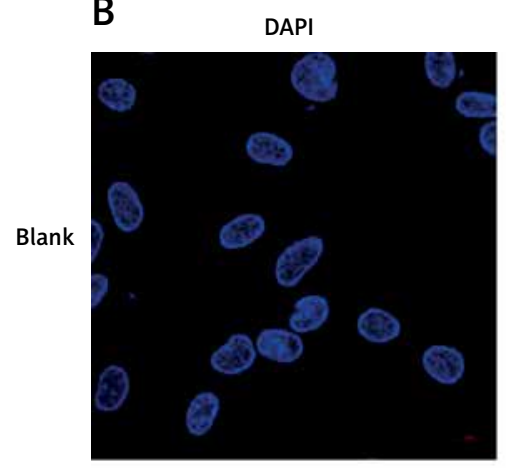

miRNA-NC

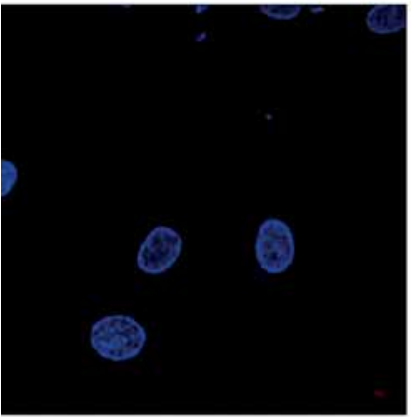

LV-NC

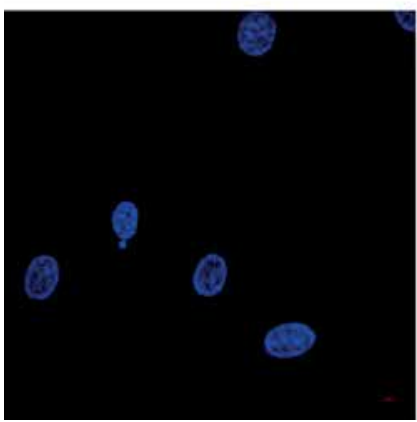

F-actin
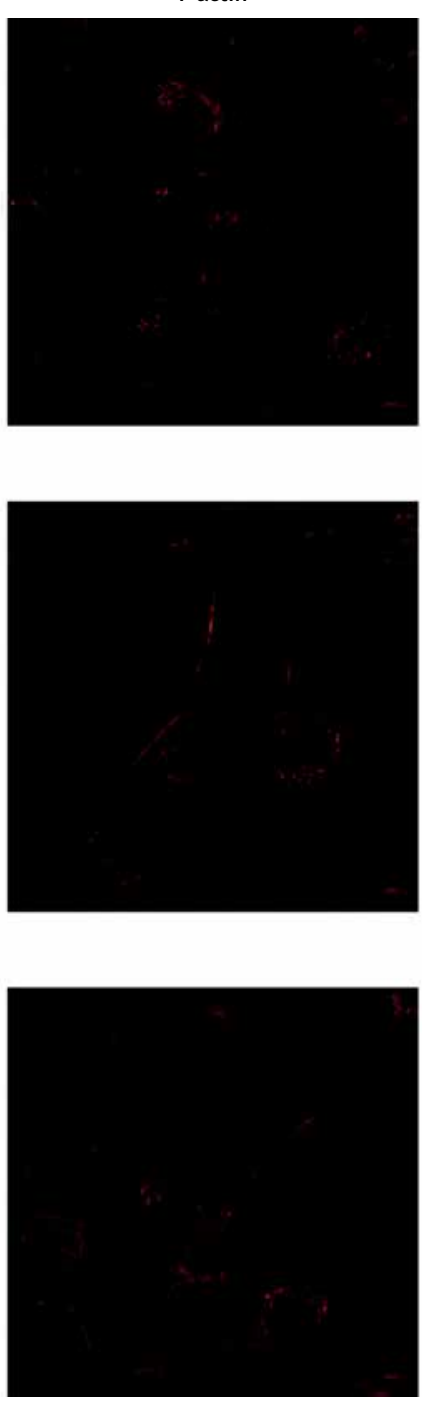

Merge
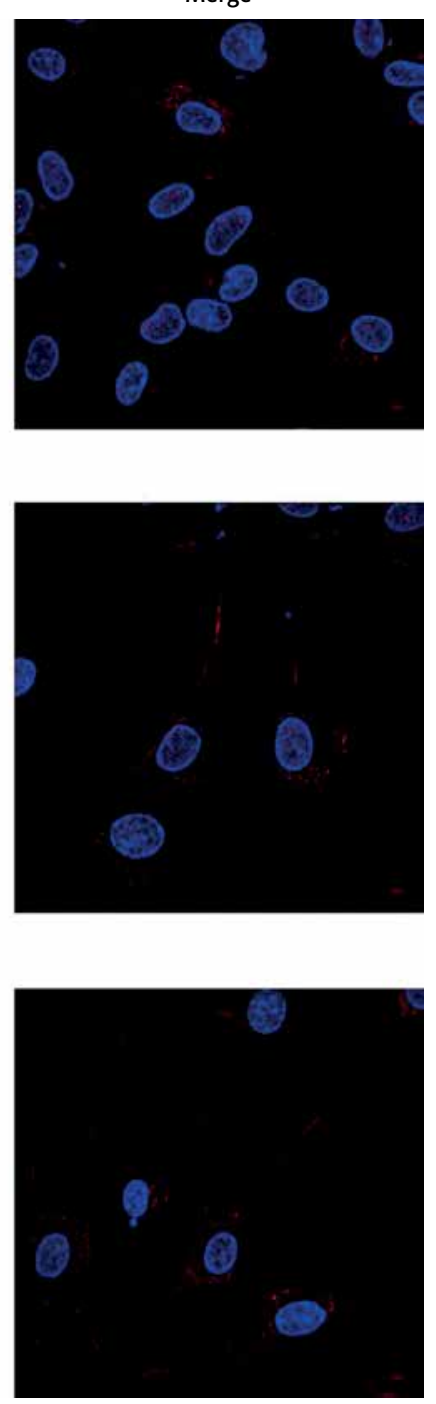

Figure 6. Cell proliferation and F-actin expression in different groups. A - Proliferation rate of different groups. B - F-actin protein expression of different groups (200x)

Blank - BSMCS treated with normal, miRNA-NC - BSMCS were transfected with miRNA-negative control (NC), LV-NC - BSMCS were transfected with LV-negative control (NC), TGF- $\beta 1$ - BSMCS were treated with $10 \mathrm{ng} / \mathrm{ml} T G F-\beta 1$, TGF- $\beta 1+$ miRNA-325$3 p-B S M C s$ transfected with miRNA-325-3p and treated with $10 \mathrm{ng} / \mathrm{ml}$ TGF- $\beta 1$, TGF- $\beta 1+$ miRNA-325-3p + LV-ILK - BSMCS transfected with miRNA-325-3p and ILK and treated with $10 \mathrm{ng} / \mathrm{ml} \mathrm{TGF-} \beta 1$. ${ }^{* * *} P<0.001$, compared with blank group;

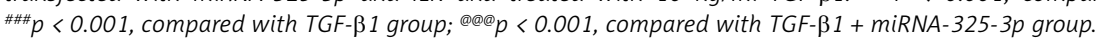


B

DAPI

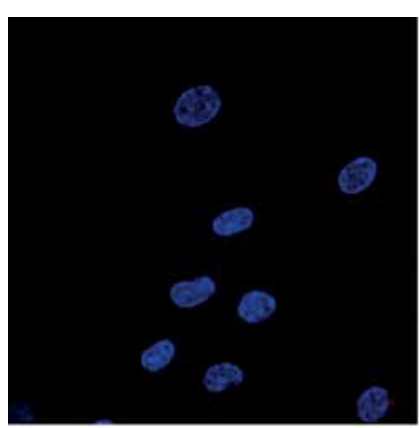

TGF- $\beta 1+$ miRNA-325-3p miRNA-325-3p + LV-ILK
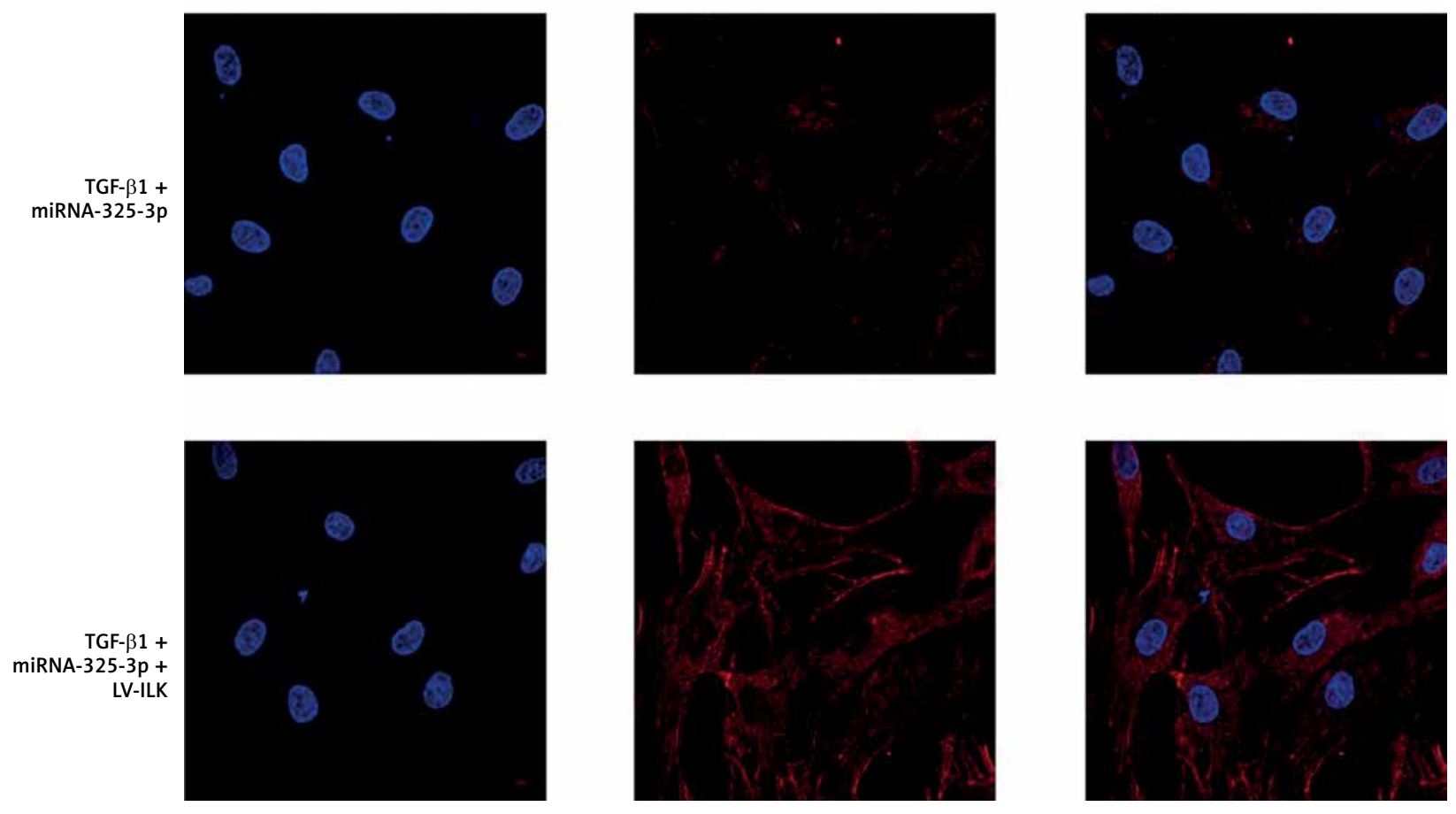

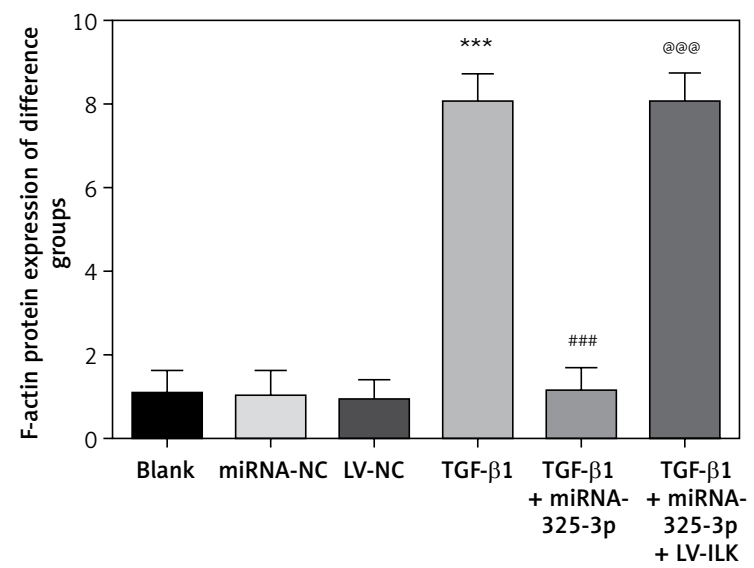

Figure 6. Cont. B - F-actin protein expression of different groups (200x)

Blank - BSMCs treated with normal, miRNA-NC - BSMCs were transfected with miRNA-negative control (NC), LV-NC - BSMCS were transfected with $L V$-negative control (NC). TGF- $\beta 1-B S M C s$ were treated with $10 \mathrm{ng} / \mathrm{ml}$ TGF- $\beta 1$, TGF- $\beta 1+$ miRNA-325$3 p-B S M C s$ transfected with miRNA-325-3p and treated with $10 \mathrm{ng} / \mathrm{ml}$ TGF- $\beta 1$, TGF- $\beta 1+$ miRNA-325-3p + LV-ILK - BSMCs transfected with miRNA-325-3p and ILK and treated with $10 \mathrm{ng} / \mathrm{ml}$ TGF- $\beta 1$. ${ }^{\star * *} P<0.001$, compared with blank group;

$\# \# p<0.001$, compared with TGF- $\beta 1$ group; $@ @ p<0.001$, compared with TGF- $\beta 1+$ miRNA-325-3p group. 
TGF- $\beta 1$ group was significantly higher compared with that of the blank group ( $p<0.001$, Figure 6 B). When miRNA-325-3p was supplemented, the F-actin protein expression of the TGF- $\beta 1+$ miRNA325-3p group was significantly lower compared with the TGF- $\beta 1$ group $(p<0.001$, Figure 6 B). With ILK transfection, the F-actin protein expression of the TGF- $\beta 1+$ miRNA-325-3p + LV-ILK group was significantly higher compared with the TGF- $\beta 1+$ miRNA-325-3p group ( $p<0.001$, Figure $6 \mathrm{~B})$.

\section{$\alpha-S M$-actin and SM-22 $\alpha$ protein expression}

Cellular immunofluorescence significantly increased the expression of $\alpha$-SM-actin and significantly reduced that of $S M-22 \alpha$ compared with those of the blank group ( $p<0.001$, Figures 7 A, B). The supplementation of miRNA-325-3p significantly reduced the expression of $\alpha$-SM-actin and significantly increased that of SM-22 $\alpha$ compared with values of the TGF- $\beta 1$ group ( $p<0.001$, Figures $7 \mathrm{~A}, \mathrm{~B})$. ILK transfection significantly increased the expression of $\alpha$-SM-actin while significantly reducing that of SM-22 $\alpha$ compared with those of the TGF- $\beta 1+$ miRNA-325-3p group $(p<0.001$, Figures 7 A, B).

\section{ILK, TLR 4, MyD88, and NF- $\kappa B(p 65)$ protein expression}

Cellular immunofluorescence significantly increased the expression levels of ILK, TLR 4, MyD88, and NF- $\mathrm{KB}(\mathrm{p} 65)$ proteins in the TGF- $\beta 1$ group compared with those of the compared blank group ( $p<0.001$, respectively, Figure 8 ). The miRNA-325$3 p$ supplement significantly reduced expression of ILK, TLR 4, MyD88, and NF- $\mathrm{KB}(\mathrm{p} 65)$ proteins in the TGF- $\beta 1+$ miRNA-325-3p group compared with the TGF- $\beta 1$ group ( $p<0.001$, Figure 8$)$. ILK transfection significantly increased expression levels of the ILK, TLR 4, MyD88, and NF- $\mathrm{KB}(\mathrm{p} 65)$ proteins in the TGF- $\beta 1+$ miRNA-325-3p + LV-ILK group compared with the TGF- $\beta 1+$ miRNA-325-3p group $(p<0.001$, Figure 8).

\section{Expression of myocardin and SRF proteins}

Cellular immunofluorescence significantly increased expression levels of myocardin and SRF proteins in the TGF- $\beta 1$ group compared with compared the blank group $(p<0.001$, Figures 9 A, B, respectively). The miRNA-325-3p supplement significantly reduced expression levels of myocardin and SRF proteins in the TGF- $\beta 1+$ miRNA-325-3p group compared with the TGF- $\beta 1$ group $(p<0.001$, Figures $9 \mathrm{~A}, \mathrm{~B}$, respectively). ILK transfection significantly increased expression levels of myocardin and SRF proteins in the TGF- $\beta 1+$ miRNA-325-3p + LV-ILK group compared with the TGF- $\beta 1+$ miRNA-325-3p group ( $p<0.001$, Figures 9 A, B, respectively).

\section{Relative gene and protein expression}

The results of RT-qPCR assay show that the mRNA expression of miRNA-325-3p was significantly down-regulated in the TGF- $\beta 1$ group compared with the blank group ( $p<0.001$, Figure 10 ). Compared with the TGF- $\beta 1$ group, the expression levels of miRNA-325-3p of the TGF- $\beta 1+$ miRNA325-3p and TGF- $\beta 1+$ miRNA-325-3p + LV-ILK groups were significantly up-regulated $(p<0.001$, Figures $10 \mathrm{~A}, \mathrm{~B}$, respectively). Compared with the blank group, ILK, TLR 4, MyD88, NF- $\mathrm{B}(\mathrm{p} 65)$, myocardin, and SRF gene and protein expression were significantly up-regulated in the TGF- $\beta 1$ group $(p<0.001$, Figures $10 \mathrm{~A}, \mathrm{~B}$, respectively,). miRNA325-3p transfection significantly down-regulated ILK, TLR 4, MyD88, NF-кB(p65), myocardin, and SRF gene and protein expression levels in the TGF- $\beta 1+$ miRNA-325-3p group compared with the TGF- $\beta 1$ group $(p<0.001$, Figures $10 \mathrm{~A}, \mathrm{~B}$, respectively). The ILK supplement significantly up-regulated expression levels of ILK, TLR 4, MyD88, NF$\kappa \mathrm{B}(\mathrm{p} 65)$, myocardin, and SRF genes and proteins in the TGF- $\beta 1+$ miRNA-325-3p + LV-ILK group compared with the TGF- $\beta 1+$ miRNA-325-3p group $(p<0.001$, Figures $10 \mathrm{~A}, \mathrm{~B}$, respectively).

\section{Correlation between miRNA-325-3p and ILK}

In the Mul group, no significant differences were observed between the miRNA-NC and the miRNA-325-3p groups ( $p>0.05$, Figure 11). In WT groups the relative luciferase was significantly reduced in the miRNA-325-3p group compared with that of the miRNA-NC group ( $p<0.001$, Figure 11).

\section{Discussion}

PBOO refers to a class of conditions manifested by difficulties in urination caused by increased obstruction to urinary flow due to anomalies in the bladder neck and/or the urethra [15]. In this study, a model of rats with PBOO was established to investigate pathological changes and the degree of fibrosis in it. The results showed that the homeostasis between the apoptosis and proliferation of the SMC at the outlet of the bladder had been disrupted, and a significantly higher degree of fibrosis was detected. This suggests that BSMC hyperproliferation-induced fibrosis may serve as a major contributor to PBOO.

The BSMCs were shown to have undergone a series of adaptations in response to harmful stimulation, including hypertrophy, phenotypic plasticity, proliferation, apoptosis, and, ultimately, the functional decompensation of the bladder. When PBOO occurs, lowered expression of contractile proteins has been reported to result from reversible phenotypic plasticity in the damaged BSMCs and transformation in the corresponding 

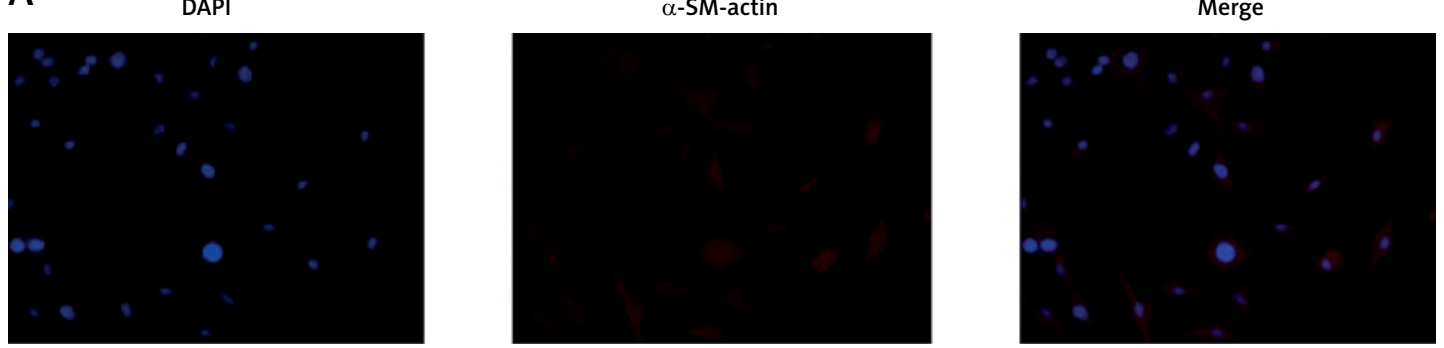

miRNA-NC
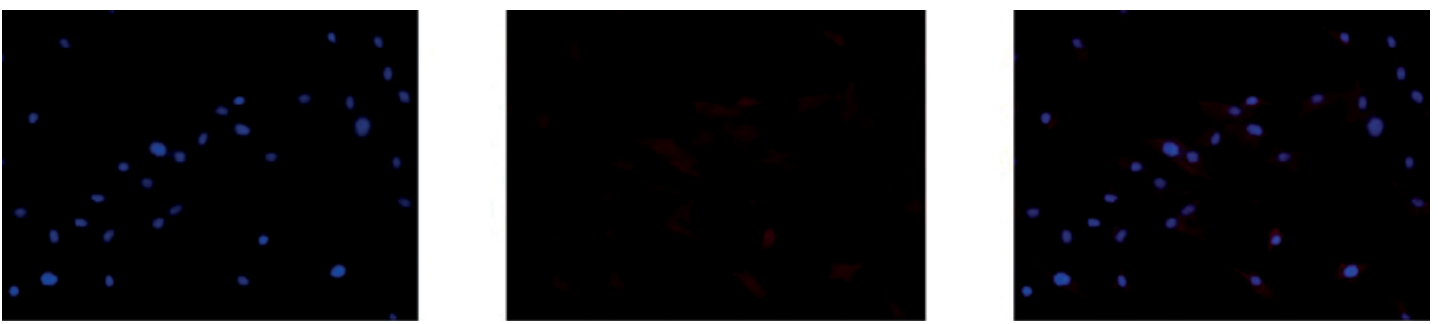

V-NC
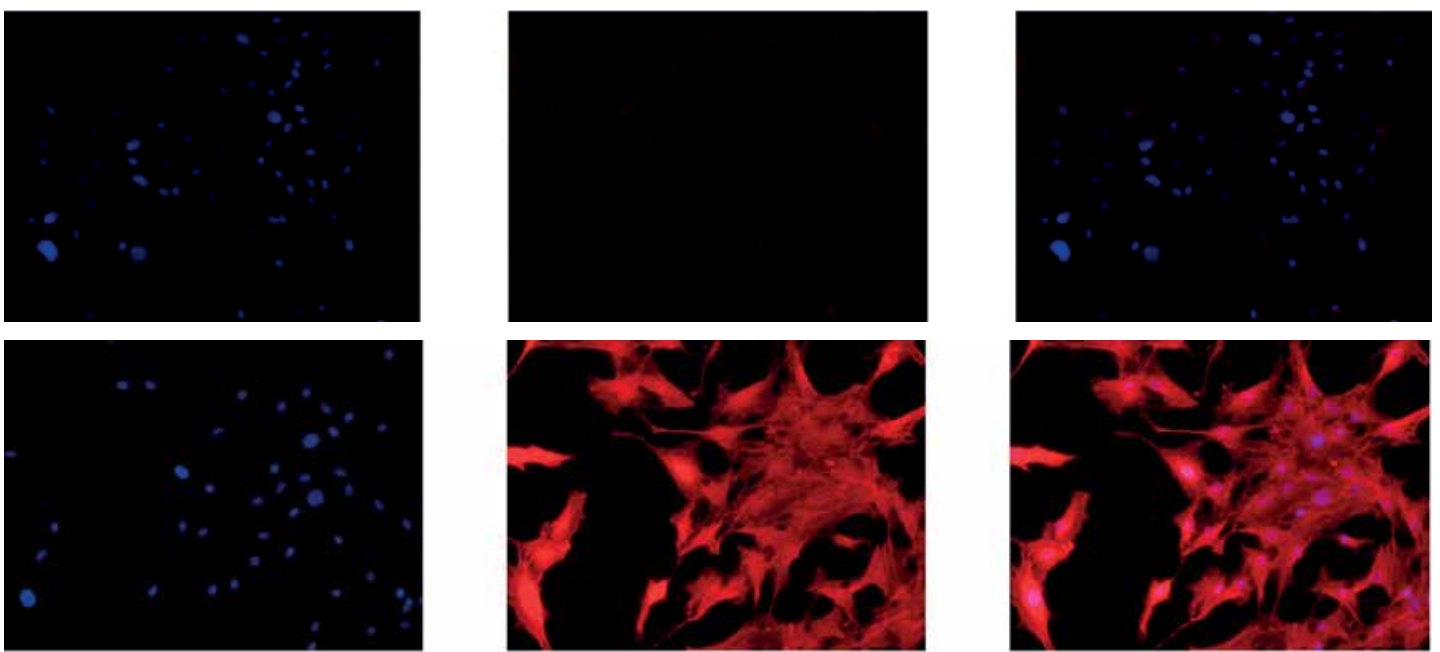

TGF- $\beta 1+$ miRNA-325-3p
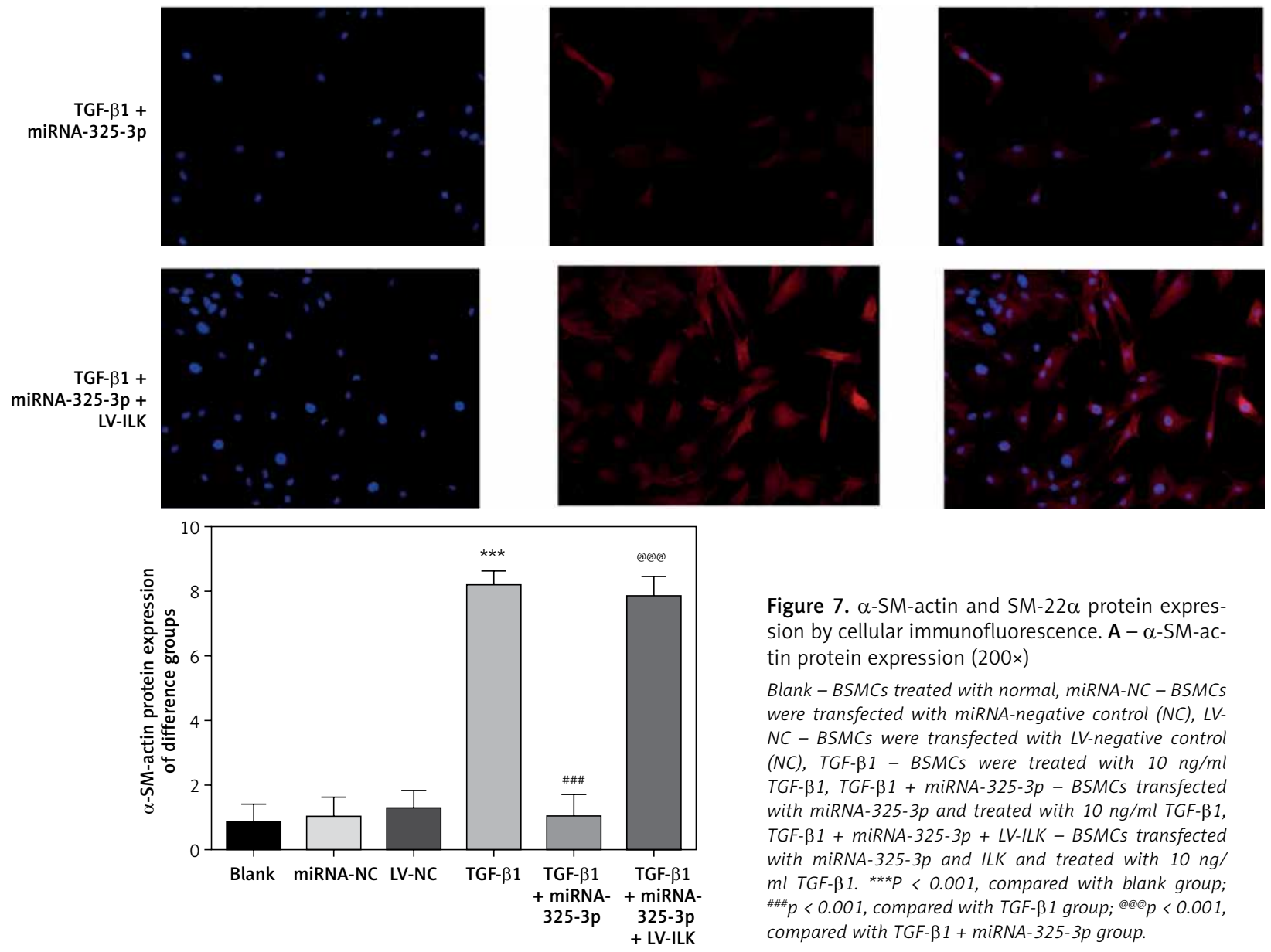

Figure 7. $\alpha$-SM-actin and SM-22 $\alpha$ protein expression by cellular immunofluorescence. $A-\alpha-S M-a c-$ tin protein expression (200x)

Blank - BSMCS treated with normal, miRNA-NC - BSMCS were transfected with miRNA-negative control (NC), LV$N C$ - BSMCS were transfected with $L V$-negative control (NC), TGF- $\beta 1$ - BSMCs were treated with $10 \mathrm{ng} / \mathrm{ml}$ TGF- $\beta 1, T G F-\beta 1+$ miRNA-325-3p - BSMCs transfected with miRNA-325-3p and treated with $10 \mathrm{ng} / \mathrm{ml}$ TGF- $\beta 1$, TGF- $\beta 1+$ miRNA-325-3p + LV-ILK - BSMCs transfected with miRNA-325-3p and ILK and treated with $10 \mathrm{ng} /$ $\mathrm{ml} \mathrm{TGF-} \beta 1 .{ }^{* * *} P<0.001$, compared with blank group;

\#\#\# $p<0.001$, compared with TGF- $\beta 1$ group; @@ $p<0.001$, compared with TGF- $\beta 1+$ miRNA-325-3p group. 

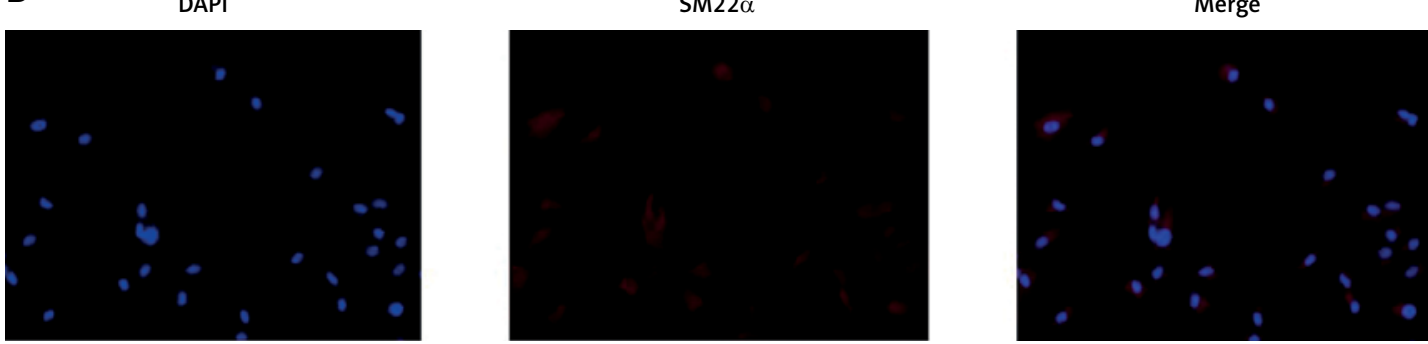

miRNA-NC
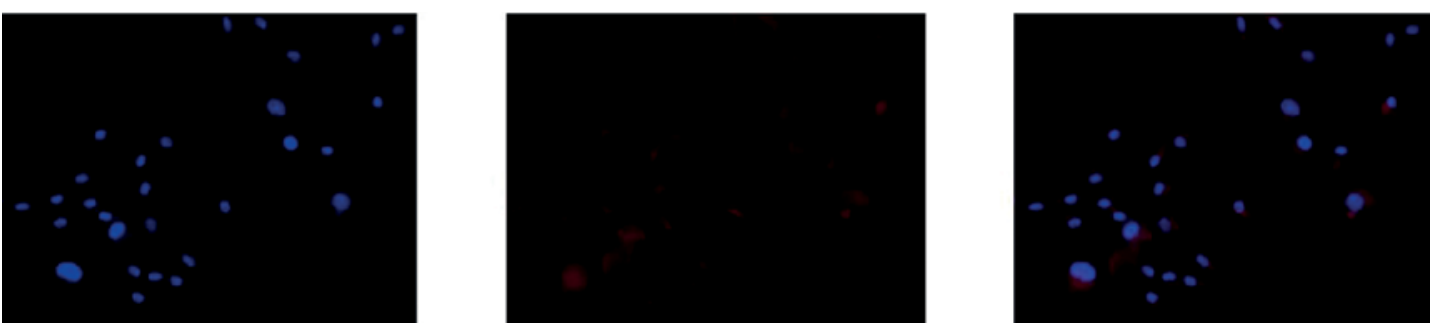

LV-NC
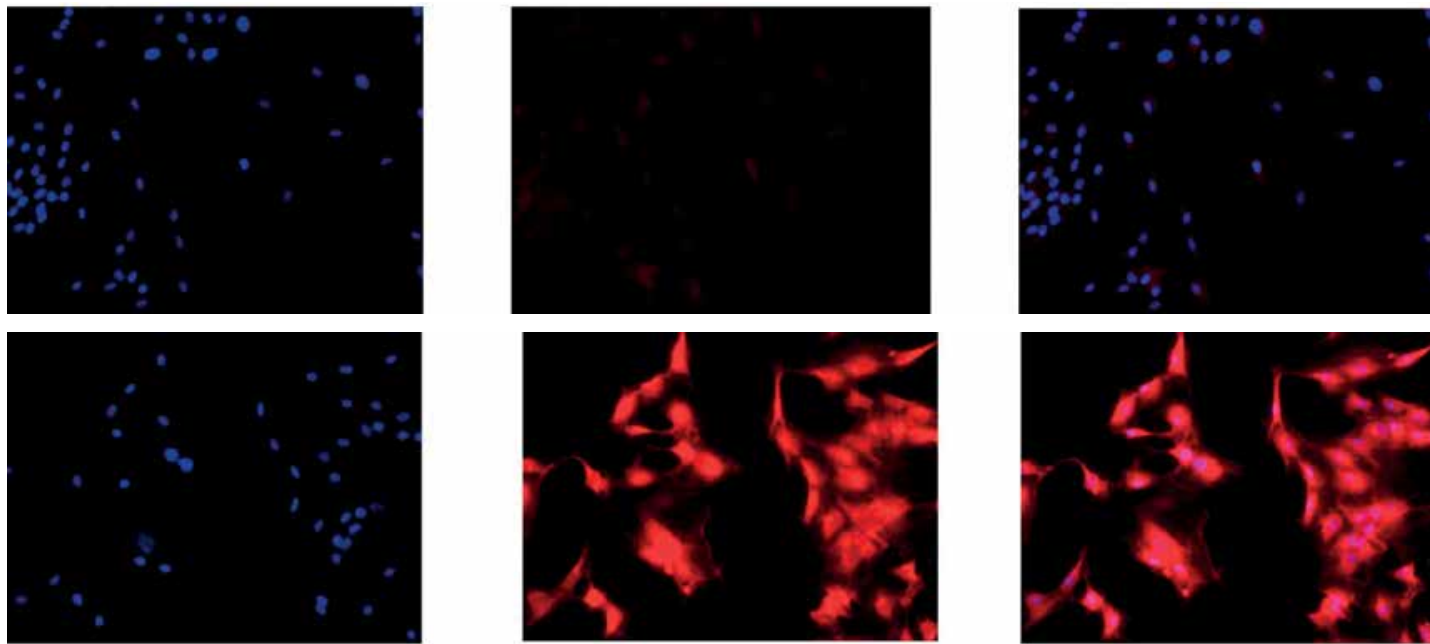

TGF- $\beta 1+$ miRNA-325-3p
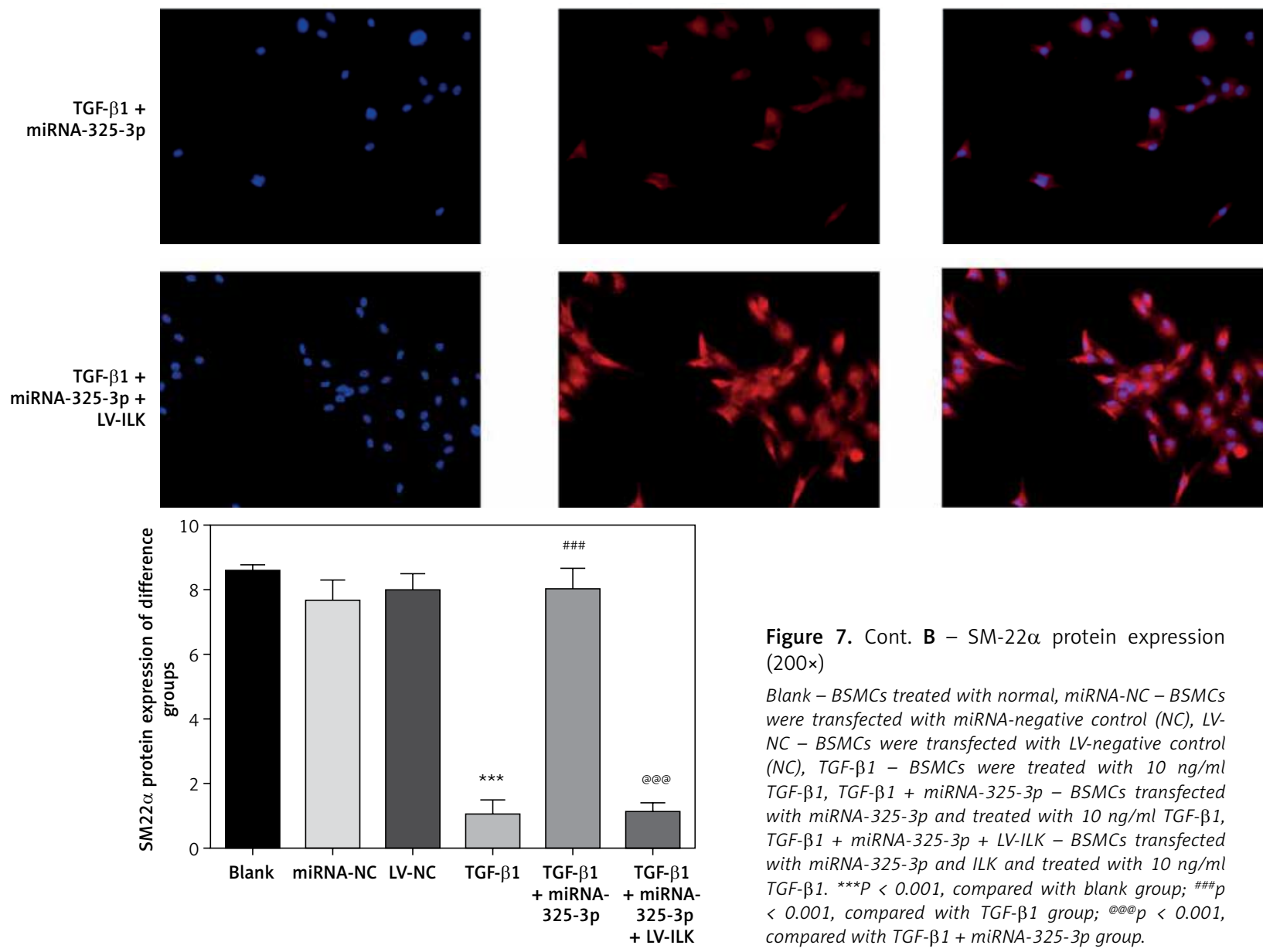

Figure 7. Cont. B - SM-22 $\alpha$ protein expression (200x)

Blank - BSMCs treated with normal, miRNA-NC - BSMCs were transfected with miRNA-negative control (NC), LV$N C$ - BSMCS were transfected with LV-negative control (NC), TGF- $\beta 1$ - BSMCs were treated with $10 \mathrm{ng} / \mathrm{ml}$ TGF- $\beta 1, T G F-\beta 1+$ miRNA-325-3p - BSMCs transfected with miRNA-325-3p and treated with $10 \mathrm{ng} / \mathrm{ml}$ TGF- $\beta 1$, TGF- $\beta 1+$ miRNA-325-3p + LV-ILK - BSMCs transfected with miRNA-325-3p and ILK and treated with $10 \mathrm{ng} / \mathrm{ml}$ TGF- $\beta 1$. ${ }^{* * *} P<0.001$, compared with blank group; $\#$ \#\# $<0.001$, compared with TGF- $\beta 1$ group; @@ $p<0.001$, compared with TGF- $\beta 1+$ miRNA-325-3p group. 

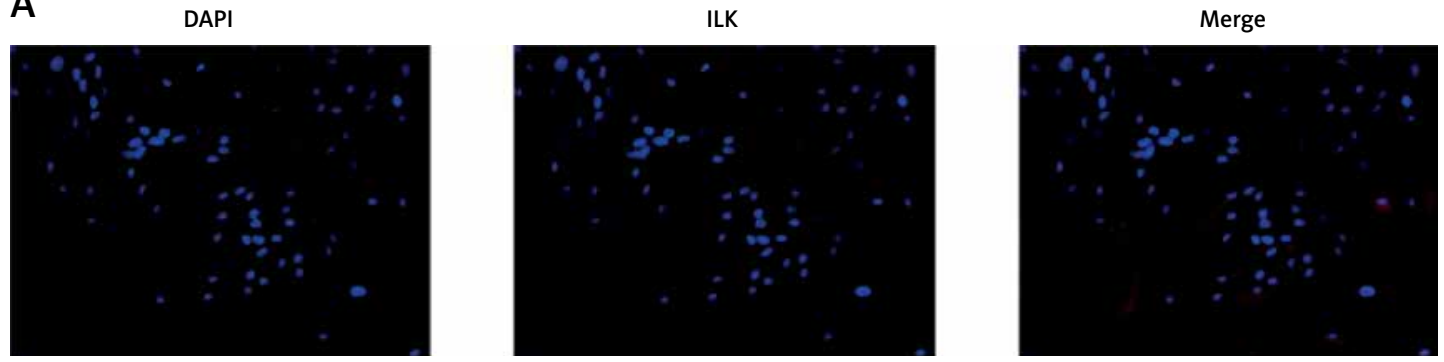

miRNA-NC
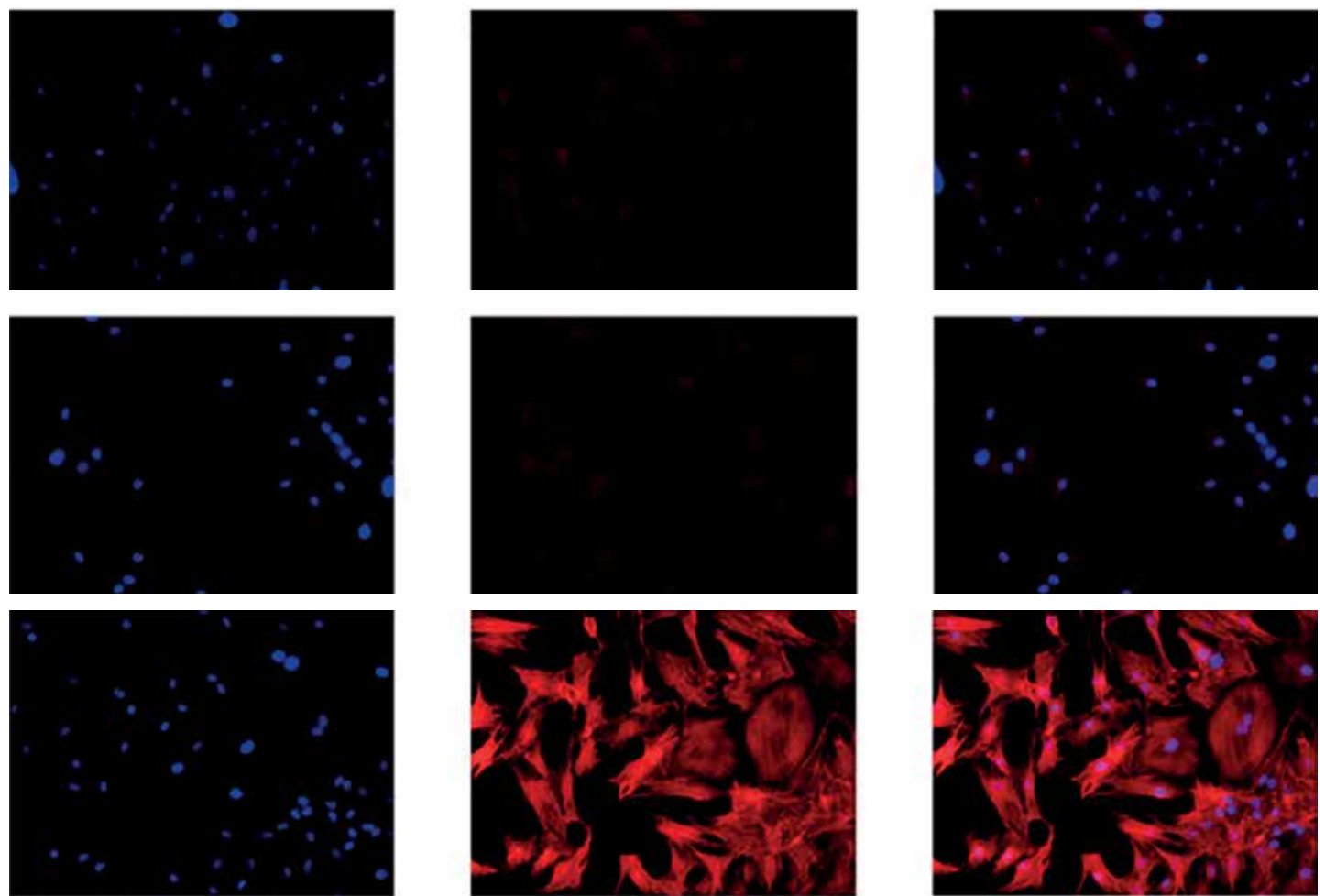

TGF- $\beta 1+$ miRNA-325-3p
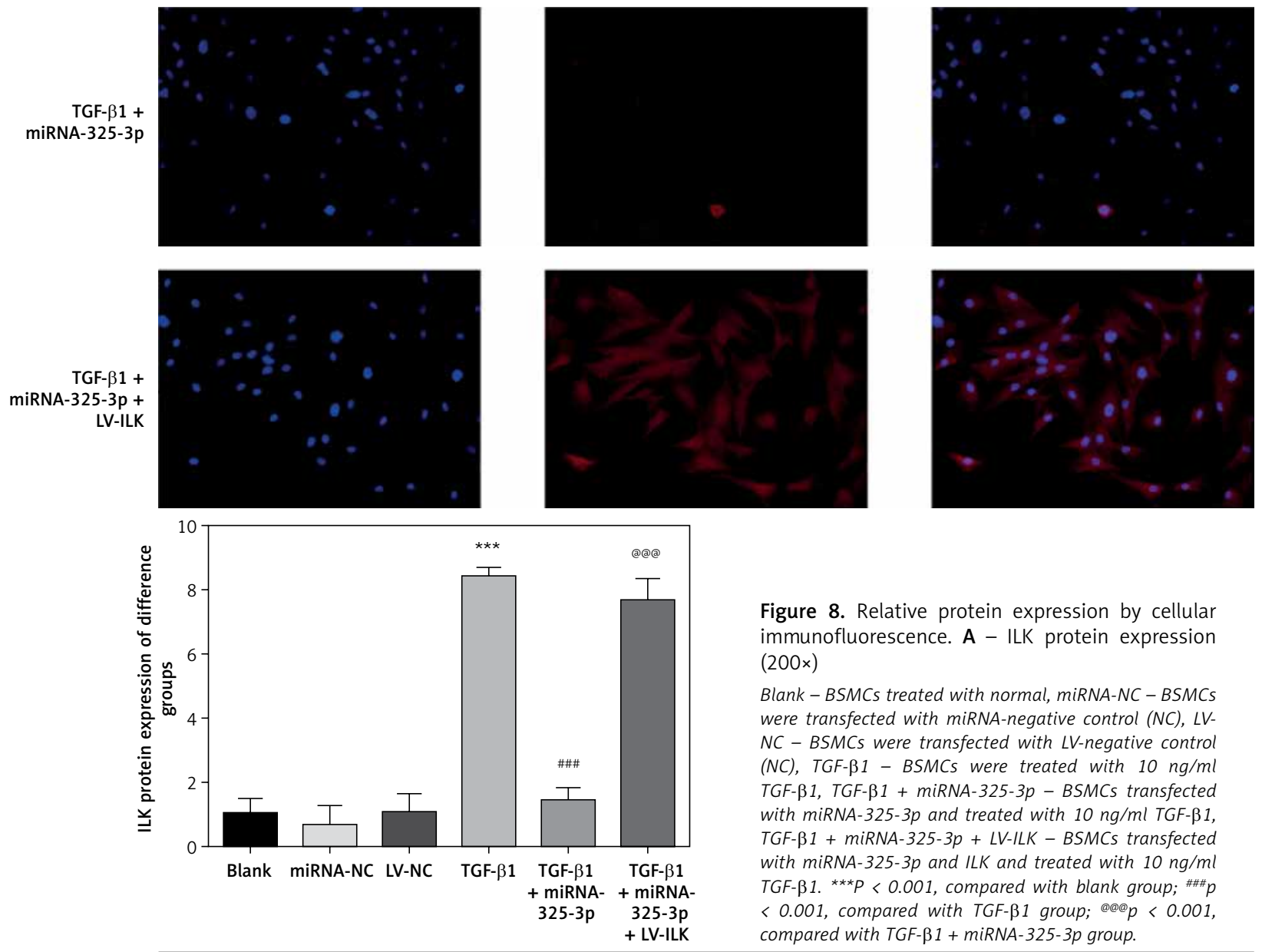

Figure 8. Relative protein expression by cellular immunofluorescence. A - ILK protein expression (200x)

Blank - BSMCs treated with normal, miRNA-NC - BSMCs were transfected with miRNA-negative control (NC), LV$N C$ - BSMCS were transfected with $L V$-negative control (NC), TGF- $\beta 1$ - BSMCs were treated with $10 \mathrm{ng} / \mathrm{ml}$ TGF- $\beta 1, T G F-\beta 1+$ miRNA-325-3p - BSMCs transfected with miRNA-325-3p and treated with $10 \mathrm{ng} / \mathrm{ml}$ TGF- $\beta 1$, TGF- $\beta 1+$ miRNA-325-3p + LV-ILK - BSMCs transfected with miRNA-325-3p and ILK and treated with $10 \mathrm{ng} / \mathrm{ml}$ TGF- $\beta 1$. ${ }^{* * *} P<0.001$, compared with blank group; ${ }^{\# \# p} p$ $<0.001$, compared with TGF- $\beta 1$ group; @@ $p<0.001$, compared with TGF- $\beta 1+$ miRNA-325-3p group. 

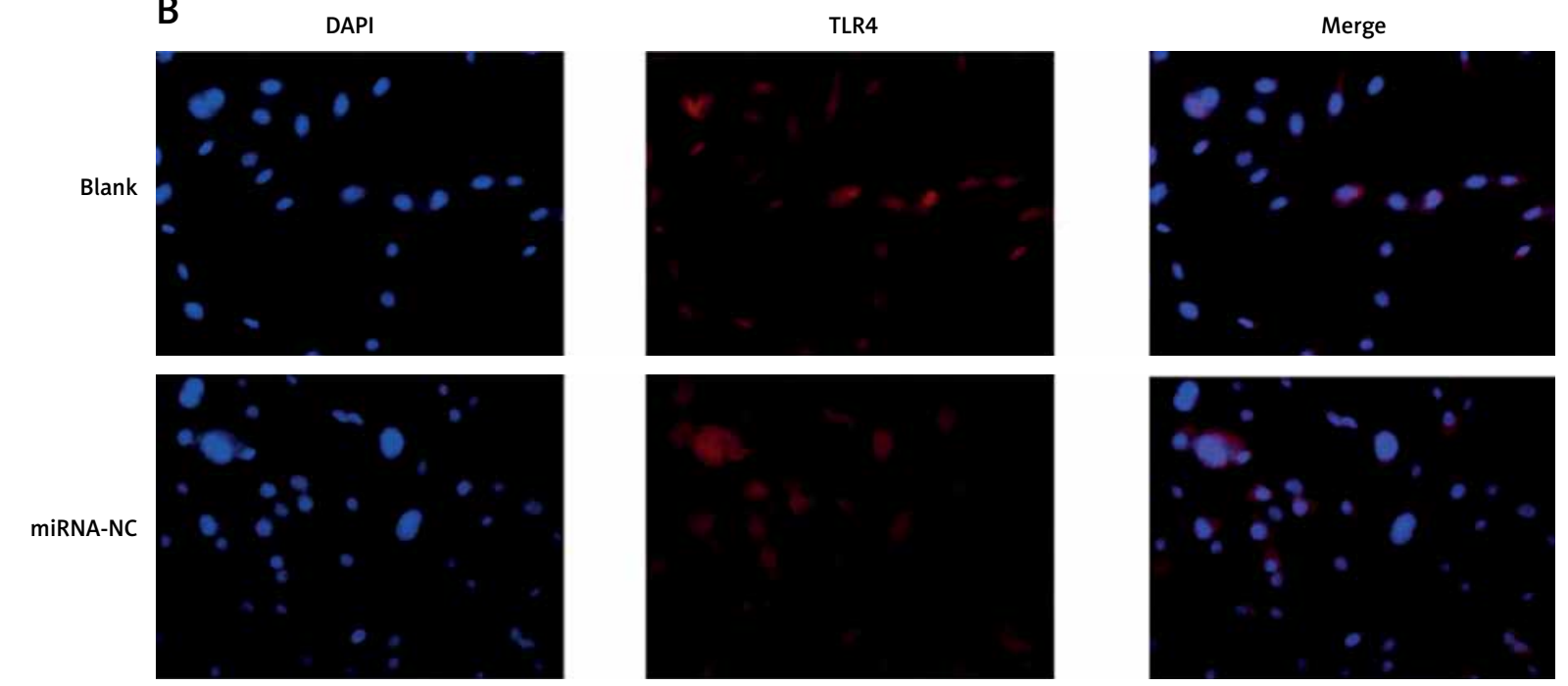

LV-NC
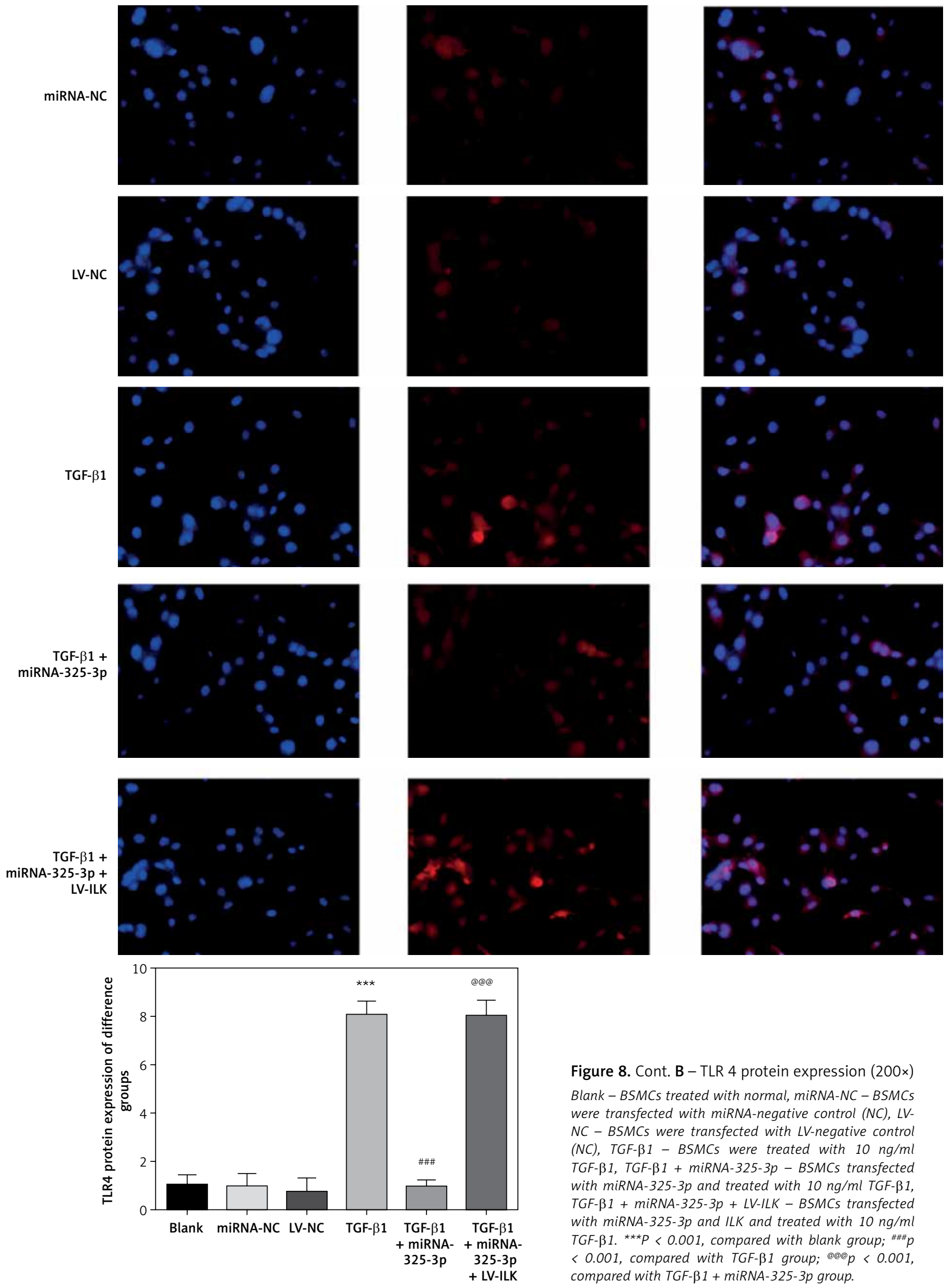

Figure 8. Cont. B - TLR 4 protein expression (200x) Blank - BSMCs treated with normal, miRNA-NC - BSMCs were transfected with miRNA-negative control (NC), LV$N C-B S M C s$ were transfected with $L V$-negative control (NC), TGF- $\beta 1$ - BSMCs were treated with $10 \mathrm{ng} / \mathrm{ml}$ TGF- $\beta 1, T G F-\beta 1+$ miRNA-325-3p - BSMCs transfected with miRNA-325-3p and treated with $10 \mathrm{ng} / \mathrm{ml}$ TGF- $\beta 1$, TGF- $\beta 1+$ miRNA-325-3p + LV-ILK - BSMCS transfected with miRNA-325-3p and ILK and treated with $10 \mathrm{ng} / \mathrm{ml}$ TGF- $\beta 1 .{ }^{* * *}>0.001$, compared with blank group; ${ }^{\# \# \#}$ $<0.001$, compared with TGF- $\beta 1$ group; @@ $p<0.001$, compared with TGF- $\beta 1+$ miRNA-325-3p group. 


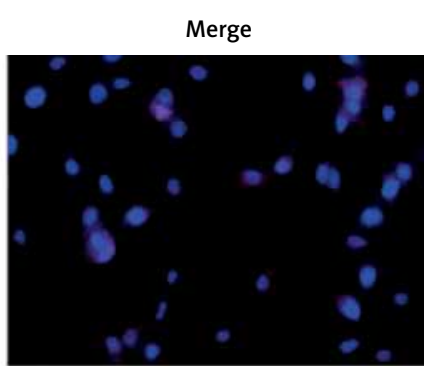

Blank
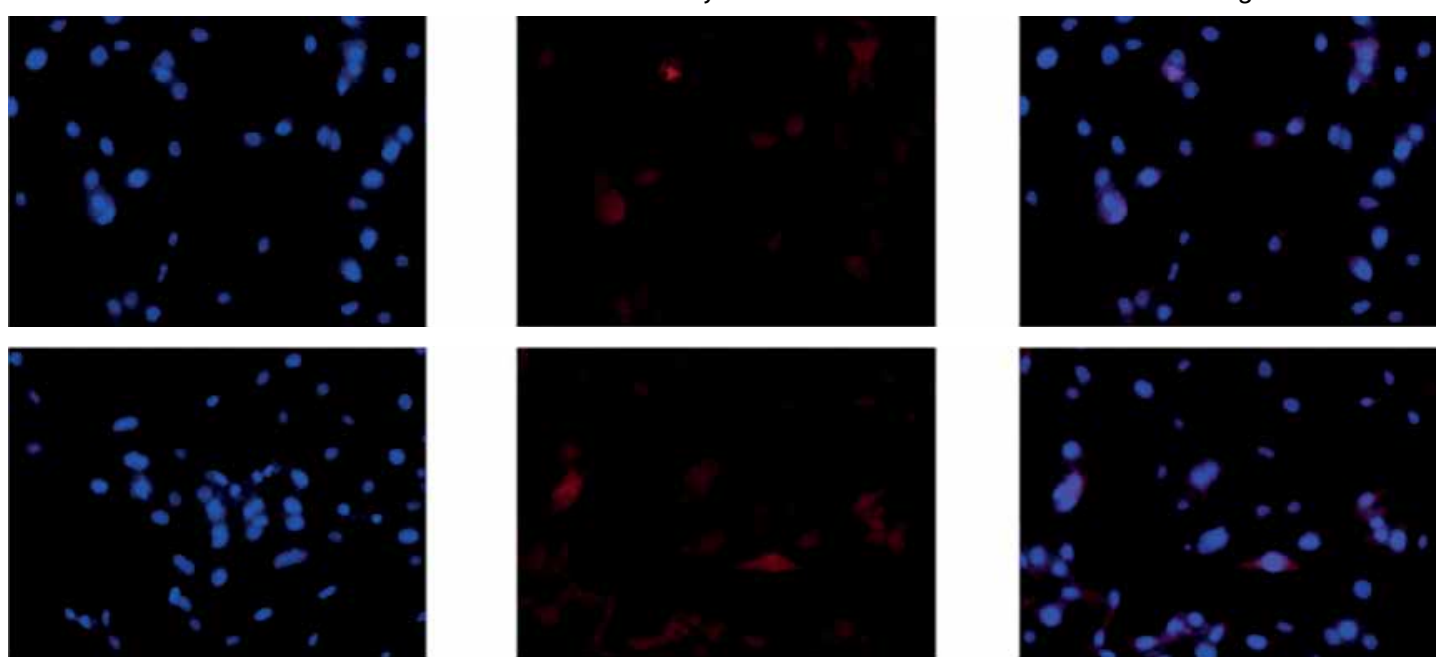

miRNA-NC
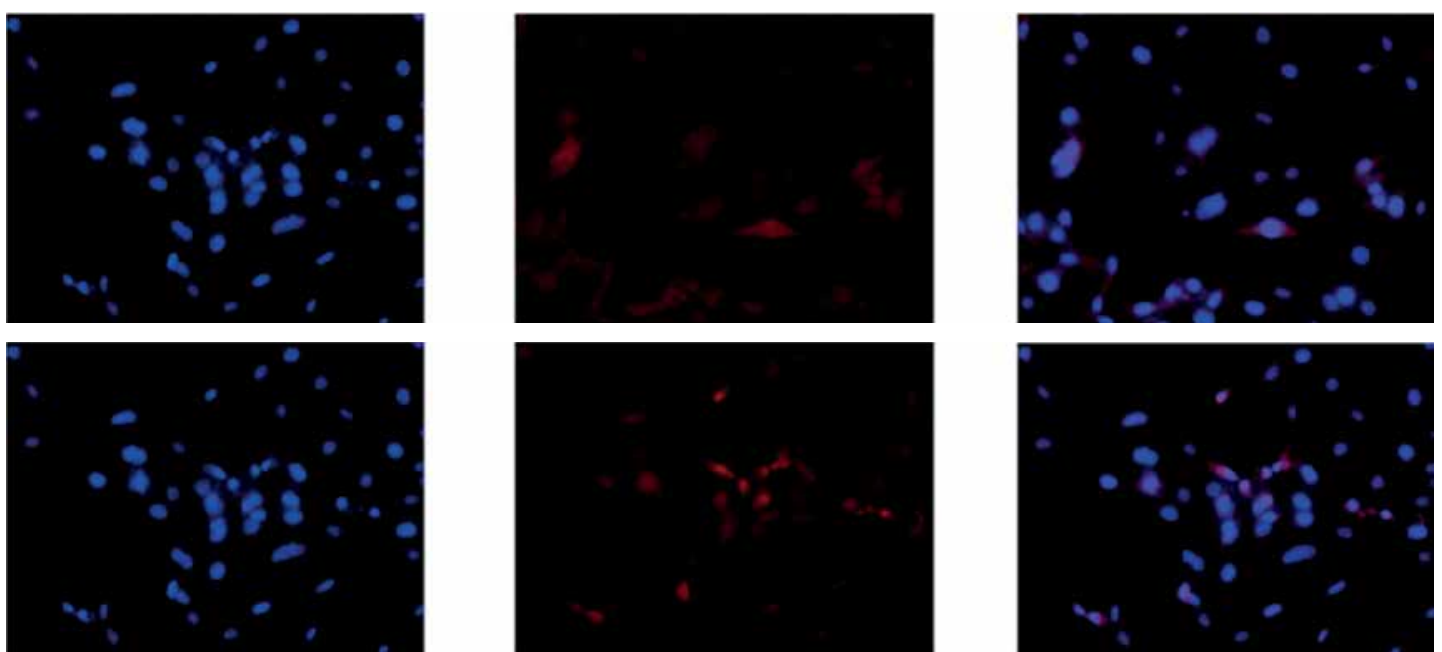

LV-NC
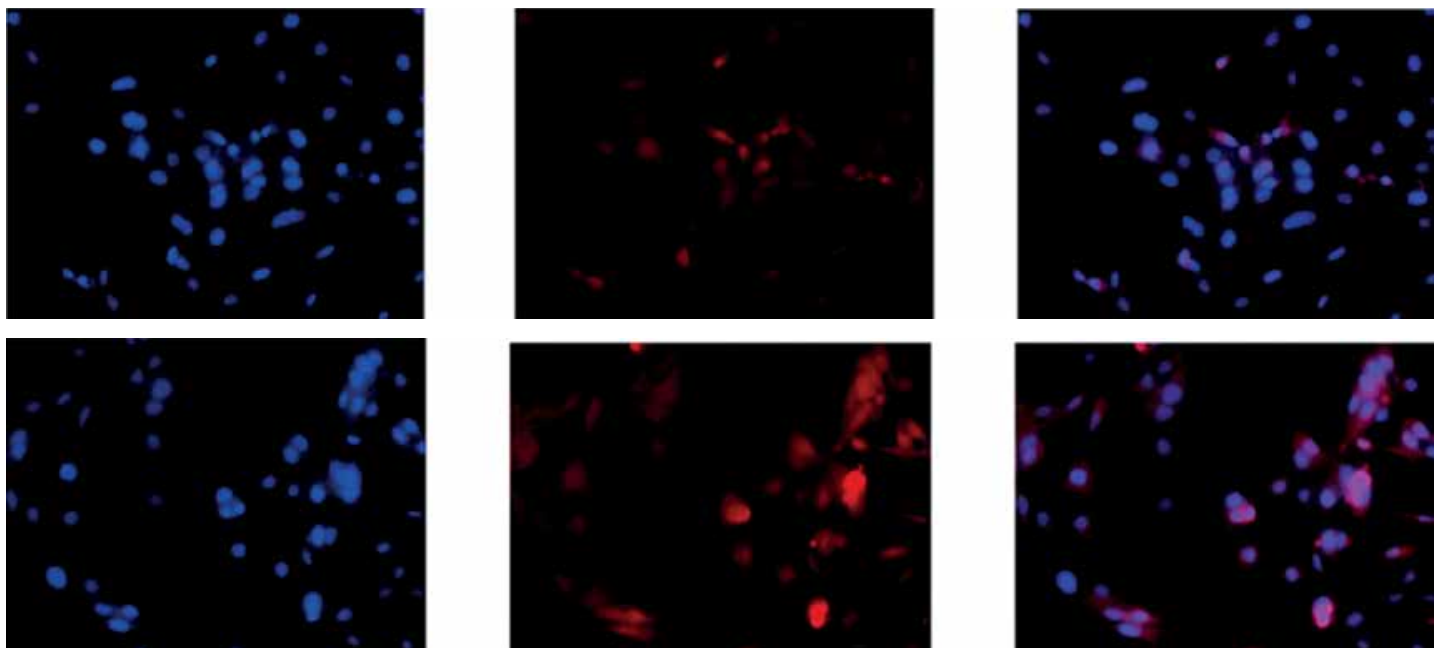

TGF- $\beta 1+$
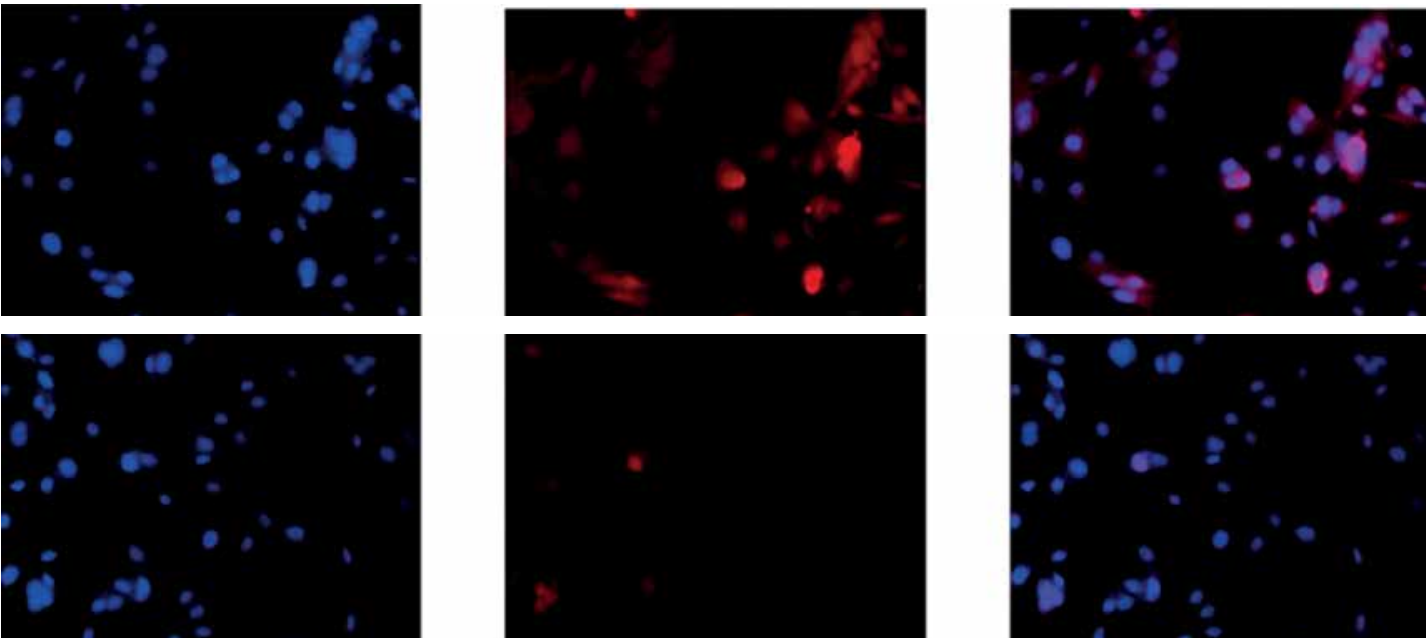

miRNA-325-3p
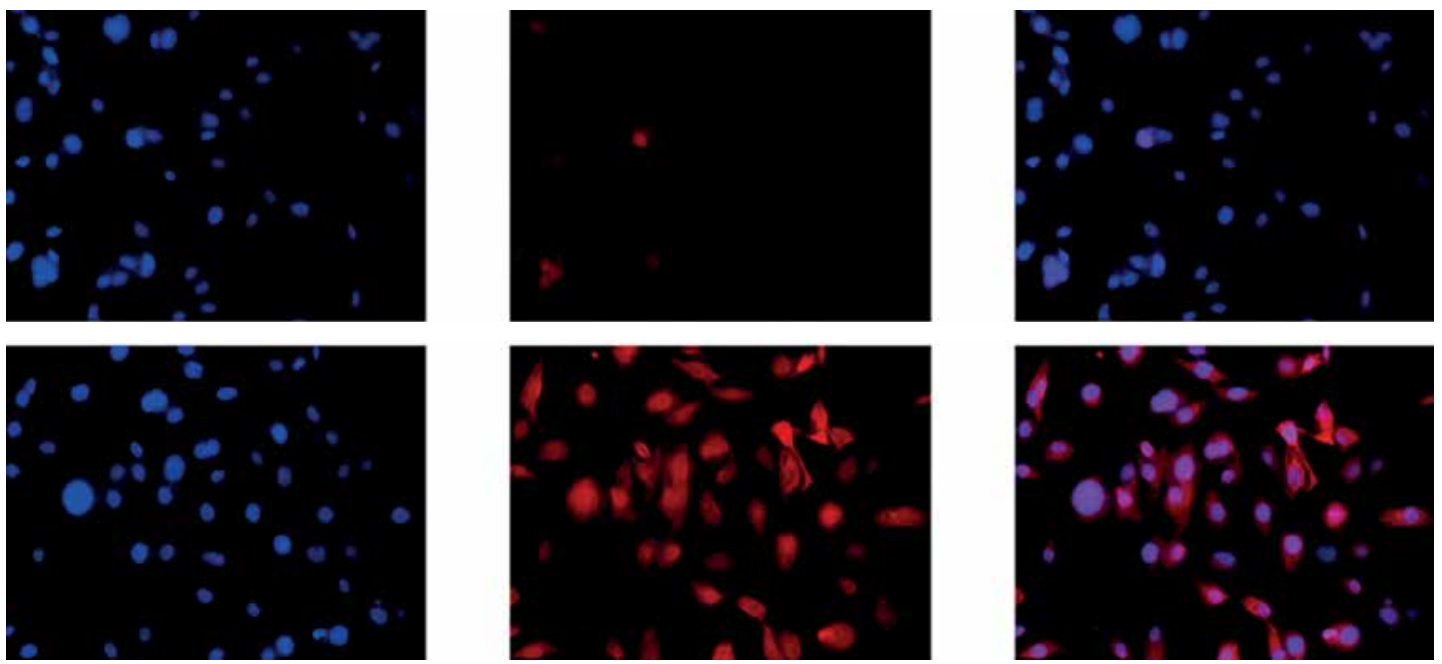

TGF- $\beta 1+$ miRNA-325-3p +

LV-ILK
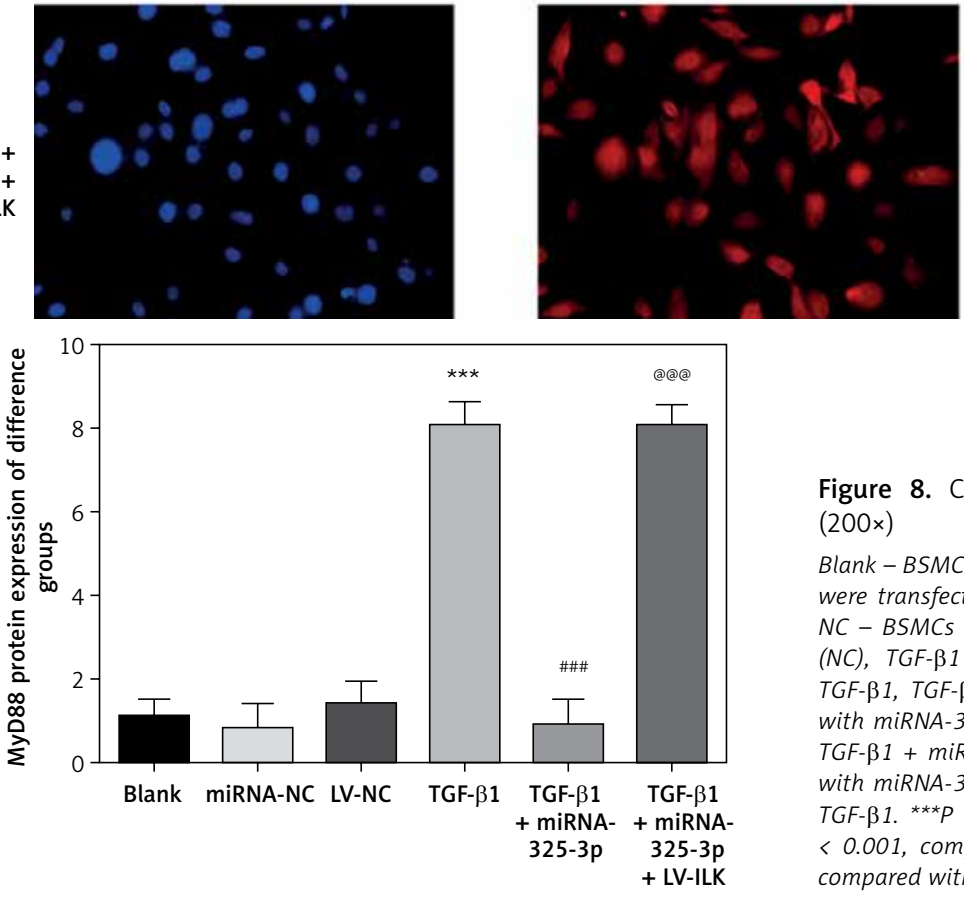

Figure 8. Cont. C - MyD88 protein expression (200x)

Blank - BSMCs treated with normal, miRNA-NC - BSMCs were transfected with miRNA-negative control (NC), LV$N C$ - BSMCS were transfected with $L V$-negative control (NC), TGF- $\beta 1$ - BSMCs were treated with $10 \mathrm{ng} / \mathrm{ml}$ TGF- $\beta 1, T G F-\beta 1+$ miRNA-325-3p - BSMCs transfected with miRNA-325-3p and treated with $10 \mathrm{ng} / \mathrm{ml}$ TGF- $\beta 1$, TGF- $\beta 1+$ miRNA-325-3p + LV-ILK - BSMCs transfected with miRNA-325-3p and ILK and treated with $10 \mathrm{ng} / \mathrm{ml}$ TGF- $\beta 1$. ${ }^{* * *} P<0.001$, compared with blank group; ${ }^{\# \# p}$ $<0.001$, compared with TGF- $\beta 1$ group; @@ $p<0.001$, compared with TGF- $\beta 1+$ miRNA-325-3p group. 
DAPI
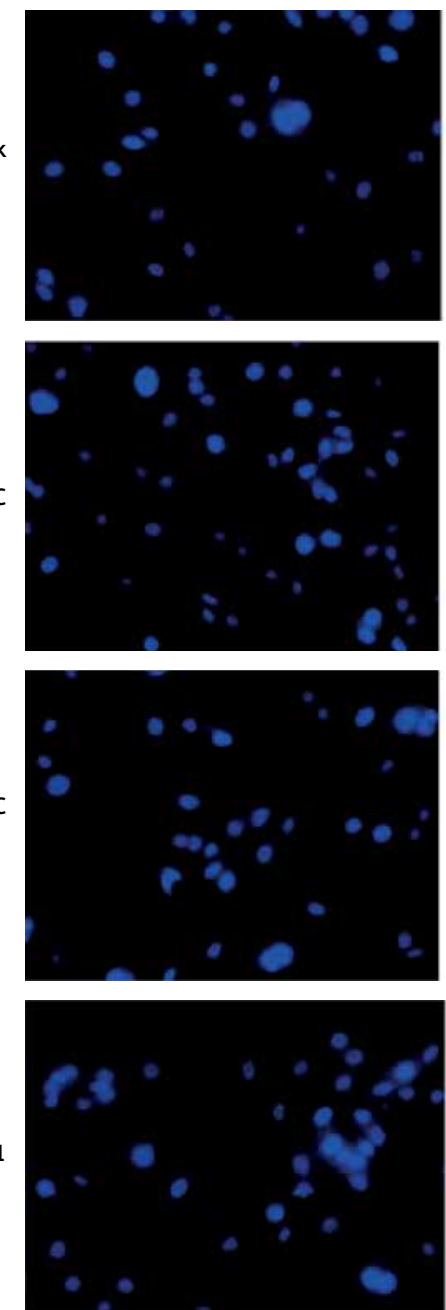

TGF- $\beta 1+$ miRNA-325-3p

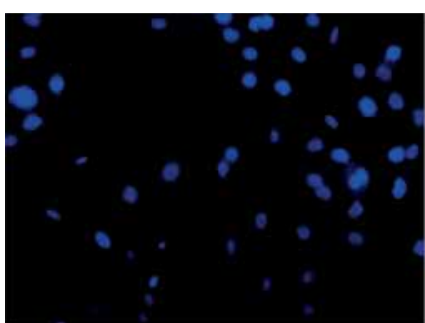

TGF- $\beta 1+$ miRNA-325-3p +

LV-ILK
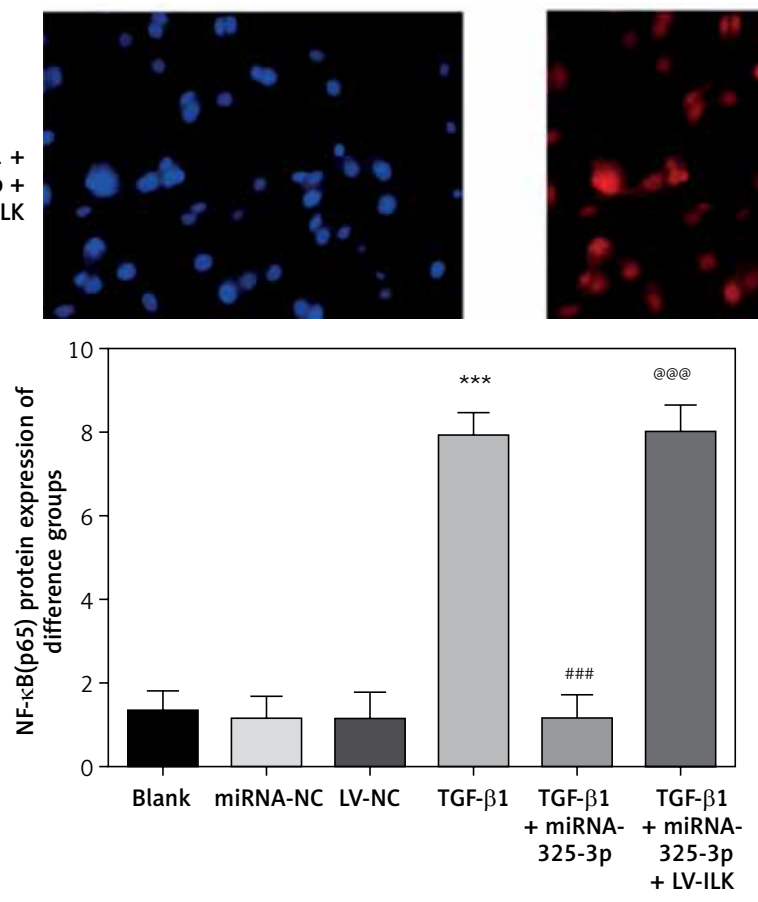

NF- $\kappa B(p 65)$
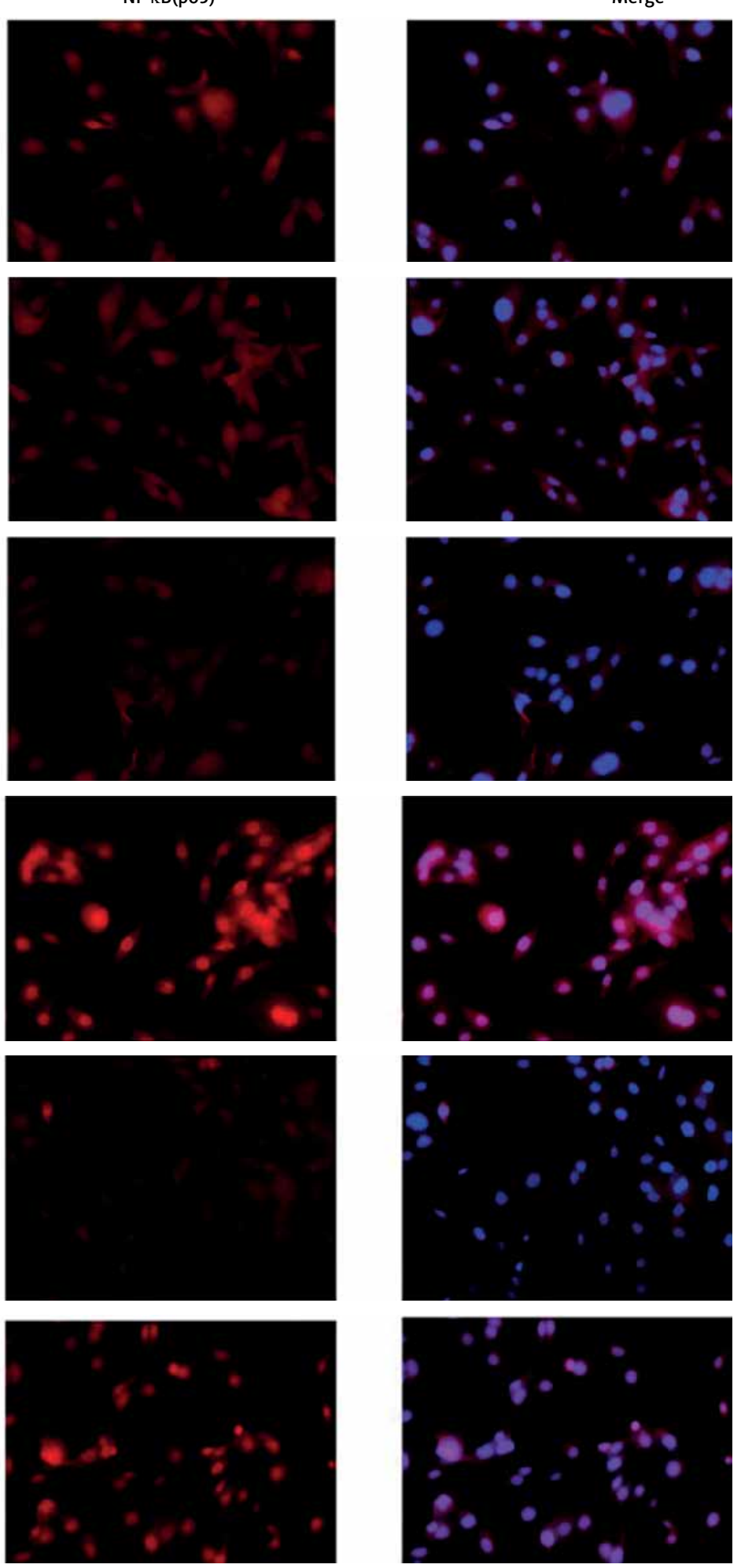

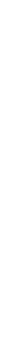



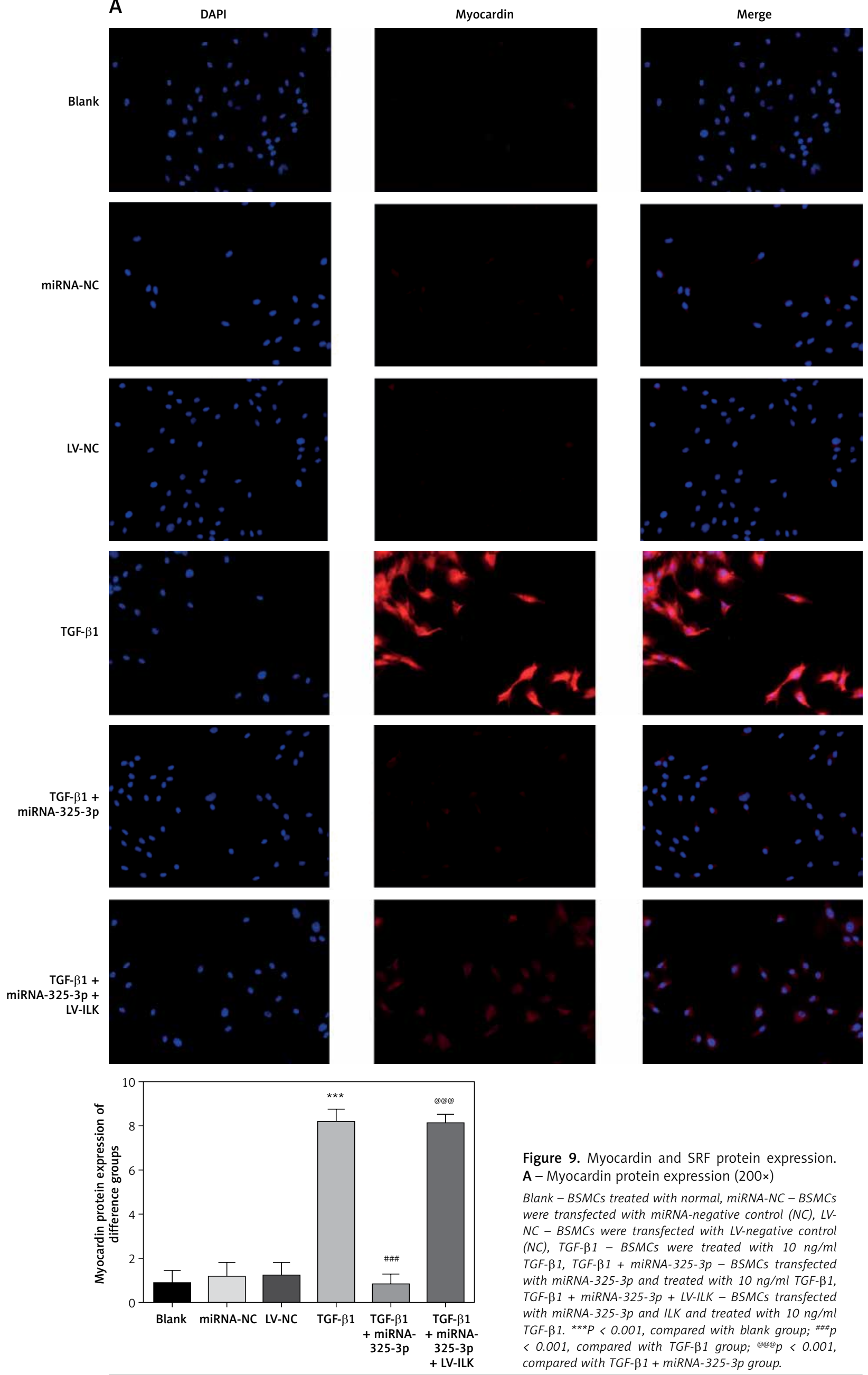

Figure 9. Myocardin and SRF protein expression. A - Myocardin protein expression (200x)

Blank-BSMCs treated with normal, miRNA-NC-BSMCS were transfected with miRNA-negative control (NC), LV$N C$ - BSMCS were transfected with $L V$-negative control (NC), TGF- $\beta 1$ - BSMCs were treated with $10 \mathrm{ng} / \mathrm{ml}$ TGF- $\beta 1, T G F-\beta 1+$ miRNA-325-3p - BSMCs transfected with miRNA-325-3p and treated with $10 \mathrm{ng} / \mathrm{ml}$ TGF- $\beta 1$, TGF- $\beta 1+$ miRNA-325-3p + LV-ILK - BSMCs transfected with miRNA-325-3p and ILK and treated with $10 \mathrm{ng} / \mathrm{ml}$ TGF- $\beta 1$. ${ }^{* * *} P<0.001$, compared with blank group; ${ }^{\# \# p} p$ $<0.001$, compared with TGF- $\beta 1$ group; @@ $p<0.001$, compared with TGF- $\beta 1+$ miRNA-325-3p group. 

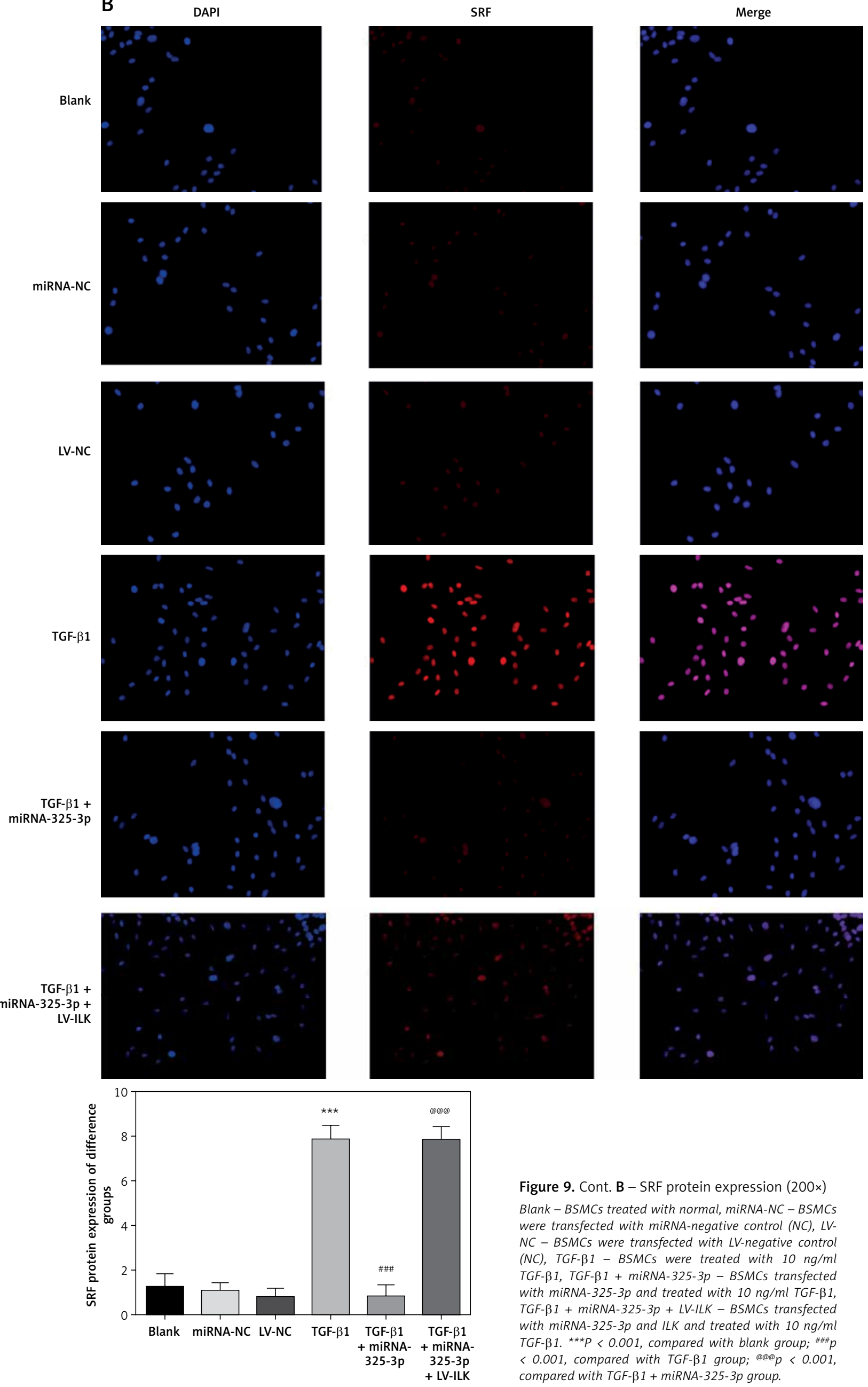

Figure 9. Cont. B - SRF protein expression (200x)

Blank - BSMCs treated with normal, miRNA-NC - BSMCs were transfected with miRNA-negative control (NC), LV$N C-B S M C s$ were transfected with $L V$-negative control (NC), TGF- $\beta 1$ - BSMCs were treated with $10 \mathrm{ng} / \mathrm{ml}$ TGF- $\beta 1, T G F-\beta 1+$ miRNA-325-3p - BSMCs transfected with miRNA-325-3p and treated with $10 \mathrm{ng} / \mathrm{ml}$ TGF- $\beta 1$, TGF- $\beta 1+$ miRNA-325-3p + LV-ILK - BSMCs transfected with miRNA-325-3p and ILK and treated with $10 \mathrm{ng} / \mathrm{ml}$

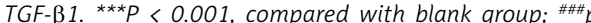
$<0.001$, compared with TGF- $\beta 1$ group; $@ @$ @ $<0.001$, compared with TGF- $\beta 1+$ miRNA-325-3p group. 

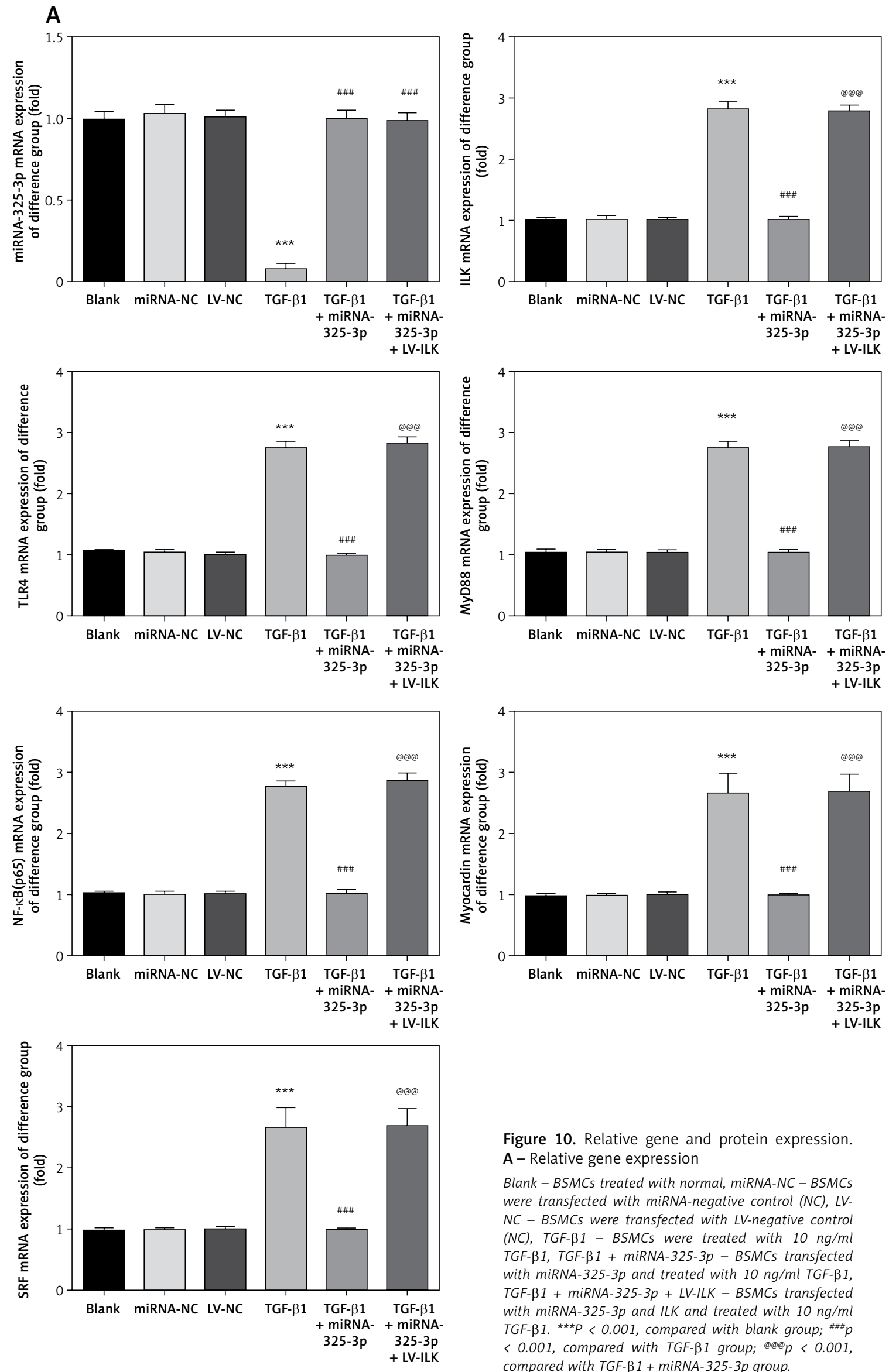

Figure 10. Relative gene and protein expression. A - Relative gene expression

Blank - BSMCs treated with normal, miRNA-NC-BSMCS were transfected with miRNA-negative control (NC), LV$N C-B S M C S$ were transfected with $L V$-negative control (NC), TGF- $\beta 1$ - BSMCS were treated with $10 \mathrm{ng} / \mathrm{ml}$ TGF- $\beta 1, T G F-\beta 1+$ miRNA-325-3p - BSMCs transfected with miRNA-325-3p and treated with $10 \mathrm{ng} / \mathrm{ml} T \mathrm{TGF}-\beta 1$, TGF- $\beta 1+$ miRNA-325-3p + LV-ILK - BSMCs transfected with miRNA-325-3p and ILK and treated with $10 \mathrm{ng} / \mathrm{ml}$

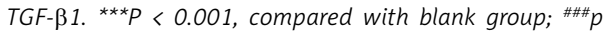
$<0.001$, compared with TGF- $\beta 1$ group; @@ $p<0.001$, compared with TGF- $\beta 1+$ miRNA-325-3p group. 
B

Blank miRNA-NC LV-NC TGF- $\beta 1$ TGF- $\beta 1$ TGF- $\beta 1$

+ miRNA- + miRNA

325-3p 325-3p

+ LV-ILK
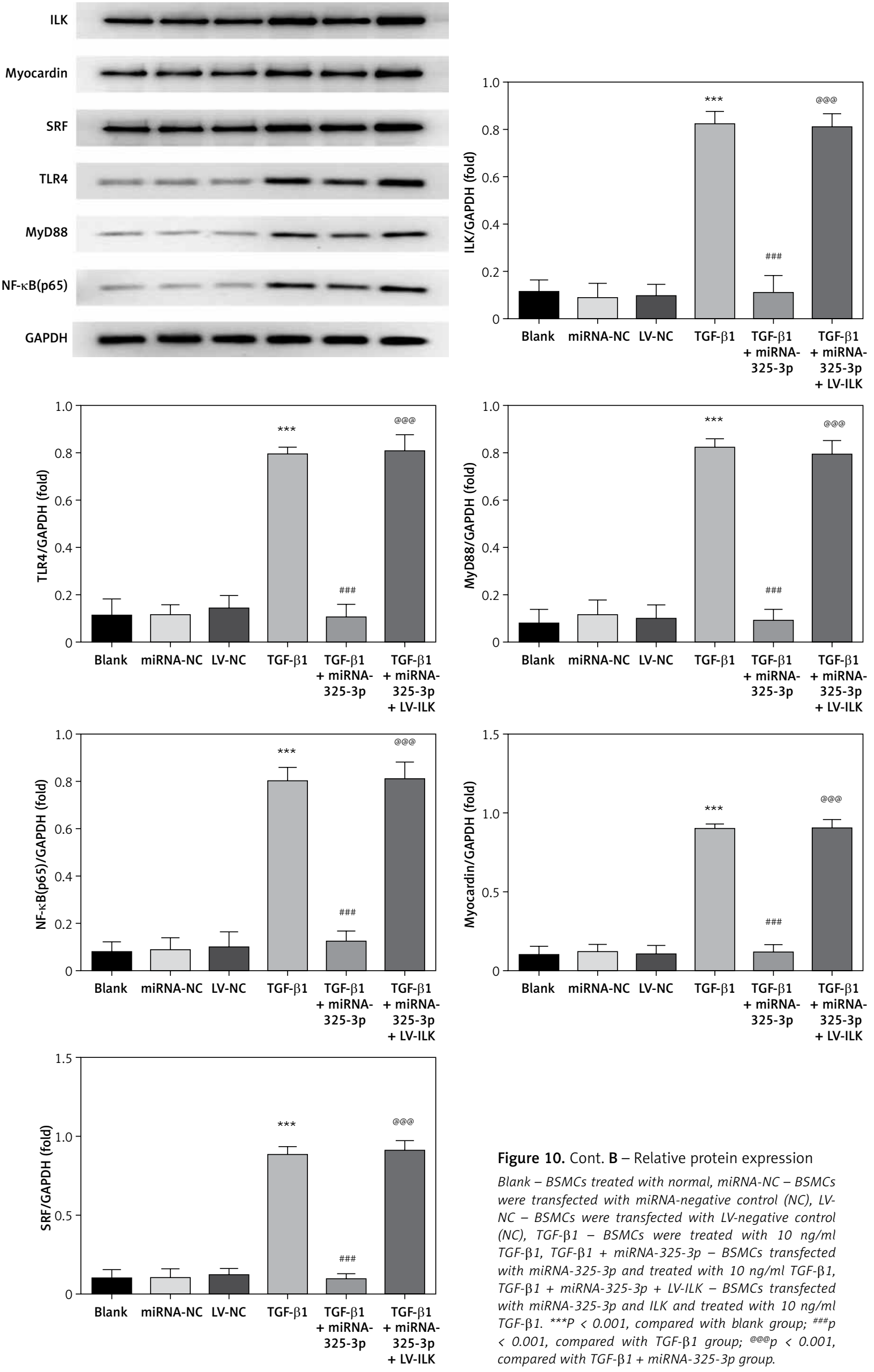

Figure 10. Cont. B - Relative protein expression

Blank - BSMCs treated with normal, miRNA-NC - BSMCs were transfected with miRNA-negative control (NC), LV$N C-B S M C s$ were transfected with $L V$-negative control (NC), TGF- $\beta 1$ - BSMCS were treated with $10 \mathrm{ng} / \mathrm{ml}$ TGF- $\beta 1, T G F-\beta 1+$ miRNA-325-3p - BSMCs transfected with miRNA-325-3p and treated with $10 \mathrm{ng} / \mathrm{ml}$ TGF- $\beta 1$, TGF- $\beta 1+$ miRNA-325-3p + LV-ILK - BSMCS transfected with miRNA-325-3p and ILK and treated with $10 \mathrm{ng} / \mathrm{ml}$ TGF- $\beta$ 1. ${ }^{* * *} P<0.001$, compared with blank group; ${ }^{* \# *} p$ $<0.001$, compared with TGF- $\beta 1$ group; $@ @ p<0.001$ compared with TGF- $\beta 1+$ miRNA-325-3p group. 


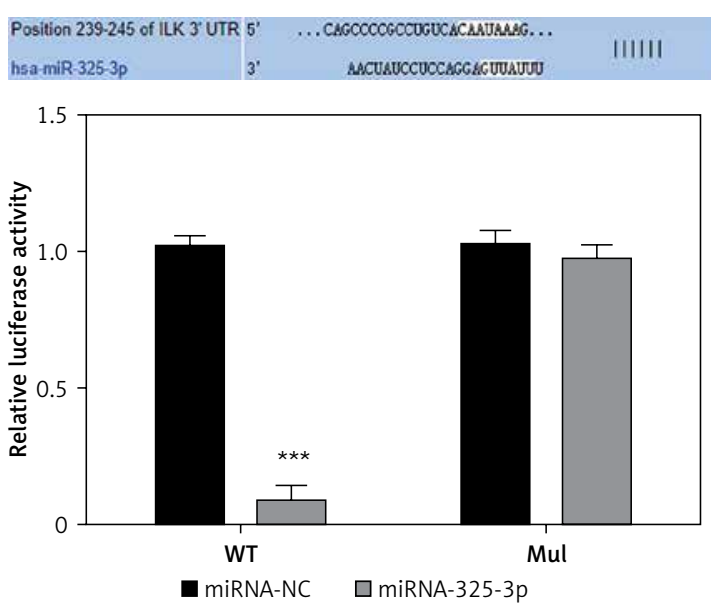

genes, leading to significant proliferation and contractile dysfunction in the BSMCs [16]. PBOO-induced vasoactive substance production by local inflammatory cells in the bladder, such as transforming growth factor $\beta 1$ (TGF- $\beta 1$ ), basic fibroblast growth factor (bFGF), and heparin-binding epidermal growth factor (HB-EGF), can stimulate BSMC proliferation [17]. Kanematsu et al. [18] provided further evidence for the presence of phenotypic plasticity in human and rat BSMCs, as well as resultant bladder fibrosis caused by subsequent changes in BSMC proliferation and ECM secretion. Therefore, PBOO-induced BSMC phenotypic plasticity is considered to be an initial event, followed by changes in BSMC proliferation and migration. In this study, an in-vitro PBOO model was constructed by using TGF- $\beta 1$ to stimulate primary BSMCs, and the results revealed a significant increase in the rate of BSMC proliferation as well as a markedly higher degree of fibrosis. Moreover, miR-325-3p gene expression was significantly reduced.

The miRNA family is a large group of small non-coding RNAs, with lengths ranging from 19 to $22 \mathrm{nt}$ and the shared function of regulating target mRNA levels through imperfect binding to specific sites within the $3^{\prime} U T R$ region of mRNA sequences. Moreover, miRNAs are known to regulate epigenetic inheritance and modification, including DNA methylation, RNA modification, and histone modification [19]. The imperfect complementarity between miRNAs and their targets determines the intricacy of the miRNA-miRNA interaction. Although miRNA expression is relatively low in normal physiological conditions, it plays a vital role in the maintenance of normal physiological function of the bladder detrusor muscle. Studies evaluating miRNAs in the bladder detrusor muscle $[20,21]$ have reported that in Dicer-knockout mouse models, miRNA exhaustion occurs in the bladder detrusor muscle after 10 weeks of observation, in which case voiding dysfunction, frequent urination, and
Figure 11. Correlation between miRNA-325-3p and ILK ${ }^{* * \star} P<0.001$, compared with miRNA-NC. reduced anticholinergic properties are observed. miRNA disorders can also lead to bladder dysfunction, including bladder pain syndrome [22, 23], inflammation-induced hyperactivity [21], and responses to outlet obstruction (in both animal and human studies) [7, 10, 12, 21, 24]. Further, miRNAs are known to have regulatory effects on specific cell phenotypes in the urinary tract, such as stimulating BSMC proliferation and modulating uroepithelial permeability [23]. In this study, a PBOO model was established using TGF- $\beta 1$ and primary BSMCs, where cell proliferation and fibrosis were found to have accelerated significantly and miR-325-3p gene expression was noted to have decreased remarkably. The transfection of miR-325-3p into primary BSMCs was shown to efficiently inhibit TGF$\beta 1$-induced hyperproliferation and the resultant fibrosis. A gene assay of the dual-luciferase reporter suggested that ILK is a target of miR-325-3p.

ILK is a multifunctional protein with a molecular mass of $59 \mathrm{kDa}$ that was first described by Hannigan in a study on integrin $\beta 1$ binding proteins in 1996. It has also been identified as a serine/ threonine protein kinase involved in integrin-mediated signal transduction that is expressed in a wide range of mammal cells [12]. ILK is involved in diverse physiological functions as its kinase domain interacts with integrin $\beta$ subunit cytoplasmic tails and extracellular integrin domains connected to the extracellular matrix. Wu et al. studied the role of ILK in the phenotypic plasticity of SMCS, and discovered a negative correlation between ILK and RhoA/ROCK activity in the gene expression of phenotypic plasticity markers of SMCs as well as a supportive role of ILK in maintenance of the contractile phenotype of SMCs [25-28]. The results of this study suggest that transfection of BSMCs with miR-325-3p can reduce the ILK expression, thus further inhibiting TGF- $\beta 1$-mediated BSMC hyperproliferation and fibrosis. In addition, the

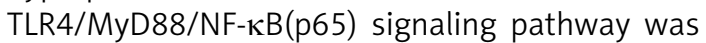
strongly inhibited in this way. 
The activated TLR4/MyD88/NF- $\mathrm{B}(\mathrm{p} 65)$ signaling pathway has been reported to play an important role in the development of inflammation and fibrosis [29-31], and it has been proposed that it is regulated by ILK [32]. Moreover, it has recently been discovered that the TLR4/MyD88/NF- $\mathrm{KB}(\mathrm{p} 65)$ signaling pathway can regulate expression levels of the serum response factor (SRF) and myocardin [33]. The most effective known SRF coactivator myocardin discovered by Eric Olson's laboratory is able to activate SMC phenotypic plasticity, as well as a series of SRF-regulated transcription of gene encoding cytoskeletal proteins and contractile associated proteins [33, 34]. The results of this study showed that increased ILK expression upon TGF- $\beta 1$ 's stimulation can activate the TLR4/ MyD88/NF-KB(p65) signaling pathway, substantially alter the gene and protein expression levels in the downstream SRF and myocardin, and promote BSMC proliferation and fibrosis. However, the TGF- $\beta 1$-mediated BSMC hyperproliferation and fibrosis were inhibited following the transfection of miR-325-3p into the BSMCs, where this also reduced the ILK expression, lowered the activity of the TLR4/MyD88/NF- $\mathrm{KB}(\mathrm{p} 65)$ signaling pathway and inhibited the gene and protein expression levels in the downstream SRF and myocardin.

In conclusion, miR-325-3p inhibits activation of the TLR4/MyD88/NF- $\mathrm{B}(\mathrm{p} 65)$ signaling pathway by regulating ILK expression to reduce BSMC hyperproliferation and fibrosis in the PBOO model.

\section{Acknowledgments}

This study was supported by National Natural Science Foundation of China (No. 81300572), the Natural Science Foundation of Jiangsu Province (Nos. BK 20181093 and BK2011860), the Medical Science Fund for Young Scholars of Jiangsu Province (No. QNRC2016676), and the Medical Research Program of Jiangsu Commission of Health (No. M2020086).

Zhaofei Liu, Yiduo Zhou and Ziyang Liu - equal contribution to this research.

\section{Conflict of interest}

The authors declare no conflict of interest.

\section{References}

1. Kitta T, Kanno Y, Chiba H, et al. Benefits and limitations of animal models in par tial bladder outlet obstruction for translational research. Int J Urol 2018; 25: 36-44.

2. Lee CL, Kuo HC. Pathophysiology of benign prostate enlargement and lower urinary tract symptoms: current concepts. Ci Ji Yi Xue Za Zhi 2017; 29: 79-83.

3. Liu Q, Luo D, Yang T, Liao B, Li H, Wang KJ. Protective effects of antimuscarinics on the bladder remodeling after bladder outlet obstruction. Cell Physiol Biochem 2017; 44: 907-19.
4. Hashimoto N, Kiyono T, Saitow F, Asada M, Yoshida M. Reversible differentiation of immortalized human bladder smooth muscle cells accompanied by actin bundle reorganization. PLoS One 2017; 12: e0186584.

5. Wiafe B, Adesida A, Churchill T, Adewuyi EE, Li Z, Metcalfe P. Hypoxia-increased expression of genes involved in inflammation, dedifferentiation, pro pro-fibrosis, and extracellular matrix remodeling of human bladder smooth muscle cells. In vitro Cell Develop Biol Animal 2017; 53: 58-66.

6. Mendell JT, Olson EN. MicroRNAs in stress signaling and human disease. Cell 2012; 148: 1172-87.

7. Ekman M, Bhattachariya A, Dahan D, Uvelius B, Albinsson A, Swärd K. Mir-29 repression in bladder outlet obstruction contributes to matrix remodeling and altered stiffness. PLoS One 2013; 8: e82308.

8. Shi B, Zhu Y, Laudon V, Ran L, Liu Y, Xu Z. Alterations of urine TGF-beta1 and bFGF following bladder outlet obstruction: a predictor for detrusor contractibility? Urol Int 2009; 82: 43-7.

9. Zhu Y, Shi B, Xu Z, et al. Are TGF-beta1 and bFGF correlated with bladder underactivity induced by bladder outlet obstruction? Urol Int 2008; 81: 222-7.

10. Duan LJ, Qi J, Kong XJ, et al. MiR-133 modulates TGF- $\beta 1$ induced bladder smooth muscle cell hypertrophic and fibrotic response: implication for a role of microRNA in bladder wall remodeling caused by bladder outlet obstruction. Cell Signal 2015; 27: 215-27.

11. Wang N, Duan L, Ding J, et al. MicroRNA-101 protects bladder of BOO from hepoxia-induced fibrosis by attenuating TGF- $\beta$-smad2/3 signaling. IUBMB Life 2019; 71: 235-43.

12. Gheinani AH, Kiss B, Moltzahn F, et al. Characterization of miRNA-regulated networks, hubs of signaling, and biomarkers in obstruction-induced bladder dysfunction. JCl Insight 2017; 2: e89560.

13. Wu SP, Yang Z, Li FR, Liu XD, Chen HT, Su DN. Smad7-overexpressing rat BMSCs inhibit the fibrosis of hepatic stellate cells by regulating the TGF- $\beta 1 /$ Smad signaling pathway. Exp Ther Med 2017; 14: 2568-76.

14. Sun J, Wang J, Lu W, et al. MiR-325-3p inhibits renal inflammation and fibrosis by targeting CCL19 in diabetic nephropathy. Clin Exp Pharmacol Physiol 2020; 47: 1850-60.

15. Kitta T, Kanno Y, Chiba H, et al. Benefits and limitations of animal models in partial bladder outlet obstruction for translational research. Int J Urol 2018; 25: 36-44.

16. Mannikarottu AS, Disanto ME, Zderic SA, Wein AJ, Chacko $S$. Altered expression of thin filamentfilament-associated proteins in hypertroph ied urinary bladder smooth muscle. Neurourol Urodyn 2006; 25: 78-88.

17. Liu Q, Luo D, Yang T, Liao B, Li H, Wang KJ. Protective effects of antimuscarinics on the bladder remodeling after bladder outlet obstruction. Cell Physiol Biochem 2017; 44: 907-19.

18. Kanematsu A, Ramachandran A, Adam RM. GATA GATA-6 mediates human bladder smooth muscle differentiation: involvement of a novel enhancer element in regulating alpha alpha-smooth muscle actin gene expression. Am J Physiol Cell Physiol 2007; 293: C1093-102.

19. Coskun E, Ercin M, Gezginci-Oktayoglu S. The role of epigenetic regulation and pluripotency-related microRNAs in differentiation of pancreatic stem cells to beta cells. J Cell Biochem 2018; 119: 455-67.

20. Sadegh MK, Ekman M, Rippe C, Uvelius B, Swärd K, Albinsson S. Deletion of Dicer in smooth muscle affects voiding pattern and reduces detrusor contractility and neuroeffector transmission. PLoS One 2012; 7: e35882. 
21. Zhang S, Lv JW, Yang P, et al. Loss of dicer exacerbates cyclophosphamide-induced bladder overactivity by enhancing purinergic signaling. Am J Pathol 2012; 181: 937-46.

22. Freire VS, Burkhard FC, Kessler TM, Kuhn A, Draeger A, Monastyrskaya K. MicroRNAs may mediate the downregulation of neurokinin-1 receptor in chronic bladder pain syndrome. Am J Pathol 2010; 176: 288-303.

23. Monastyrskaya K, Sánchez-Freire V, Gheinani AH, et al. miR-199a-5p regulates urothelial permeability and may play a role in bladder pain syndrome. Am J Pathol 2013; 182: 431-48.

24. Sadegh MK, Ekman M, Krawczyk K, et al. Detrusor induction of miR-132/212 following bladder outlet obstruction: association with MeCP2 repression and cell viability. PLoS One 2015; 10: e0116784.

25. Gheinani AH, Burkhard FC, Rehrauer H, Fournier CA, Monastyrskaya K. MicroRNA MiR-199a-5p regulates smooth muscle cell proliferation and morphology by targeting WNT2 signaling pathway. J Biol Chem 2015; 290: 7067-86.

26. Shen D, Li J, Lepore JJ, et al. Aortic aneurysm generation in mice with targeted deletion of integrinintegrin-linked kinase in vascular smooth muscle cells. Circulation Res 2011; 109: 616-28.

27. Kogata N, Tribe RM, Fässler R, Way M, Adams RH. Integrin-linked kinase controls vascular wall formation by negatively regulating Rho/ROCK-mediated vascular smooth muscle cell contraction. Genes Dev 2009; 23: 2278-83.

28. Shafieian M, Chen S, Wu S. Integrin-linked kinase mediates CTGF-induced epithelial to mesenchymal transition in alveolar type II epithelial cells. Pediatr Res 2015; 77: 520-7.

29. Luo S, Gong J, Cao X, Liu S. Ligustilide modulates oxidative stress, apoptosis, and immunity to avoid pathological damages in bleomycin induced pulmonary fibrosis rats via inactivating TLR4/MyD88/NF-KB P65. Ann Transl Med 2020; 8: 931.

30. Liu P, Li F, Qiu M, He L. Expression and cellular distribution of TLR4, MyD88, and NF-kappaB in diabetic renal tubulointerstitial fibrosis, in vitro and in vivo. Diabetes Res Clin Pract 2014; 105: 206-16.

31. Wu L, Du L, Ju Q, et al. Silencing TLR4/MyD88/NF-kappaB signaling pathway alleviated inflammation of corneal epithelial cells infected by ISE. Inflammation 2021; 44 633-44.

32. Wang MX, Zhao XJ, Chen TY, et al. Nuciferine alleviates renal injury by inhibiting inflammatory responses in fructose-fed rats. J Agric Food Chem 2016; 64: 7899910

33. Xia X, Zhou C, He X, Liu C, Wang G, Sun X. The relationship between estrogen-induced phenotypic transformation and proliferation of vascular smooth muscle and hypertensive intracerebral hemorrhage. Ann Transl Med 2020; 8: 762.

34. Miano JM. Myocardin in biology and disease. J Biomed Res 2015; 29: 3-19. 